\title{
Economic Interests, Worldviews and Identities: Theory and Evidence on Ideational Politics
}

\section{Working Paper}

\section{Author(s):}

Ash, Elliott; Mukand, W. Sharun; Rodrik, Dani

Publication date:

2021-11

Permanent link:

https://doi.org/10.3929/ethz-b-000533395

Rights / license:

In Copyright - Non-Commercial Use Permitted

Originally published in:

Center for Law \& Economics Working Paper Series 2021(16) 


\section{$\boldsymbol{G H}$ zürich}

\section{Center for Law \& Economics Working Paper Series}

Number 16/2021

Economic Interests, Worldviews and Identities: Theory and Evidence on Ideational Politics

Elliott Ash

Sharun W. Mukand

Dani Rodrik 


\title{
Economic Interests, Worldviews, and Identities
}

\author{
Theory and Evidence on Ideational Politics*
}

\author{
Elliott Ash Sharun W. Mukand Dani Rodrik \\ ETH Zurich University of Warwick Harvard University
}

November 4, 2021

\begin{abstract}
We distinguish between ideational and interest-based appeals to voters on the supply side of politics, and integrate the Keynes-Hayek perspective on the importance of ideas with the Stigler-Becker approach emphasizing vested interests. In our model, political entrepreneurs discover identity and worldview "memes" (narratives, cues, frames) that shift beliefs about voters' identities or their views of how the world works. We identify a complementarity between worldview politics and identity politics and illustrate how they may reinforce each other. Furthermore, we show how adverse economic shocks may result in a greater incidence of ideational politics. We use these results to analyze data on 60,000 televised political ads in U.S. localities over the years 2000 through 2018. Our empirical work quantifies ideational politics and provides support for the key model implications, including the impact of higher inequality on both identity and worldview politics.
\end{abstract}

\section{Introduction}

Interest-based politics - revolving around the economic interests of elites, lobbies, rentseeking groups, or voters at large - lies at the cornerstone of political economy. The

*Contact emails: ashe@ethz.ch; s.mukand@warwick.ac.uk; dani_rodrik@hks.harvard.edu. We gratefully acknowledge discussions with and comments of Tim Besley, Arthur Blouin, Christian Bruns, Sumon Majumdar, Debraj Ray, and Kenneth Shepsle. Nianyun Li, Leo Picard, and Raghul Venkatesh provided superb research assistance. This paper incorporates many of the theoretical results from an earlier version of the paper by the latter two authors circulated under the title "The Political Economy of Ideas: On Ideas versus Interests in Policymaking" (Mukand and Rodrik, 2018). 
emphasis on vested interests has provided economists and other social scientists with a powerful conceptual lens, enabling them to shed light on policy formation, institutional change, and the persistence of inefficient policies in a variety of contexts. ${ }^{1}$ For example, such frameworks help us understand how industrial lobbies shape trade policies (Grossman and Helpman 1993), how financial interests have helped push through the repeal of the Glass-Steagall Act (Johnson and Kwak, 2010), and how the threat of expropriation by the masses has historically provided elites the incentive to democratize in some parts of the Western world (Acemoglu and Robinson, 2006).

However, an exclusive emphasis on interests would leave many important political economy questions unanswered. Political debates and struggles in the real world rarely rely solely on naked appeals to material interests. Instead, political leaders often seek support by trying to persuade the public of a particular view of how the world works - a view that enhances the desirability of the candidates' preferred policies. Alternatively, they may appeal to voters' identities, values, or some overarching normative principles (such as fairness or freedom). In one form or another, what we might call "ideational politics" seems at least as important as interest-based politics. ${ }^{2}$ Ideas have played a prominent role in institutional and policy transformations throughout history. Illustrations include not only such dramatic cases as the prohibition of the slave trade, the rise of the suffragettes, the civil rights movement, or the collapse of the socialist model the world over, but also more specific policy changes such as welfare reform, deregulation, tax cuts, privatization, and trade liberalization since the 1980s under what has come to be called "neoliberalism" or the "Washington Consensus." More recently, both Brexit in Britain and the victory of Donald Trump in the 2016 U.S. presidential election have been linked to a particular brand of identity politics that appeals not to voters' pocketbooks but to their sense of who they are and their latent aversion to "outsiders" (racial minorities or immigrants).

Indeed, the focus on interests in contemporary political economy is of rather recent vintage. It was not just classical economists such as Ricardo and Marx, but also Keynes (1936) and Hayek (1949), who considered ideas to be important drivers of political change. Keynes (1936) famously observed "it is ideas, not vested interests, which are dangerous for good or evil."

\footnotetext{
${ }^{1}$ See Stigler (1971) and Becker (1983) for early accounts and Persson et al. (2000) and Acemoglu (2003)for good surveys.

${ }^{2}$ See Rodrik (2014) for an informal treatment of these issues and a variety of illustrations.
} 
In this paper we provide a conceptual framework that allows us to think about ideas as a political vehicle distinct from and in addition to interests. Our focus is on political entrepreneurship on the supply side of politics, where a challenger and an incumbent compete for votes by offering different policy platforms. The innovation is that we allow the challenger to engage in ideational politics. We highlight two different types of ideational politics in particular: "worldview politics" and "identity politics." Worldview politics refers to efforts to shape voters' understanding of how the world works, thereby altering their perceptions of the mapping from policies to outcomes. Identity politics refers to efforts to make particular latent identities (such as ethnicity, religion, race, etc.) more salient, rendering voters' utility more congruent with members of the relevant identity group.

Examples of worldview politics are the Mont Pelerin Society's successful marketing of a particular type of economic liberalism, investments made by the Koch brothers in libertarian think tanks and research institutes, and the role of the financial sector in convincing regulators as well as a broader segment of the public that "what is good for Wall Street is good for America." 3 These illustrations come closest to what Keynes and Hayek had in mind when they wrote about the importance of ideas in driving policy.

Examples of identity politics are also ubiquitous in current political discourse, ranging from the Republican Party's white identity politics to the Black Lives Matter movement. Individuals have a multiplicity of identities - revolving around ethnicity, race, religion, or nationality - any number of which can be salient at a point in time (Sen 2007). By valorizing particular racial or ethnic attributes, sending explicit (or subtle) messages about who is a native or an outsider, disseminating stereotypes about racial and religious minorities, emphasizing patriotism and national identity, or framing policy issues in such terms, political actors can render a particular identity more or less salient. $^{4}$

We consider a standard political economy model where policy is driven ex anteby the preferences of a median voter who is low-income. We focus on the problem faced by

\footnotetext{
${ }^{3}$ On the efforts of Koch brothers and other libertarian business leaders, see Mayer (2017). The argument that the financial sector cognitively captured policymakers' and elites' worldviews has been advanced by Johnson and Kwak (2010) as well as Buiter et al. (2014).

${ }^{4}$ There is a large literature in other disciplines on identity construction in a variety of contexts. See Wendt (1999), Ruggie (1998) and Anderson (1976) in political science, and the survey by Cerulo (1997) in sociology. Haidt (2012) reports on research from biology suggesting that individuals have a 'hive switch' that helps make identities salient and bind an individual to a particular group.
} 
a high-income political challenger, who faces a difficult task: how to push through a new policy with distributional effects that the median voter believes will lower his income. In the absence of ideational politics, the preferences of the median voter are aligned closely with his (perceived) economic interests, and the challenger's policy cannot be adopted. But ideational politics broadens the range of possibilities. The challengeror an allied "political-ideational complex" of think tanks, pundits, partisan media, and political entrepreneurs - can disseminate ideas that alter the median voter's worldview or identity (or both).

Hence we allow the challenger to allocate resources towards the search and discovery of "memes" that catalyze ideational politics. ${ }^{5}$ A meme is some combination of cues, narratives, symbols, or indeed any choice of communication that is deployed by political entrepreneurs to shift the electorate's views about how the world works or to make an identity salient. In other words, memes are the concrete vehicle that enable politicians to channel ideas in the political marketplace. ${ }^{6}$

Depending on whether an idea affects voter beliefs about the world or preferences about identity, we have two corresponding kinds of memes. If a meme affects a voter's belief about how the world works, we label it a "worldview meme" producing worldview politics. If a meme affects a voter's sense of who he or she is, we label that an "identity meme" that triggers identity politics. The politician's decision of whether to focus on searching for an identity or worldview meme (or both) depends on what is politically advantageous.

Identity politics works by transforming a low-income voter's preferences ex post: the median voter may now be willing to vote for a (rich) political challenger with whom

\footnotetext{
${ }^{5}$ The notion of a meme was introduced by Dawkins (1976) when discussing how some cultural ideas and rituals spread very easily among anyone exposed to them - be it through rhetoric, slogans, speech, or gestures.

${ }^{6}$ Consider for example the politics of austerity. According to Skidelsky and Fraccaroli (2017), one reason why fiscal austerity and balanced budgets resonate with the public is that "people think of the government's finances very much as they think of their own household's finances. Since every household knows that it has to balance its books," so do they presume for the government. Here is how Angela Merkel deploys the meme in a speech attacking deficit spending: "The root of the crisis is quite simple. One should simply have asked a Swabian housewife, here in Stuttgart, in Baden-Wurttemberg. She would have provided us with a short, simple, and entirely correct piece of life-wisdom: that we cannot live beyond our means. This is the core of the crisis. . . Then why is the world in this difficult place? Well, we have too often put our trust in experts that were not really experts... When we come together now to think about how one should answer these new global questions, we should put less faith in self-proclaimed experts, and instead follow one principle: the principle of common sense!" (Merkel, 2008, emphasis added). See also Farrell and Quiggin (2011), from which this quote is taken.
} 
he shares an identity marker such as religion or race. By raising the salience of one type of identity (religion or race) over another (class), the political entrepreneur drives a wedge between a low-income individual and the status-quo policy of redistribution from the rich to the poor. A worldview meme is similar, but it works by changing voter perceptions of how the world works. Here the aim is to persuade the (low-income) voter that adoption of the new policy is actually in his interest, since the state of the world has changed. So a policy that (previously) hurt the interests of the median voter is no longer perceived to do so. Our model also allows "full-spectrum ideational politics," with both policy and identity memes being deployed. ${ }^{7}$ We will examine the conditions under which the political challenger invests in one or both of these types of memes.

Our framework makes several contributions. First, we clarify the analytical distinction between ideas and interests and show how ideas can be incorporated in political economy models. In doing so, we integrate the Keynes-Hayek perspective on the importance of ideas with the standard political-economy frameworks that typically emphasize material interests. A frequent contention of social constructivists is that the role of ideas in shaping interests renders formal rational-choice models of the type that economists and many political scientists work with irrelevant or inappropriate ( see Ruggie, 1998; Cerulo, 1997). Our model shows that there is in fact no incompatibility between constructivist arguments and formal or rational-choice modeling.

Second, we show how ideas and interests can feed into each other. On the one hand, economic interests drive the kind of ideas that politicians put forward. As Shepsle and Noll (1985) puts it, ideas can be regarded as "hooks on which politicians hang their objectives and further their interests." However, ideas also shape interests. They do so by altering voter preferences ex post and/or shifting their worldviews, in both cases changing rankings over policies.

Third, we show that identity and worldview politics are each variants of a broader category, which we may call ideational politics. By clarifying the similarities as well as differences between identity and worldview politics, our paper helps bring together two

\footnotetext{
${ }^{7} \mathrm{~A}$ possible example of a meme that combines both is Donald Trump's statement, "I will build a great, great wall on our southern border, and I will make Mexico pay for that wall." This meme combines elements of a policy response, while also emphasising identity (natives versus immigrants). Similarly, during the 2006 Venezuelan election Manuel Rosales attempted to unseat President Chavez by promising to issue a Mi Nigra (i.e., "my dark-skinned woman") card that would directly transfer oil revenues to the poor - combining policy and identity memes in one initiative.
} 
large, disparate literatures. ${ }^{8}$ We provide a simple way to integrate, but also distinguish, these two forms of ideational politics. Our framework provides a potential template to explain the heterogeneity in ideational politics both across time and place. We use this template in the empirical analysis of U.S. political advertising and provide suggestive evidence on the quantitative significance of different variants of ideational politics.

Fourth, we identify a complementarity between worldview and identity politics: either kind of ideational politics increases the return to the other kind. This is somewhat surprising, since we may expect politicians' resource constraint to generate a natural substitutability between the two types of ideational politics. On this view, allocating more resources towards making identity salient would leave fewer resources to change worldviews. However, there are two reasons why there may be a complementarity instead. First, we have an "association effect" where a low-income person gets utility from identifying with and sharing an identity with the high-income identity group (e.g., whites). The utility from belonging to the rich identity group would then be increasing in this group's relative income. Consequently, low-income white voters may be willing to support a policy (say financial deregulation) that benefits the rich, white minority, since it gives them an indirect bump in utility through association with other (now very) rich white beneficiaries of this policy. Second, this mechanism is reinforced by an additional "income-identity tradeoff" effect. The income loss from supporting the pro-rich policies of the challenger renders some low-income voters immune to the pull of identity that they share with the challenger. A successful worldview meme increases the returns to the identity meme by persuading low-income voters that there is less income downside from supporting the rich challenger.

The complementarity between worldview politics and identity politics gives us some insight into their contemporaneous presence in our political life. Identity politics and worldview politics are often jointly used in political messaging campaigns. ${ }^{9}$ In our

\footnotetext{
${ }^{8}$ The fact that identity may be politically constructed draws on a large literature in the social sciences, much of it discussed in Fearon and Laitin (2000). Similarly, the role of political entrepreneurs in shaping worldviews has been recognized as far back as Lenin (1902), Downs (1957), and recently formalized by Bénabou (2008).

${ }^{9}$ Frank (2007) observed that the "poorest county in America" voted Republican and puzzled at the "tragically inverted form of class consciousness that makes such individuals make common cause with the assortment of millionaires . . . pushing the Republican economic agenda of tax-cuts, deregulation, free trade and corporate welfare" (Bartels et al. 2006). Hacker and Pierson (2020) provide a detailed account of the Republican Party's exploitation of white racial consciousness to push a prorich economic policy agenda. In many countries over the past decade (as in Russia, Venezuela, and Turkey) populist policy themes were accompanied with a shrill nationalism directed against minorities
} 
empirical analysis, we report some evidence of complementarity in messaging in U.S. political campaigns.

Finally, our model sheds light on the impact of inequality on ideational politics. We show that a rise in inequality increases the reward to the rich from this type of messaging. When income gaps become larger, the returns to the rich from discovering a worldview meme that persuades the median voter, for example, that lower taxes are in the interests of not only the rich, but also the low-income median voter, are much higher. Similarly, an effective identity meme that catalyzes identity around issues such as gay marriage, women's rights, and immigration can serve as a "wedge" that gives low-income voters a reason to vote for the high-income party when economic interests would normally pull them in the opposite direction. ${ }^{10}$

In the empirical section of the paper, we take these theoretical insights to the data in the context of U.S. political advertising. To analyze political messaging, we use microdata on advertising for the years 2000-2018, where we have detailed information on the sponsoring politicians, the locations of airings, and the issue content of the ads. The exogenous variation in employment and inequality comes from Chinese import competition (Dorn et al., 2020).

Our empirical analysis bears out the model's key implications. We find evidence for an increase in ideational politics in areas that were worst hit by the China trade shock. In particular, Republicans intensify messaging on moral values like abortion and gay marriage, a response that would be difficult to explain without a model of ideas. Further, we find that in response to the China trade shock, there is more frequent advertisements that jointly invoke identity issues - abortion and morality and worldview issues - taxes and deficits. The more intense joint messaging about both identity and worldview in response to higher inequality is consistent with the model's predictions about complementarity of the two types of ideational politics.

The empirical findings are robust to a variety of checks for specification and sampling. Consistent with the exogeneity of the instrument, the aforementioned shifts in ideational advertising occurred only after the employment shocks in the mid-2000s (starting 2008-2010); they are not observed in the earlier period (2000-2002). Further,

${ }^{10}$ See the related analysis of Hacker and Pierson (2020). As Ashok et al. (2015) have noted: "despite the large increases in economic inequality since 1970, American survey respondents exhibit no increase in support for redistribution . . . demand for income redistribution in the U.S. has remained flat by some measures and decreased for others."
} 
we can rule out that these effects are just increases in polarization across all partisan priorities. Finally, we use data on Gallup's "Most Important Problem" survey to show that the effects are not driven by changes in voter preferences about identity-based issues.

These theoretical and empirical results add to the economics literature on ideas, narratives, and identity politics. This literature has expanded greatly in recent years. ${ }^{11}$ While we cannot do full justice to this literature, we note a few related papers.

On the theory side, Bénabou et al. (2015) examines how political economy concerns affect a government's incentive to affect the evolution of religious beliefs and allow scientific progress and growth. Shayo (2009) presents a model where individuals care about group status and are willing to sacrifice income to vote for identity. ${ }^{12}$ Grossman and Helpman (2021) develop a model in which cultural associations of lower-skill individuals are driven by the conflict between identifying with "the nation as a whole," a category which includes the high-skilled individuals, and the cognitive-dissonance cost that arises to the extent their material circumstances differ from the national average. They show that an adverse economic shock can induce a change in social and cultural identification patterns whereby lower-skill individuals begin to see themselves as members of a narrower group. Bonomi et al. (2021) analyze how policy conflicts can heighten individuals' attachments to their identity groups. Finally, our notion of the role of memes as the vehicle of ideas is related to recent work on the economics of narratives by Akerlof and Snower (2016), Collier (2016), and Shiller (2017).

Empirically, this paper adds to the burgeoning literature on the power of ideas in policymaking. There is a large literature on how media messaging influences votes (e.g. Strömberg, 2015), with a smaller literature on how it influences enacted policies (Galletta and Ash, 2021). Ash et al. (2020) show that a training course for judges in economics - a bundle of worldview memes - caused the judges to take a more conservative approach in their rulings and to use more economics reasoning in their opinions. The closest papers have looked at the political effects of the China Shock. Autor et al. (2020) show that the China shock increased support for Republicans and

\footnotetext{
${ }^{11}$ The first version of this paper was written in August 2015.

${ }^{12}$ Two equilibria emerge in Shayo's paper: a high redistribution equilibrium in which class is salient and a low redistribution equilibrium in which national identity is salient. While the issues that motivate the present paper are broader, we show, as in these papers, that there is a close relationship between attitudes towards redistribution and the salience of non-materialistic identities (religion or nation).
} 
viewership of Fox News Channel. Cerrato et al. (2018) find that the China Shock causes more negative attitudes toward immigrants and minorities, while opinions about free trade are not affected. Similar effects have been documented in a number of European countries (see Rodrik, 2020). Our empirical analysis complements these previous papers with a focus on the supply side of ideational politics. Rather than looking at the effects on citizens, we look at how meme production among politicians shifts in response to the state of higher inequality triggered by China import competition.

The plan of the paper is as follows. In Section 2 we set up the various elements of our conceptual framework and analyze comparative statics in equilibrium. Section 3 describes and reports the empirical analysis. Section 4 concludes.

\section{Theoretical Framework}

We describe below a minimal political economy framework with democratic political institutions where the interests of the median voter (who is poor) drive the incumbent's choice of policy in favour of the status-quo. The key innovation of our framework is that political entrepreneurs have the scope to alter the political status-quo by introducing "ideas" that may shape both the worldviews and identity preferences of the median voter. In order to make our point in the most transparent manner, our benchmark model is highly stylized and does not provide explicit micro-foundations for the operation of memes - an assumption that is subsequently relaxed in Appendix A.3.

\subsection{Setup}

We now describe the framework in some detail.

Policymaking and Beliefs about the World: Politicians can directly affect perceived payoffs associated with policy choices by introducing ideas that shift beliefs about the underlying state of the world. We assume that policymakers have a choice between two state-contingent policies, where the underlying state of the world can be either $S_{0}$ or $S_{1}$. Here the prior probability that the state is $S_{1}$ in period $T_{0}$, equals $\mu_{0}=P\left(S_{1}\right)$.

The policymaker chooses between either retaining the status-quo policy $a_{0}$ or adoption of a new policy $a_{1}$. The policymaker's dilemma is that there is a distributional 
conflict between the rich and the poor in some states of the world and not others. In particular, while the rich always benefit from the adoption of the new policy, the poor do so only in some states of the world (i.e. $S_{1}$ ). In particular, payoffs are such that the adoption of $a_{1}$ when the state is $S_{0}$, lowers the payoff of the median voter (who is 'poor') and results in an (expected) income that equals $\bar{y}_{P}^{1}\left(S_{0}\right)$. This income is lower than what he would have earned under the status quo policy $a_{0}$ since his payoff in either state equals $\bar{y}_{P}^{0}\left(S_{0}\right)=\bar{y}_{P}^{0}\left(S_{1}\right)>\bar{y}_{P}^{1}\left(S_{0}\right)$. In contrast, in state $S_{1}$, both the rich and the poor are better off with the adoption of the new policy $a_{1}$. Therefore, adoption of policy $a_{1}$ when the state is $S_{1}$ results in the the poor earning an income of $\bar{y}_{P}^{1}\left(S_{1}\right)+g$, with a per capita gain $g>0$. The rich benefit from the new policy $a_{1}$ in all states of the world and earn an income of $\bar{y}_{R}^{1}\left(S_{0}\right)+\alpha g=\bar{y}_{R}^{1}\left(S_{1}\right)+\alpha g$ where $\bar{y}_{R}^{1}\left(S_{1}\right) \geq \bar{y}_{R}^{1}\left(S_{0}\right)$ and $\alpha \geq 1$.

In order to capture the distributional conflict between the rich and the poor from the choice of policies, we assume that the probability that the underlying state is $S_{0}$ (i.e. $1-\mu_{0}$ ) in the period $T=0$ is high enough such that all individuals who are poor prefer the status quo policy $a_{0}$.

Preferences, Income and Identity Markers: There are a unit mass of citizens each of whom obtains utility from his income as well as his identity. An individual $j$ obtains an income $y_{j k}=\bar{y}_{k}+\tau_{j}$ that is a function of whether he belongs to the class $k$, which can be rich $R$ or poor $P$, with expected income $\bar{y}_{k}$, where $\bar{y}_{R}>\bar{y}_{P}$. Furthermore, heterogeneity in an individual's income arises from the realisation of an individual-specific random variable $\tau_{j}$, with distribution $G$ which is assumed - for simplicity - to be uniform, i.e. $\tau_{j} \sim U\left[-\frac{1}{2 \phi_{k}}, \frac{1}{2 \phi_{k}}\right]$ with $\phi_{k}$ being the density of income group $k \in\{R, P\} .^{13}$

In addition, each individual is endowed with a vector of identity based 'characteristics' or 'markers' that may affect his payoff - such as ethnicity, religion, race or nationality. For simplicity, in what follows we allow for all individuals to belong to one

\footnotetext{
${ }^{13}$ Observe that heterogeneity amongst the poor can be built in two (equivalent) ways. The first is what we have described above, with heterogeneity in initial income driven by the realization of a random variable $\tau_{j}$. Alternatively (and equivalently), we can assume that incomes are binary in that they are either high $\bar{y}_{R}$ (the 'rich') or low $\bar{y}_{P}$ (the 'poor'). However, in this interpretation the heterogeneity in net income arises due to differences in individual-specific adjustment costs $\tau_{k}$ such as the cost of worker retraining and inter-sectoral mobility.
} 
such identity marker that can be either $A$ or $B .{ }^{14}$ Accordingly, an individual's payoff in any period is:

$$
v_{j}=y_{j k}+\lambda_{m} \theta_{j m}
$$

Here, individual $j$ obtains income $y_{j k}$ and an 'identity' utility $\theta_{j m}$ from membership to a group with characteristic-markers $m$, where $m \in\{A, B\}$. The magnitude of this identity payoff could be large if identity is salient (i.e. $\lambda_{m}=1$ ) or small if identity is not salient (i.e. $\lambda_{m}=0$ ). While simple, our formulation allows for an individual's group identity to be affected by group-specific characteristics such as the average income of group $A$. For instance, if the adoption of $a_{1}$ when the state is $S_{0}$ increases average income of group $A$ relative to group $B$, then the corresponding identity payoff $\theta^{1}\left(S_{0}\right)$ to a voter from group $A$ may also increase - reflecting the pride from tribal affinity to a voter who belongs to the relatively rich group. In what follows, we assume that an individual obtains utility from solidarity with and the relative well-being/income of others who share their marker. ${ }^{15}$

We assume that a minority fraction $n_{R}$ of the population is rich $(\mathrm{R})$ and the remainder $n_{P}$ are poor $(\mathrm{P})$, with $n_{P}>1 / 2$. Furthermore, we assume that at the beginning of the first period, identity is not salient (i.e. $\lambda_{m}=0$ ) and an individual's payoff is driven only by their income. All individuals have either the identity marker $A$ or $B$, with a majority fraction $n_{A}$ of the population having the $A$ marker, where $n_{A}>1 / 2>n_{B}$.

The Political Structure. We begin our game with a low-income political incumbent in office who faces a political challenger who has belongs to the minority 'rich'. In addition, we assume that at this stage identity is irrelevant (i.e. not salient), even though the incumbent has the $B$ marker. Individuals compare their expected payoffs from the incumbent and the challenger, and vote for the politician under whom their

\footnotetext{
${ }^{14}$ While our current formulation assumes a single marker that can divide the population along that one dimension, in principle we could could endow each individual with a set of $M$ "primitive" characteristics or markers $\mathbf{M}_{i}=\left\{m_{i}^{1}, m_{i}^{2}, \ldots, m_{i}^{M}\right\}$ where these primitive characteristics or markers can be a wide variety of aspects of an individual that may (or may not) be "active" or politically salient, such as his ethnicity, religion, wealth, language or even his height or hair colour.

${ }^{15}$ Alternatively, this identity payoff may be state-dependent and be larger or smaller in some states of the world. This alternative formulation of the model would treat this identity payoff as being state dependent where an individual's group identity is very important and in other states much less so. The political entrepreneur may get individuals to invest in a particular identity by persuading them that the state of the world has changed and group identity is important. We discuss this further in Appendix A.3.
} 
payoff is higher. If elected, this rich political challenger will adopt his preferred policy $a_{1}$ in the next (final) period.

Given this political structure, there are only two scenarios under which a political challenger from the rich group (in a minority) can get elected and enact $a_{1}$. The first possibility is that sheer chance may play a role in enabling his election. In particular, the political incumbent's relative popularity shock $\delta$, where $\delta \sim\left[-\frac{1}{2 \psi}, \frac{1}{2 \psi}\right]$ may affect the electoral fortunes of the challenger. ${ }^{16}$ The second possibility, is the one we focus on. Here the political challenger actively tries to get elected (and enact $a_{1}$ ) through engaging in "ideational" politics.

\subsection{Memes and the Nature of Politics}

The political challenger's difficulty is to transform the political status-quo that favours the incumbent belonging to the majority poor group (and favours the status-quo policy $\left.a_{0}\right)$. However, overturning the political status-quo requires the discovery of a meme by the political challenger (or indeed any allied "political-ideational complex" of partisan think tanks, spin doctors, academic-political commentariat in the media). We conceive of a meme as political advertising broadly construed - some combination of cues, narratives, symbols or targeted communication that channelises ideas to voters such that exposure to it shifts a voter's worldview and/or makes identity salient.

Political entrepreneurs deploy memes and transform an individual's identity or alter his worldview in a variety of ways. ${ }^{17}$ For instance, political entrepreneurs may manipulate beliefs by the direct exploitation of behavioural biases in voter processing of information. ${ }^{18}$ It is well documented that media "framing" can "prime" the voter into identifying with a particular social identity and/or buy into a policy worldview. ${ }^{19}$

\footnotetext{
${ }^{16}$ These distributional assumptions will ensure closed form solutions, so long as the distributional 'support' for $\delta$ is not too 'narrow' compared to $\tau$.

${ }^{17}$ There is a large literature arguing that politicians and the news media can 'prime' voters about issues (including identity) (see DellaVigna and Gentzkow (2010) for a survey). For example, in the U.S. context, Kinder and Sanders (1996), Mendelberg (2001), and Jackson (2011) provide evidence on priming racial identity. Blouin and Mukand (2019) provide evidence on how propaganda was used to 'erase' ethnic identity in Rwanda. Similarly, Wilkinson (2006) discusses how religious identity is primed for electoral purposes in India.

${ }^{18}$ These biases include anticipatory utility (Benabou and Tirole, 2002, 2006), 'coarse thinking' (Mullainathan, Schwartztein and Shleifer (2008)), salience and attention (Genniaoli and Shleifer, 2010) or peer-influence heuristics (see Levy and Razin, 2016) among others.

${ }^{19}$ On framing, Stephen Breyer (1981, pp. 320) recounts how the Kennedy hearings on regulation attempted to shift public opinion in favour of airline (de)regulation by trying to ensure that the
} 
Finally, memes can be deployed to exploit information asymmetries (Glaeser, 2005; Jain et al., 2014) or persuade voters (Alonso and Câmara, 2016).

Some of the above mechanisms emphasize the supply side and the discovery of memes, while others highlight the role of demand-side structural factors that make voters more susceptible to belief shifts due to exposure to a meme. We are agnostic in this paper about the precise mechanism through which a politician shifts voter beliefs and/or gets them to invest in an identity. Accordingly, we develop a minimal framework where the discovery and deployment of memes is fraught with uncertainty and requires skill, knowledge of local context, resources, and luck. In addition, our formulation also allows for differences in the effectiveness of memes due to changes in underlying structural conditions. For instance, receptivity of voters to memes may be much higher when they are unhappy with the prevailing status-quo - due to a recession, high unemployment, or a history of conflict, for example. For simplicity, we relegate our discussion of the mechanism through which these memes work to A.3.

Identity Memes. Individual attitudes towards a policy are often mediated through identity. As suggested by Akerlof and Kranton (2000), identities are expressed as and associated with support for a corresponding set of policy choices. ${ }^{20}$ So if an individual's group identity becomes salient, he obtains a payoff from taking actions (or preferring policies) that are consistent with this identity. For example, if an individual's ethnic marker $A$ becomes active, he gets utility from association with the (high income/status) $A$ group. In this case a poor voter may well support a pro-rich policy $a_{1}$, that is against his economic interest. Therefore, by catalyzing identity, a rich political entrepreneur can generate political support for a policy amongst the poor, that (on purely income grounds) may have been lacking otherwise.

regulatory reform was "seen as one of 'lower prices' and 'helping the consumer' (since it) can pick up support, time and effort from many person". On priming, see Molden (2014) for a survey. The non-informational change in preferences (due to priming) is well documented in social psychology (see also Dietrich and List, 2011).

${ }^{20}$ To take one example, Campbell (2002) argues that "efforts to reform, if not dismantle, U.S. welfare policies during the 1970s and 1980s were led by politicians who reframed means-tested welfare programs as stipends and services that were being provided to African Americans and other minorities, but paid for by allegedly exorbitant taxes on working-class whites. The idea was to frame the issue of welfare reform in such a way as to divide the working class along racial lines and generate support among white voters for reform (Quadagno et al., 1994)." 
Worldview Memes. This meme works by persuading voters that the underlying state of the world has changed to $S_{1}$, such that adoption of $a_{1}$ now benefits both the rich and the poor. In particular if in period $T=0$, the prior beliefs that the state of the world is $S_{1}$ are given by $\mu_{0}$, then the worldview meme changes beliefs of the underlying state to $\mu_{1}$ in period $T_{1}$, where $\mu_{1}>\mu_{0}$. By altering (especially poor) voter beliefs about the underlying state of the world, the policy meme is effective in making policy $a_{1}$ politically viable.

Learning and Discovery of Memes. A political challenger who further expends resources $e(i, w)$ successfully "discovers" an identity meme with probability $i$ and a worldview meme with probability $w$ where $e(i, w)=\frac{\beta\left[\varphi^{I}(.) i+\varphi^{W} w\right]^{2}}{2 a}$. Here $\varphi^{I}, \varphi^{W}$ are sufficiently large, such that the arguments for $i, w$ each are bounded by 1 .

The technology of discovering both identity and worldview memes is very similar and is a function of not just the political challenger's ability $a$, but also the prevailing structural conditions that may differ for identity memes $\left(\varphi^{I}\right)$ or worldview memes $\left(\varphi^{W}\right)$. For instance, if a country has had a history of ethnic conflict then it may be easier to make ethnic identity an 'active' politically salient characteristic, i.e. the cost $\varphi^{I}$ will be relatively low. Alternatively, a lower $\varphi^{W} \in[0, \bar{\varphi}]$ captures a variety of scenarios that suggest that it may be easier to discover worldview memes. For instance, in the aftermath of a financial crisis that has resulted in exploding deficits, it may be easier to persuade voters that austerity is the appropriate policy because of the readily available meme about the government (like an individual) "living within its means."21

Finally, actions taken by the incumbent in control of government can also make it more difficult for any political challenger to discover and deploy memes. For instance, this could be achieved by any measures enacted by the government that curb media freedom (such as libel laws or restrictions on private media), increase repression as well as engage in counter-propaganda. We model this in a very simple way by assuming that if the incumbent government incurs a cost $c(b)$, then with probability $b$ the political challenger's costs of discovering a meme are higher since $\beta$ equals $\beta_{1}$ and with

\footnotetext{
${ }^{21}$ We should also point out that if a new policy innovation comes into the horizon (either because of the input of policy innovators, think-tanks or experimentation by a neighbouring country), then by providing a skein of respectability, it makes it easier for entrepreneurs to 'market' this policy. This corresponds to the Keynes's (1936) emphasis on the notion that once ideas are generated by 'academic scribblers' (or 'intellectuals' in Hayek's (1949) account) they are ripe for the being exploited by political entrepreneurs. See Lopez and Leighton (2012) for a good discussion.
} 
probability $1-b$ the costs equal the status quo with $\beta_{0}=1$, where $c^{\prime}, c^{\prime \prime}>0$ and $c(1)$ is sufficiently large such that $b<1$.

We now describe the timing of decision making where the political challenger (who belongs to the higher income group which is in a minority) tries to defeat the incumbent from the majority low-income majority, by making either identity salient and/or shifting worldviews.

The Timing of Decision Making. In period $\mathrm{T}=0$, nature moves and structural conditions $\varphi^{I}, \varphi^{W}$ are realised that can make it easier or more difficult for the political challenger to engage in ideational politics. The political incumbent observes these structural conditions and takes a costly action $c(b)$ with the aim of making it more difficult for the political challenger to be successful in discovering a meme.

In the first period $T=1$ a political challenger is (randomly) chosen from the set of individuals who are rich (i.e. belong to the rich group R). ${ }^{22}$ This political challenger observes the realization of $\beta$ as well as structural conditions and evaluates how much (if any) resources to allocate to "discover" (with probability $i$ ) an identity meme and/or (with probability $w$ ) a worldview meme. Depending on whether an identity and/or worldview meme are discovered, there will be a (i) shift in voter preferences as ethnicity becomes an "active" characteristic that affects individual payoffs, (ii) shift in beliefs about the likelihood that the underlying state of the world is $S_{1}$.

The second period $T=2$ begins with the realisation of the political incumbent's relative popularity shock (e.g. charisma) given by $\delta$, which can be positive or negative and elections take place with each citizen voting for the candidate who maximises their expected payoffs.

In the last period $T=3$, the winner of majority of votes is announced and implements the policy that maximises his or her payoff. Voter payoffs are also realised.

\subsection{Full-Spectrum Ideational Politics: Equilibrium Analysis}

In order to examine the incentives facing the high-income political challenger (with a passive $A$ marker) to engage in full-spectrum ideational politics when facing a low-

\footnotetext{
${ }^{22}$ More generally, the challenger can be chosen from the entire population. Here we directly assume that the political challenger differs on the only dimension that is salient at the beginning of the first period, namely, income.
} 
income political incumbent with a $B$ identity marker we start with the median voter's decision. Given that his decision will be pivotal, we focus on the trade-offs facing the low-income median voter, when both identity is salient and beliefs about the underlying state of the world have shifted towards $\mu_{1}$. In this case, the perceived tradeoff facing a low-income voter with the $A$ identity made salient from electing the rich challenger (who adopts policy $a_{1}$ ) instead of the low-income challenger (who sticks to status-quo $a_{0}$ ) is given by (see A.2): ${ }^{23}$

$$
\left.\left\{\mu_{1}[g]+\left(1-\mu_{1}\right) \bar{y}^{10}\left(S_{0}\right)\right]\right\}+\left[\theta^{10}\left(S_{0}\right)\right]+\mu_{1}\left[\theta^{10}\left(S_{1}\right)-\theta^{10}\left(S_{0}\right)\right] \geq \tau_{j}+\delta .
$$

The term in the curly brackets is the worldview effect that arises from the worldview meme. This worldview effect is the expected payoff to a low-income voter from the shift in his belief that the underlying state $S_{1}$ when policy $a_{1}$ is adopted. This results in a payoff that equals $g$ (when the state is $S_{1}$ with probability $\mu_{1}$ ) and a payoff of $\bar{y}^{10}\left(S_{0}\right)$ when the state is perceived to be $S_{0}$, where $\bar{y}^{10}\left(S_{0}\right)=\bar{y}^{1}\left(S_{0}\right)-\bar{y}^{0}\left(S_{0}\right)<0$. The second term on the right hand side is the identity polarization effect that equals the payoff to an individual from adopting $a_{1}$ when his group identity is salient and perceptions of the state being $S_{0}$ are unchanged - this equals $\theta^{10}\left(S_{0}\right)=\left[\theta^{1}\left(S_{0}\right)-\theta^{0}\left(S_{0}\right)\right]$. Finally, consider the last term on the left-hand side of the inequality that captures the complementarity across the two memes. This term shows that the worldview meme increases the returns to identity polarization. In particular, it is the increase in the payoff from the identity polarization that accrues to a $A$ individual, due to a change in beliefs about the state of the world being $S_{1}$. For example, this occurs if a poor group $A$ person believes that adoption of policy $a_{1}$ disproportionately benefits his identity group in state $S_{1}$ than if the state remained $S_{0}$.

The above equation captures the key trade-offs that underlie voter decision making. In Appendix A.2 we describe the solution to the political equilibrium that describes the political challenger's optimal choice of $i^{*}$, the probability of discovering an identity meme and $w^{*}$, the probability of discovering a worldview meme as well as the optimal effort allocated by the incumbent $c^{*}$ to prevent discovery of memes that change the political status-quo in the first place. We summarise our results in the following

\footnotetext{
${ }^{23}$ Since the focus of much of our analysis is on the median voter who is poor and $A$ (i.e. $P, A$ ) in what follows we suppress the $P, A$ notation unless we need to explicitly distinguish with those who are rich $R$ and/or $B$.
} 
proposition below.

Proposition I: There exists an equilibrium $i^{*}, w^{*}, b^{*}$ given by the expressions (14)(15), such that the political incumbent raises the cost of discovering a meme with probability $b^{*}$ and the political challenger invests resources $e\left(i^{*}\right), e\left(w^{*}\right)$. In this equilibrium there is the discovery with probability:

(i) $i^{*}\left(1-w^{*}\right)$ of only an identity meme and we have the politics of identity;

(ii) $w^{*}\left(1-w^{*}\right)$ of only a worldview meme and there is worldview politics;

(iii) $i^{*} w^{*}$ of both worldview/identity memes and there is full-spectrum ideational politics;

(iv) $\left(1-\pi_{c}^{0}\right)\left(1-w^{*}\right)\left(1-i^{*}\right)$ of neither identity or worldview memes such that economic "interests rule".

Proof: See Appendix A.2. $\odot$

The above proposition delineates the set of possible outcomes. The search and discovery of memes that are political game-changers is a difficult and uncertain process. The above proposition depicts how with (a positive probability) different configurations of ideational politics may arise. For instance, a history of racial, caste or religious conflict makes it easier for political entrepreneurs to make identity salient in some countries (e.g. India or the U.S.). In contrast, if the social or reputational fixed cost to the politician for deploying racial memes is sufficiently high, we may well have $i^{*}=0$ and there will be no politics of identity. Similarly, structural economic conditions in Latin America make it much easier for political entrepreneurs to discover worldview memes that make populist policies attractive in Latin America (Dornbusch and Edwards, 1990). In this if a worldview meme is the only one that is discovered, we will have worldview politics as the only form of ideational politics in operation. Of course, even if resources are allocated towards the discovery of identity or worldview memes, it is entirely possible (given the stochastic nature of the discovery process) that neither such meme is discovered and we remain in a world with class conflict - where "economic interests" rule.

Our benchmark model made important simplifications. In particular, our benchmark model does not provide explicit micro-foundations to the operation of memes and account for how they alter beliefs and make identity salient. We relax these as- 
sumptions in Appendix A.3. Furthermore, our model restricted political equilibrium to a single electoral cycle - we sketch out the implications of relaxing this assumption in Mukand and Rodrik (2018).

\subsubsection{Worldviews and Identitites: Complementarity in Ideational Politics}

We now analyse whether "identity politics" and "worldview" politics are substitutes or complements. To address this issue, we begin by observing that there is a direct substitutability that arises from the political challenger's resource constraint. This effect is straightforward and arises from the technology of 'discovering' memes, where allocation effort towards the discovery of an identity meme leaves the entrepreneur with fewer resources to allocate towards the discovery of the worldview meme. However, there is a more subtle effect that works in the opposite direction. In particular, there are conditions under which there exists a natural complementarity between investments in worldview and in identity politics.

We show that the returns to investing in the discovery of an identity (or worldview) meme are increasing in the resources allocated to discovering a worldview (or respectively identity) meme. In particular, Appendix A.2 shows that $d i / d w$ is positive when complementarity between investment in identity and worldview memes is sufficiently strong. This condition is described in the proposition below.

Proposition II: If $\left[\left(\mu_{1}-\mu_{0}\right)\left[\theta^{10}\left(S_{1}\right)-\theta^{10}\left(S_{0}\right)\right]+\left(1-2 \mu_{0}\right)\left[g+y^{01}\left(S_{0}\right)\right]-2 \varphi^{I} \varphi^{W}>0\right.$ : (a) we have a sufficient condition for ideational complementarity with di/dw $>0$;

(b) then greater identity polarization (i.e. $\left[\theta^{10}\left(S_{1}\right)-\theta^{10}\left(S_{0}\right)\right]$ ) will result in increased production of worldview memes.

The above proposition (part (a)) implies that full-spectrum ideational politics may be more effective than the sum of its two parts - namely, identity and worldview politics. There are two distinct sources that underpin this complementarity between worldview politics and the politics of identity.

First, the complementarity between identity and worldview politics is driven by worldview meme induced changes in the "association" effect - the payoff to a poor $A$ person from sharing an identity with the higher status (and average income) $A$ group. This intuition for this source of complementarity is easiest to observe when 
the identity driven utility is driven by (for example) relative group income. Suppose that the relative income of the $A$ 's is higher when the state is perceived to be $S_{1}$ (and $a_{1}$ adopted) rather than when the state is $S_{0}$ (and the status-quo policy $a_{0}$ retained). This means that a worldview meme, by persuading the voter that the state is $S_{1}$, can increase the payoff from identity to those who belong to the $A$ group. Therefore, in the presence of the "association" effect on identity, it is optimal for the political entrepreneur to invest more in discovering a worldview meme. For example, lowincome white voters may be willing to support a policy that benefits a rich minority (e.g. financial deregulation), if its adoption gives them an indirect bump in utility through association with other (now very) rich white beneficiaries of this policy.

This association effect is reinforced by an additional consideration. Remember that if voters perceive that the underlying state is $S_{0}$, then the adoption of policy $a_{1}$ has a negative impact on the income of the poor. Nevertheless, once identity is made salient, a subset of the poor will support this policy for reasons of loyalty to the identity group, even though supporting this policy has a negative impact on their income. To see this observe the impact of a worldview meme that persuades the poor citizen that the state has switched to $S_{1}$. Such a change in beliefs due to the worldview meme makes adoption of the new policy $a_{1}$ optimal for all the poor $A$ voters as the negative income effect of identity disappears. Therefore (in the presence of the worldview meme), supporting policy $a_{1}$ on grounds of identity is no longer perceived to be costly to the poor. This additional source of ideational complementarity makes it optimal for the political entrepreneur to invest more in identifying a worldview meme.

Part (b) of the above proposition suggests that greater identity polarization will be associated with the prevalence of inconsistent (and even contradictory) worldviews. For example, beliefs such as "President Obama is a Muslim" may coexist with beliefs that low taxes and fiscal austerity may be optimal for the poor and the country - even in the midst of a recession.

To see this, observe that the impact of an exogenous increase in identity polarization has two effects. First, by increasing the payoff from identity, this polarisation makes it attractive for the rich political challenger to discover such identity memes. This is because such identity memes help persuade the low-income citizen to vote on the basis of their identity, rather than their class interest. Furthermore, the ideational complementarity effect (see Proposition II (a)), ensures that this higher investment in 
the discovery of identity memes also gives rise to a higher production of worldview memes. This is because of the impact of greater identity polarization on the strength of the "association effect" amongst the subset of the poor that has a $A$ marker. This effect increases in size because relative income (and status) of the $A$ group goes up under $a_{1}$ (e.g low taxes or financial deregulation). In other words, the low-income voter gets more utility from identifying with his $A$ group in state $S_{1}$.

\subsubsection{Inequality and Ideational Politics}

Now consider the impact on the nature of ideational politics of an increase in inequality. To fix ideas, consider the example of a policy choice between high and low taxation. Here we assume that under the status-quo state $S_{0}$, the preferred policy of the median voter (who is poor) is the high tax policy $a_{0}$, while the preferred policy of the rich is the lower tax policy $a_{1}$. Suppose there is an exogenous shock (e.g., technological change or greater import competition) that results in an increase in income inequality in both states of the world. We capture this inequality in the form of higher wages of the rich, i.e. a higher $\bar{y}_{R}$.

This rise in inequality has two effects on the rich political challenger's incentives to engage in ideational politics. First, the direct income benefits to a rich political challenger from adoption of $a_{1}$ (i.e. lower taxes) are higher when inequality is higher. ${ }^{24}$ Therefore, under higher inequality, the rich challenger has a higher incentive to discover a worldview meme that the state is $S_{1}$ (i.e., that low taxes are good for all voters).

Second, observe that the higher inequality also gives rise to a higher incentive to engage in identity politics. The rise in inequality disproportionately benefits the identity group $A$, who constitute most of the rich. This gives rise to an ideational complementarity that is easiest to illustrate through the "association effect." In particular, if the political challenger can get the poor to identify with the rich through their common identity $A$, then he makes the increase in inequality more palatable to the poor by providing some associative status and utility. ${ }^{25}$

\footnotetext{
${ }^{24}$ In particular, the payoff to the rich challenger (captured by the rents $\mathcal{R}$ ) from being elected goes up with higher inequality. This is because a rich entrepreneur will implement policy $a_{1}$ (lower taxes) that boosts his utility and equal $\left(1-\mu_{1}\right) \bar{y}_{R A}^{1}\left(S_{0}\right)+\mu_{1} \bar{y}_{R A}^{1}\left(S_{1}\right)$ (indeed this follows from $d i^{*} / d \mathcal{R}>0$ (see appendix)).

${ }^{25}$ It can be argued that the political-ideational complex has played an important role in strengthening this 'association effect' by persuading citizens to buy into a worldview (and/or identity) that makes it easier to justify and live with prevailing high inequality. This is consistent with Piketty's
} 
Thus, greater economic inequality not only increases the incentive to engage in the politics of changing worldviews but also to introduce identity politics. Together, both these effects increase the likelihood that with an increase in inequality, there is both more intense identity polarization as well as greater prevalence of worldview memes. Therefore, the effect of higher inequality it to always increase the likelihood of both kinds of ideational politics, which together are likely to mitigate the prospect of higher taxes. We now use these ideas to empirically analyze ideational politics through the lens of economic inequality.

\section{Ideational Politics: An Empirical Exploration}

Our paper has emphasised the interdependence of ideas and economic interests. However, since both ideas and economic interests are endogenous, it is difficult to tell them apart empirically. Indeed, this is a problem with much of the case-based political economy literature highlighting the role of one or the other. This literature typically does not specify how an interest-based argument would be distinguished from an ideas-based one, leaving the conclusions open to alternative interpretations. ${ }^{26}$ If an economic interest or political party pushes a particular policy, is that because they have a vested interest in that policy or because of ideational forces that shaped their understanding of where their economic interests lie?

Thus, any empirical exercise that examines both ideational and interest-based politics faces an initial measurement challenge in distinguishing "ideas" from economic "interests" as defined above. We need a plausible way to classify identity memes and

(2014) conclusion that there has been a "huge change in the social representation of inequality" (pp. 419). Piketty draws on examples from popular culture to argue that they offer a "hymn to a just inequality, based on merit, education and the social utility of elites." This is corroborated by Carlsson et al. (2016), who provide empirical evidence that suggests that worldviews about what is fair, just, and meritocratic can be shaped by political entrepreneurs.

${ }^{26}$ For example, Calomiris and Haber (2014) argue that the financial crisis of 2008-2009 was the product of an alliance of interests between big banks and community groups. The former wanted lax regulation while the latter wanted cheap housing credit for low-income groups. As such, the argument seems to be about vested interests. But one is left wondering why community groups such as ACORN bought into a worldview that favored leveraging poor households with excessive amounts of debt that they might not be able to service down the line. Conversely, ideas-based accounts of Germany's advocacy of austerity policies in the euro zone (e.g. Blyth, 2013) downplay the structural role of Germany as a creditor nation with little economic slack -- leaving the country with much to gain and little to lose from such policies. 
distinguish them from worldview meme-messages. Moreover, there should be a plausible way to measure the intensity of memes - messages being supplied by each political party. In this paper, we measure ideational politics using records on political advertising. Using information on the issues that politicians talk about in their ads, we can quantify variation in ideational politics. In particular, we can attend to political issues related to worldviews and those related to identity.

A second challenge is that, even with a measurement of ideational politics in hand, there is the problem of endogenous selection of messaging types. Many factors contribute to variation in ideational politics, so getting at the model's predictions requires a natural experiment. In this section, we shed light on the mechanisms underlying ideational politics indirectly, by examining it through the prism of inequality. Our conceptual framework suggests that an increase in unemployment and/or inequality will provide the party of the rich and the party of the poor with different incentives to search and discover memes. Accordingly, we analyze the China import shock as a natural experiment for this purpose.

\subsection{The China Shock and Ideational Politics}

We examine the effects of increased exposure to trade and foreign competition following China's accession to the WTO - the so-called "China Shock" (Autor et al., 2016). As documented in a series of papers, local labour markets in the U.S. with industries more exposed to trade with China had a rise in unemployment, factory closures, and wage declines for all workers, increasing wage inequality (Acemoglu et al., 2016; Autor et al., 2014; Galle et al., 2017; Caliendo et al., 2019; Autor et al., 2020). We examine the impact of this geographical variation in unemployment and inequality on the supply of political messages in local media markets by the two main political parties - the Republican and the Democratic Party, respectively representing the economic interests of the rich and the poor.

To organize ideas, say there are two types of local labour markets - those that were more exposed to competition (and the resultant economic dislocation and wage inequality) from China (the CS regions) and those that were not (non-CS regions). In this context, the "China Shock" - by increasing unemployment and wage inequality would sharpen class conflict and increase the demand for higher taxes and redistributive transfers. Our conceptual framework suggests that there would be a relatively greater 
shift towards ideational politics in CS regions compared to non-CS regions. More concretely:

Rise of Ideational Politics in CS regions. The political party that represents the interests of the higher income voter (i.e. the Republican party) will have a greater incentive than the political party that represents the interests of the poor (i.e. Democrats) to engage in ideational politics in CS regions (i.e. "China shock") as compared to non-CS regions. This intensity of ideational politics can be measured in terms of both the number of messages as well as their variety/distinctiveness.

(ii) The Republican Party and Identity Politics. The Republican party should have more of an incentive to engage in "identity politics" in CS regions as compared to non-CS regions. This will result in the greater production and dissemination of identity memes/messages that distract the low-income median voter from seeking policies to address adverse economic shocks by making other aspects of identity salient. In particular, the share of political advertising from the Republican party should be higher on identity issues such as gay marriage, women's rights, and immigration.

(iii) Inequality and Worldview Politics. Our conceptual framework suggests that while both parties will engage in worldview politics, the Republican party has more of an incentive to do so - to disseminate messages that budget balance, austerity and low taxes are good for the interests of the poor - in CS regions as compared to non-CS regions.

(iv) Inequality and Ideational complementarity. Our framework predicts that political messages using both identity and worldview memes are likely to be higher in Republican political advertising in CS-regions than non-CS regions.

These predictions motivate the subsequent analysis. We examine the impact of the China shock on political messaging over the period 2000 through 2018. We compare differences in the nature of political advertising by Democrats and Republicans across media markets that have been more strongly exposed to the China shock. 


\subsection{Political Advertising Data}

The main dataset is on political television advertisements (hereafter "ads"). The Wesleyan Media Project (WMP) database (previously called the Wisconsin Ads Project) has rich data on political advertising over the last two decades. ${ }^{27}$ In particular, WMP has data on over 60,000 unique political advertisements for election years from 2000 through 2018. The data for 2000 through 2008 include congressional (house and senate), gubernatorial, and presidential election ads. The data starting in 2010 include local (mayor, city council) elections. In addition, the sample expanded from the top 75 media markets to the top 100 markets in 2004, with all 200 markets starting 2008. ${ }^{28}$

Beyond the differences in the sample of races, the variables collected have varied somewhat across years. We undertook extensive cleaning and pre-processing to make the data as consistent as possible (see Appendix B.1). Appendix Figure B.1 shows illustrative Democrat and Republican ads from the database.

The WMP annotators use a total of 84 issue tags when labeling the ads. The full list is shown in Appendix Table B.1. Many of these issues are closely related to each other, and some are quite rare. Therefore we merged the closely related issues with each other, and we produced a shorter list of 30 issue categories. The merging of issues is detailed in Appendix Table B.2. For example, "Taxes" includes both "Taxes" and "2017 Tax Reform Bill".

The number of ads for each issue is shown in Figure 1 Panel A. First, we see that, unsurprisingly, issues related to economic interests, such as economy, taxes, healthcare, jobs, and education, are commonly invoked. Yet other issues with a central ideational component, such as moral values, foreign policy, abortion, and gun control, are also often discussed in advertising. As a stylized fact, then, we can establish that ideational politics are plentiful in political advertising. Certainly, interests are commonly invoked, but a lot of political messaging has to do with things that are not related to material interests.

\footnotetext{
${ }^{27}$ This data has been used in a range of previous research. Fowler et al. (2018) use the data for a book-length descriptive analysis of U.S. political advertising. A noteworthy paper, Sides et al. (2021), use a border discontinuity design to demonstrate a causal effect of advertising exposure on local election vote shares. Galletta and Ash (2021) shows that in areas with higher exposure to conservative news, candidates shift advertising content away from welfare issues toward taxes and deficits.

${ }^{28}$ Appendix Figure B.2 shows the number of distinct ads across the different election types, separately by party. Appendix Figure B.3 shows the number of ads in the database by party over time.
} 
Figure 1: Ad Counts By Issue and Party

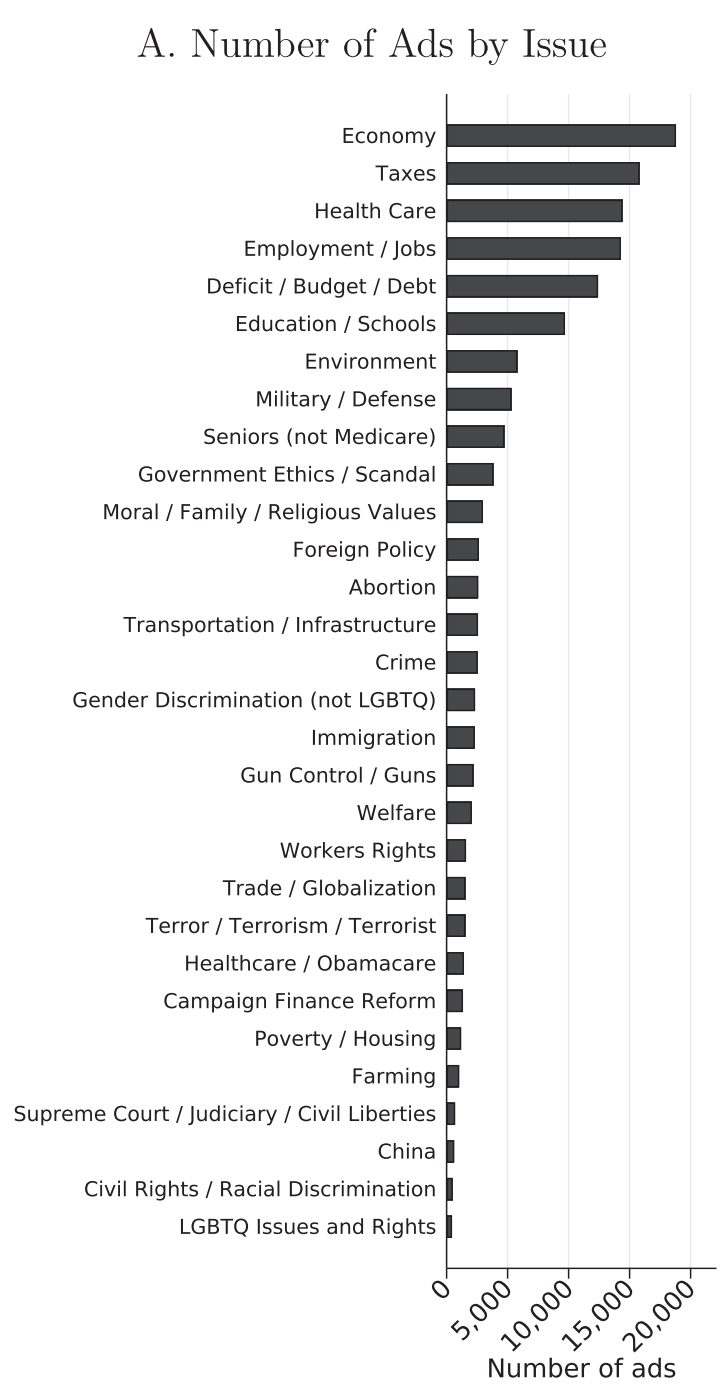

B. Party Difference in Ads by Issue

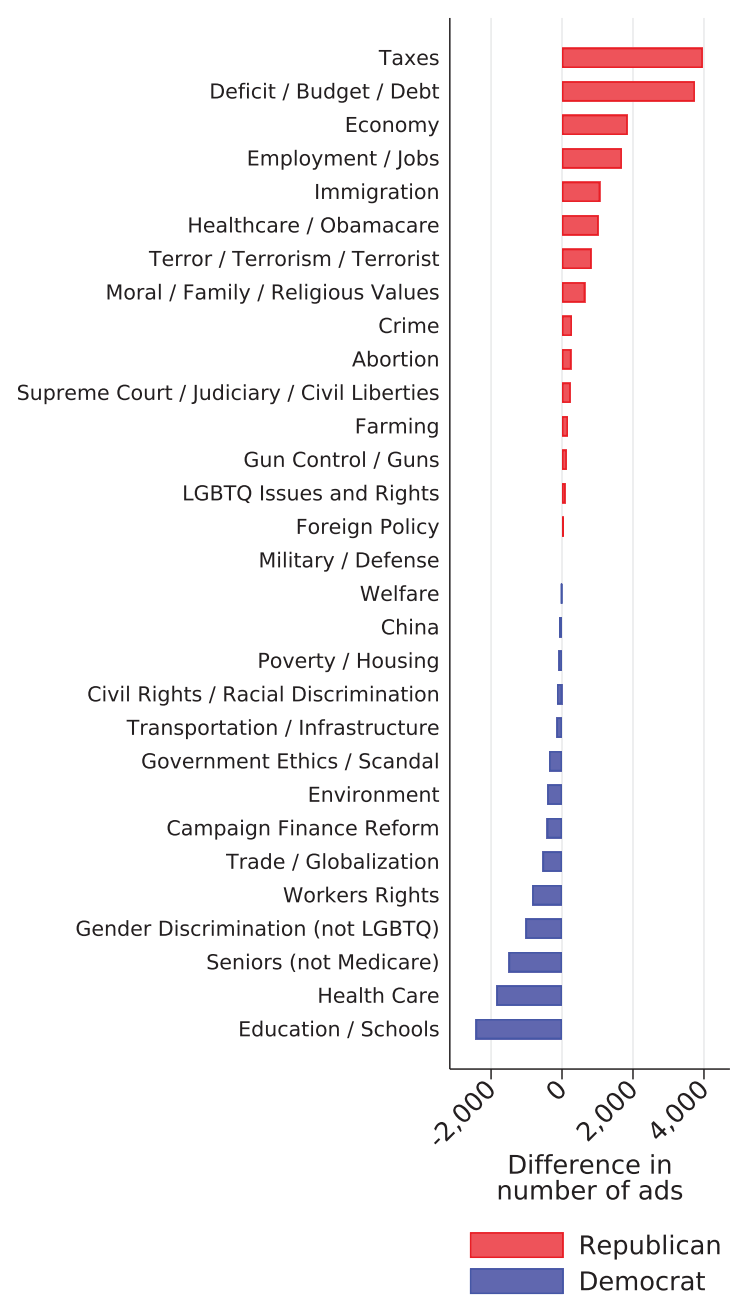

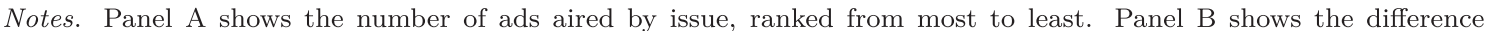
between Republicans and Democrats in the number of ads aired, sorted from most Republican to most Democrat. 
Next, Figure 1 Panel B shows the differences by issue between the political parties in their allocation of ads across issues. The differences in ads intuitively reflect the differences in the policy priorities of the parties. Republicans tend to allocate time to taxes and deficits, for example, while Democrats spend more ad time on education and healthcare. Some of these differences are in the ideational domain, with Republican time spent on deficits a notable example of partisan worldview politics. Further, Republicans tend to air more ads about immigration, terrorism, moral values, abortion, and gun control. Meanwhile, Democrats have different ideational priorities on gender discrimination and trade.

In the results reported below, for brevity and clarity we focus on eleven issues out of the thirty: taxes, deficits, moral values, abortion, immigration, gun control, welfare, trade, terrorism, Obamacare, and China. These eleven issues were picked based on what has been highlighted in the previous literature on ideas, polarization, and populism (e.g. Rodrik, 2020). They are relatively frequent in the ads, relatively easy to interpret in terms of their place on the left-right ideological spectrum, and have relevance to ideational politics - whether about worldview or about identity. Focusing on issue categories where the ideational versus material-interests distinction can be made more clearly allows for a cleaner empirical exercise. In the appendix we report results with all issues, and the qualitative implications are the same.

\subsection{Identifying Unemployment shocks}

This section describes the empirical strategy and estimation approach. We start by accounting for the data and how the China shock treatment is linked to the advertising issue outcomes. Then the regression specification is given and the identification assumptions are specified. We use notation that differs from the notation used above in the theoretical model.

The dataset is indexed geographically by county $c$, which are linked to commuting zone $z$, and media market area $m$. The data are indexed temporally by biennium $t$, corresponding to each two-year election cycle (1999-2000, 2001-2002, etc.). An observation corresponds to a county-biennium.

We have the data on Chinese competition from Autor et al. (2016). In the standard framework, the endogenous regressor $D_{z}$ is the change in manufacturing employment in commuting zone $z$ between 1991 and 2011. The instrument $Z_{z}$ is the sector-weighted 
predicted shift in manufacturing employment in $z$ due to Chinese import competition. It is a shift-share instrument, where the shift is the change in China exports to non-U.S. countries in a sector, and the share is the share of $z$ 's employment in that sector.

The ads dataset contains information about how many times each ad is aired on television in media market (DMA, for designated market area) $m$ during election year $t$. For each issue-DMA-biennium, we count the number of unique ads aired and the total number of ad airings. We then define $Y_{m t}^{p k}$ as the share of ads (or airings) by party $p$ (Democrat or Republican) in market $m$ on issue $k$ during election year $t$.

Commuting zones and media markets do not overlap perfectly. However, each county can be assigned to a unique commuting zone and a unique media market. Therefore, we build our dataset at the county level, where we assign to each county $c$ the China-shock variables for the associated commuting zone $z$ and the advertising variables for the associated media market $m$. The outcome for the regression is indexed as $Y_{c m z t}^{p k}$.

The empirical approach is instrumental variables, following the design in Autor et al. (2016). In the first stage, manufacturing employment is regressed on the shiftshare instrument for import competition. The regression is at the county level, using the values from the associated commuting zone. Formally, the first stage is

$$
D_{z}=\alpha_{t}+\gamma Z_{z}+\eta_{c m z t}
$$

where $\alpha_{t}$ is a year fixed effect and standard errors are clustered by commuting zone. The first stage is visualized as a binscatter diagram in Appendix Figure B.5. We obtain a Kleinbergen-Paap First-Stage F-statistic of 27.72, indicating a strong first stage.

The baseline results use the reduced form, with the advertising outcome directly regressed on the instrument:

$$
Y_{c m z t}^{p k}=\alpha_{t}+\phi Z_{z}+\nu_{c m z t}
$$

and standard errors clustered by commuting zone. In the appendix, we report twostage-least squares (2SLS) results using

$$
Y_{c m z t}^{p k}=\alpha_{t}+\phi D_{z}+\varepsilon_{c m z t}
$$


with $D_{z}$ instrumented by $Z_{z}$. To adjust for new DMA's entering the sample over time, we include a fixed effect indicating the number of years that a county is in the estimation sample.

Autor et al. (2016) provide an extensive discussion of the exogeneity of the instrument. Given the similarity of our analysis to that paper and to Autor et al. (2020), we have some reassurance about the validity of the research design. We have undertaken additional diagnostics to assess selection in the advertising issue shares. We do not see any evidence that the estimated China-shock effects on ideational politics are driven by pre-existing differences that are correlated with the instrument. ${ }^{29}$

Exogeneity is sufficient for consistent estimates in the reduced form. Consistency of 2SLS requires additionally that the data satisfy the exclusion restriction - that the China shock instrument only influences advertising through its effect on measured unemployment. That restriction is a strong assumption in our setting because Chinese import competition shocks could affect local politics through other channels besides unemployment. Thus, the reduced form is our preferred estimating specification and we report 2SLS results in the appendix.

\subsection{China Shock Effect on Ad Messaging}

This section reports the main results for the effects of the China shock on advertising content. We report estimates from the reduced form equation (3) for the years 2008 through 2018. These regressions summarize the party-specific effects of the China shock instrument on the shares of ads about each issue in this time period.

As mentioned, we focus in the main text on the ten selected issues for clarity and brevity. The results for all thirty issues are shown in Appendix Figure B.8. The noteworthy, yet unsurprising, result from looking at all issues is that both parties increase advertising about employment/jobs, reflecting responsiveness to local economic problems and that economic interests remain an important driver of political priorities.

Figure 2 reports these results as coefficient plots with 95\% confidence intervals, with the issues sorted by the Republican effect magnitude (most positive to most negative). Republicans increase ads on abortion, moral values, terrorism, gun control,

\footnotetext{
${ }^{29}$ Appendix Figure B.10 shows the main result coefplot for the first two electoral cycles, 2000/2002. The issues where we see effects in the main sample (Figure 2) do not already have an effect in this early period. Further, our results are robust to controlling for a DMA's 2000/2002 advertising shares (Appendix Figure B.11).
} 
Figure 2: China Shock Effect on Ad Issue Shares, by Party

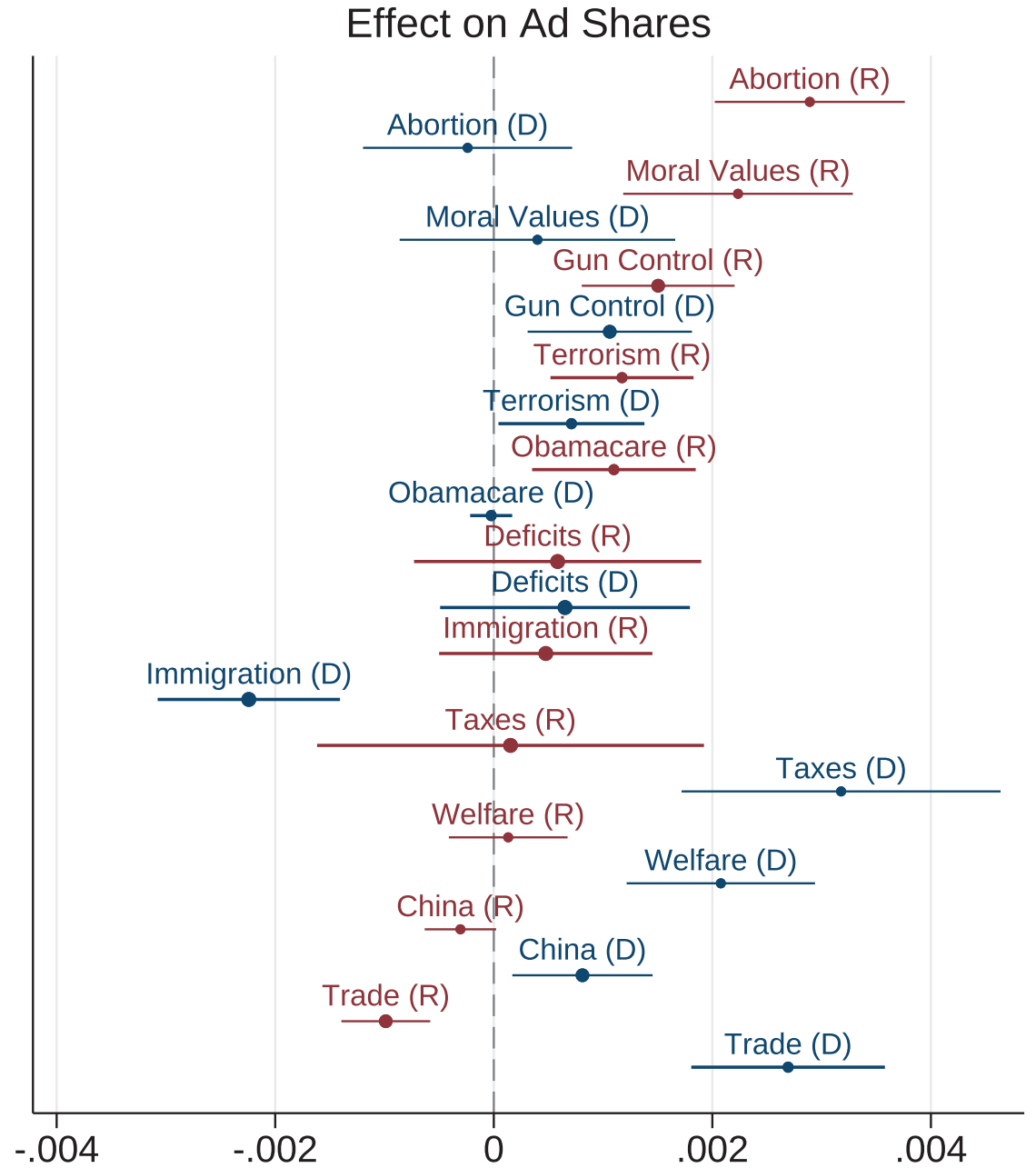

Notes. This figure shows a coefficient plot from the main reduced-form regression of advertising shares by party on the China shock instrument, for the elections from 2008 to 2018 . Red series is for Republicans, while blue is for Democrats. Error spikes give $95 \%$ confidence intervals. Coefficients sorted by Republican effect size. 
and Obamacare, while decreasing ads about trade. Democrats increase advertising related to taxes, trade, welfare, and China, while reducing ads about immigration.

These results highlight the relevance of ideational politics in conditions of economic inequality. Democrats, as the low-income party, do focus on the redistributive issues of taxes and welfare. Republicans, on the other hand, increase their focus on identityrelated issues like abortion, values, gun control, and terrorism. There are no clear economic-interests-based reasons that higher inequality would mean greater policy focus on these issues. These shifts do make sense, however, in light of an increase in the returns to identity politics.

Additional supporting results are reported in Appendix B.2. For example, if we look at the effects of the issue categories used by WMP, we see that both parties shift to economic issues in response to the China shock, but only Republicans shift to social issues (Appendix Figure B.6). Further, both parties decrease ads about the environment.

The empirical results are robust to a number of alternative specification choices. First, the main results are not sensitive to other specifications for the outcome variable on advertising (Appendix Figure B.9). The rankings are similar when looking at the share of total airings of ads, instead of the share of unique ads (Panel A). Results are similar when looking at the volume of advertising rather than shares (Panel B). Finally, the results are also similar when standardizing the outcome variables (Panel C).

Appendix Figure B.12 collects a number of additional specification checks. We produce similar results with two-stage least squares, where manufacturing unemployment is instrumented with the import competition shock (Panel A). Results are robust to adding state fixed effects (Panel B), or controlling for local county characteristics population, Republican vote share, and demographics (Panel C). The statistical significance on the main results is similar when clustering by DMA or state rather than commuting zone, or two-way clustering (Panel D).

There are two reasonable alternative explanations for these results, aside from our model's focus on changes in supply-side incentives for ideational politics. First, it could be that the effects are due to a simpler explanation - that the China shock works by increasing the partisanship or polarization of debate. That is, rather than reflecting a move to ideational politics, our estimates reflect a move by both parties toward the more partisan issues. We check for this by plotting the China-Shock effect on each 
issue against the pre-existing partisan preference for each issue. As shown in Appendix Figure B.14, there is no discernible relationship. Hence, we can rule out that our effects can be explained just by increasing polarization. A concept of ideas is needed.

Second, it could be that what we are treating as a supply-side effect is actually a demand-side effect. On this view, the China Shock works by shifting voter preferences, for example through a loss of identity as a worker. The changes in ads that we observe, then, are a pandering response to the change in voter attitudes. The evidence in Autor et al. (2020), showing that the China Shock increased Republican vote share and viewership of Fox News Channel, could be interpreted as supporting a demandside effect.

Thus we would like to check whether the supply side is also important. To assess the quantitative relevance of the demand-side explanation, we collected survey data from the Gallup Polling Social Series - in particular, the question asked of all respondents about what is currently the "Most Important Problem" (MIP) facing U.S. society. For most of the issue categories from the Wesleyan ads data, we could match them to the corresponding MIP responses (see Appendix Table B.3). We can then estimate the China shock effect on the MIP responses by issue, the same way we have done for the ads.

We are most interested in the dynamics of the effect. If there is a significant effect on the MIP responses before the shift in advertising, that would be consistent with the effect mainly being driven by preferences, with the advertising effect coming later as a follow-on to the preference effect. If, however, there is a shift in advertising before a shift in preferences, that would be inconsistent with demand-side factors being most important, and would be consistent with supply-side responses playing an important role.

Figure 3 shows the time series of the effects for two issues that are central to ideational politics among U.S. Republicans - abortion and gun rights. On the left side, we show the effects on ads by Republican politicians. On the right side, we show the effects on Gallup Most Important Problem responses for Republican survey respondents. ${ }^{30}$ We observe that starting in the 2008-2010 election cycles, there is a

\footnotetext{
${ }^{30}$ Note that from an identification perspective, it is reassuring that there is no effect in the first period of the data (2000-2002), before China import competition had significantly reshaped the manufacturing sector (see also Appendix Figure B.10). Consistent with Autor et al. (2013), the instrument is not endogenously higher in places with pre-existing ideational messaging on moral/identity issues.
} 
Figure 3: Effect on Republican Ads and Republican MIP Responses Over Time

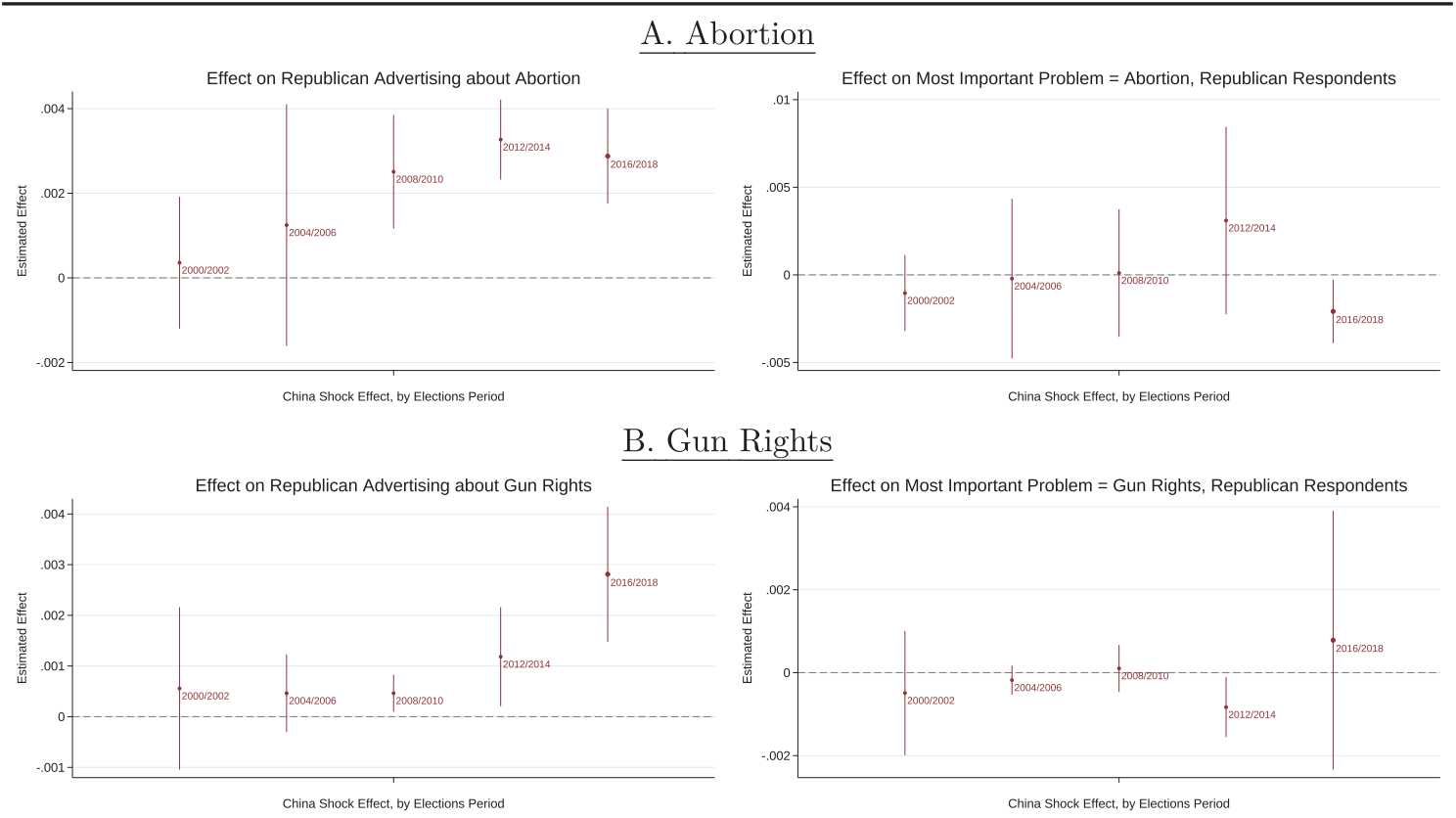

Notes. This figure shows a coefficient plot from the main regression of advertising shares (left side) and Gallup MIP response share (right side) by year for Republicans on the China shock instrument. Figures show the evolution of the effect for abortion (panel A) and gun rights (panel B). Error spikes give 95\% confidence intervals.

positive and significant effect of the China shock on Republican advertising messaging about abortion and gun rights, which grows larger over the subsequent years. For the MIP response shares, however, there is not much of an effect. We don't see a positive coefficient until 2012/2014 for abortion, and until 2016/2018 for gun rights, and none of them is close to statistically significant. These results suggest that our estimated effects on advertising are not primarily driven by demand-side changes in voter attitudes.

Appendix B.2 provides some additional supporting results on the issue of demandside changes. Overall, there is not much of an effect on the MIP response shares for any of the issues where we saw advertising effects (Appendix Figure B.15). Further, our main regression results are robust to controlling for MIP response shares, suggesting they are not a pivotal mediator for our results (Appendix Figure B.16). While we cannot completely rule out that demand-side effects are operative, our evidence is consistent with the supply-side channel being the main driver of the observed effects. 
Figure 4: Complementarity: China Shock Effect on Joint Issue Mentions

\begin{tabular}{|c|c|c|c|c|c|c|c|c|c|}
\hline & Taxes & Deficits & Trade & Immigration & Obamacare & Terrorism & LGBTQ & $\begin{array}{l}\text { Moral } \\
\text { Values }\end{array}$ & Abortion \\
\hline Employment & 0.0845 & 0.0325 & -0.0287 & 0.0049 & 0.0071 & 0.0125 & 0.0043 & 0.0499 & 0.0382 \\
\hline Taxes & & -0.0386 & -0.0128 & 0.0128 & 0.0185 & -0.0038 & 0.0042 & 0.0191 & 0.0367 \\
\hline Deficits & & & -0.0057 & 0.0143 & 0.0307 & 0.0128 & 0.0075 & 0.0117 & 0.0502 \\
\hline Trade & & & & -0.0168 & 0.0010 & -0.0016 & 0.0000 & 0.0033 & 0.0011 \\
\hline Immigration & & & & & 0.0285 & 0.0118 & 0.0004 & 0.0234 & 0.0229 \\
\hline Obamacare & & & & & & 0.0135 & 0.0017 & 0.0031 & 0.0156 \\
\hline Terrorism & & & & & & & 0.0004 & -0.0009 & 0.0084 \\
\hline LGBTQ & & & & & & & & 0.0096 & 0.0133 \\
\hline Moral Values & & & & & & & & & 0.0344 \\
\hline
\end{tabular}

Notes. Each cell in the matrix reports the reduced-form coefficient from regressing the indicated joint issue outcome (share of ads mentioning both the row issue and the column issue) on the China shock instrument. Colors indicate coefficient size, with red for positive and gray for negative. See Appendix B.3 for corresponding results on other issues, and for Democrats.

\subsection{Complementarity of Identity and Worldview Messages}

So far we have shown evidence consistent with significant messaging on ideas, and a response to inequality with identity-based messaging. The model provides an additional prediction that an increase in one type of ideational politics (e.g. identity) would increase the returns to another type of ideational politics (e.g. worldview). In this subsection we provide some suggestive evidence that throws light on this ideational complementarity.

To this end, we produce a new dataset of advertising content outcomes, based on the joint appearance of issues within the same ad. Now, we have an outcome $Y_{c z m t}^{k l p}$ as the share of ads by party $p$ that are about both issue $k$ and issue $l$, in media market $m$ at election period $t$. Excluding issue pairs that never appear together, the resulting dataset has 435 outcomes.

We then regress each joint share variable on the China instrument, following the same regression approach as above. With 435 outcomes and two political parties, we have 870 regression estimates for the baseline specification. We report a selection of 
results to make the central points. ${ }^{31}$

Figure 4 reports regression coefficients from the joint issue regressions for the selected issues, plus (un)employment. Each cell of the matrix shows the reduced-form coefficient for the joint issue indicated by the row and column. The issues are ordered roughly from those related to interests/worldview, to those related to values/identity. The matrix shows our evidence on how China shock affects joint mentions of issue pairs.

The visually striking feature of this table is the block of red at the top-right of the matrix, corresponding to the most worldview-oriented issues by row and the most identity-based issues by column. In response to the China shock, there are more ads that mix together worldview-oriented issues (such as employment, taxes and deficits) and identity-oriented issues (such as abortion and moral values). These results are consistent with the model's propositions about a complementarity between worldview and identity modes of meme production.

\section{Discussion}

This paper has developed a conceptual framework that highlights the role of ideas as a catalyst for policy and institutional change. In doing so, the paper integrates the Keynes-Hayek perspective on the importance of ideas with the Stigler-Becker materialinterests-only approach to political economy. Within the space of ideas, moreover, we show the relevance of identities and worldviews as distinct message types that reinforce each other.

The model's predictions have proven useful in organizing and analyzing data on how messaging by political parties responds to a shock to labor markets. Our empirical results on advertising are consistent with the model and are difficult to explain without ideational politics. Yet this empirical application is just a starting point. Future work could dig into the text content of ads, or even the audio and video, to get at more granular distinctions in how issues are framed and how policy agendas are pursued.

We should caution against interpreting our model too narrowly. In particular, it could be argued that rather than making a case for ideas, we have simply strengthened the argument for interests. After all, the interests of the political challenger drive

\footnotetext{
${ }^{31}$ Appendix B.3 provides additional supporting material on the complementarity results.
} 
worldview and identity memes. However, even though our present model took those interests as given, elites' desired policies could be as much a function of their identity and worldview as is the case for non-elites. Any explanation that runs only off the importance of vested interests begs the question of where powerful groups get their ideas about their interest in the first place.

Our analytical wedge between ideas and interests relies on a distinction between exante versus ex-post salience of identities and worldviews. Interests are determined by identities and worldviews that are salient ex ante. Ideas possibly intervene to transform these ex post. A broader implication of our framework, therefore, is that today's ideas become tomorrow's interests. In the very short run, it is all about interests. In the long run, it is all ideas. 


\section{References}

Acemoglu, D. (2003). Why not a political coase theorem? social conflict, commitment, and politics. Journal of comparative economics, 31(4):620-652.

Acemoglu, D., Autor, D., Dorn, D., Hanson, G. H., and Price, B. (2016). Import competition and the great us employment sag of the 2000s. Journal of Labor Economics, 34(S1):S141-S198.

Acemoglu, D. and Robinson, J. A. (2006). Economic origins of dictatorship and democracy. Cambridge University Press.

Akerlof, G. A. and Kranton, R. E. (2000). Economics and identity. Quarterly Journal of Economics, 115(3):715-753.

Akerlof, G. A. and Snower, D. J. (2016). Bread and bullets. Journal of Economic Behavior \& Organization, 126:58-71.

Alonso, R. and Câmara, O. (2016). Persuading voters. American Economic Review, 106(11):3590-3605.

Anderson, S. L. (1976). Coconsciousness and numerical identity of the person. Philosophical Studies, 30(1):1-10.

Ash, E., Chen, D. L., and Naidu, S. (2020). Ideas have consequences: The impact of law and economics on american justice. Center for Law $\&$ Economics Working Paper Series, 4.

Ashok, V., Kuziemko, I., and Washington, E. (2015). Support for redistribution in an age of rising inequality: New stylized facts and some tentative explanations. Technical report, National Bureau of Economic Research.

Autor, D., Dorn, D., Hanson, G., and Majlesi, K. (2020). Importing political polarization? the electoral consequences of rising trade exposure. American Economic Review, 110(10):3139-83.

Autor, D. H., Dorn, D., and Hanson, G. H. (2013). The china syndrome: Local labor market effects of import competition in the united states. American Economic Review, 103(6):2121-68.

Autor, D. H., Dorn, D., and Hanson, G. H. (2016). The china shock: Learning from labor-market adjustment to large changes in trade. Annual Review of Economics, 8:205-240.

Autor, D. H., Dorn, D., Hanson, G. H., and Song, J. (2014). Trade Adjustment: Worker-Level Evidence. Quarterly Journal of Economics, 129(4):1799-1860.

Bartels, L. M. et al. (2006). What's the matter with what's the matter with kansas? 
Quarterly Journal of Political Science, 1(2):201-226.

Becker, G. S. (1983). A theory of competition among pressure groups for political influence. The quarterly journal of economics, 98(3):371-400.

Bénabou, R. (2008). Ideology. Journal of the European Economic Association.

Bénabou, R., Ticchi, D., and Vindigni, A. (2015). Religion and innovation. American Economic Review, 105(5):346-51.

Benabou, R. and Tirole, J. (2002). Self-confidence and personal motivation. Quarterly Journal of Economics, 117(3):871-915.

Blouin, A. and Mukand, S. W. (2019). Erasing ethnicity? propaganda, nation building, and identity in rwanda. Journal of Political Economy, 127(3):1008-1062.

Blyth, M. (2013). Austerity: The history of a dangerous idea. Oxford University Press.

Bonomi, G., Gennaioli, N., and Tabellini, G. (2021). Identity, beliefs, and political conflict. The Quarterly Journal of Economics, 136(4):2371-2411.

Buiter, W. H. et al. (2014). The role of central banks in financial stability: How has it changed. The Role of Central Banks in Financial Stability: How Has It Changed, pages $11-56$.

Caliendo, L., Dvorkin, M., and Parro, F. (2019). Trade and labor market dynamics: General equilibrium analysis of the china trade shock. Econometrica, 87(3):741-835.

Calomiris, C. W. and Haber, S. H. (2014). Fragile by design: the political origins of banking crises and scarce credit. The Princeton economic history of the Western world. Princeton University Press, Princeton, New Jersey.

Campbell, J. L. (2002). Ideas, politics, and public policy. Annual review of sociology, 28(1):21-38.

Carlsson, M., Dahl, G. B., and Rooth, D.-O. (2016). Do politicians change public attitudes?

Cerrato, A., Ferrara, F. M., and Ruggieri, F. (2018). Why does import competition favor republicans? Available at SSRN 3147169.

Cerulo, K. A. (1997). Identity construction: New issues, new directions. Annual review of Sociology, 23(1):385-409.

Collier, P. (2016). The cultural foundations of economic failure: A conceptual toolkit. Journal of Economic Behavior \& Organization, 126:5-24.

Dawkins, R. (1976). The selfish gene.

DellaVigna, S. and Gentzkow, M. (2010). Persuasion: Empirical evidence. Annual Review of Economics, 2(1):643-669.

Dietrich, F. and List, C. (2011). A model of non-informational preference change. 
Journal of theoretical politics, 23(2):145-164.

Dorn, D., Hanson, G., Majlesi, K., et al. (2020). Importing political polarization? the electoral consequences of rising trade exposure. American Economic Review, 110(10):3139-83.

Downs, A. (1957). An Economic Theory of Democracy. Harper, New York.

Enke, B. and Zimmermann, F. (2019). Correlation neglect in belief formation. The Review of Economic Studies, 86(1):313-332.

Farrell, H. and Quiggin, J. (2011). Concensus, dissensus and economic ideas: The rise and fall of keynesianism during the economic crisis. Technical report.

Fearon, J. D. and Laitin, D. D. (2000). Violence and the social construction of ethnic identity. International organization, 54(4):845-877.

Fowler, E. F., Franz, M. M., and Ridout, T. N. (2018). Political advertising in the United States. Routledge.

Frank, T. (2007). What's the matter with Kansas?: How conservatives won the heart of America. Picador.

Galle, S., Rodríguez-Clare, A., and Yi, M. (2017). Slicing the pie: Quantifying the aggregate and distributional effects of trade. Technical report, National Bureau of Economic Research.

Galletta, S. and Ash, E. (2021). How cable news reshaped local government.

Gennaioli, N. and Shleifer, A. (2010). What comes to mind. The Quarterly journal of economics, 125(4):1399-1433.

Glaeser, E. L. (2005). The political economy of hatred. The Quarterly Journal of Economics, 120(1):45-86.

Grossman, G. M. and Helpman, E. (1993). The politics of free trade agreements.

Grossman, G. M. and Helpman, E. (2021). Identity politics and trade policy. The Review of Economic Studies, 88(3):1101-1126.

Hacker, J. S. and Pierson, P. (2020). Let them eat tweets: How the right rules in an age of extreme inequality. Liveright Publishing.

Haidt, J. (2012). The righteous mind: Why good people are divided by politics and religion. Vintage.

Hayek, F. A. (1949). The intellectuals and socialism. The University of Chicago Law Review, 16(3):417-433.

Jackson, M. S. (2011). Priming the sleeping giant: The dynamics of latino political identity and vote choice. Political Psychology, 32(4):691-716.

Jain, S., Majumdar, S., and Mukand, S. W. (2014). Walk the line: Conflict, state 
capacity and the political dynamics of reform. Journal of Development Economics, 111:150-166.

Johnson, S. and Kwak, J. (2010). 13 bankers: The Wall Street takeover and the next financial meltdown. Vintage.

Keynes, J. M. (1936). Allgemeine Theorie der Beschäftigung, des Zinses und des Geldes, volume 6.

Kinder, D. R. and Sanders, L. M. (1996). Divided by color: Racial politics and democratic ideals. University of Chicago Press.

Lenin, V. I. (1902). What is to be Done? Wellred Books.

Levy, G. and Razin, R. (2015). Correlation neglect, voting behavior, and information aggregation. American Economic Review, 105(4):1634-45.

Mayer, J. (2017). Dark money: The hidden history of the billionaires behind the rise of the radical right. Anchor.

Mendelberg, T. (2001). The Race Card: Campaign Strategy, Implicit Messages, and the Norm of Equality. Princeton Paperbacks. Princeton University Press.

Molden, D. C. (2014). Understanding priming effects in social psychology: What is "social priming" and how does it occur? Social cognition, 32(Supplement):1-11.

Mukand, S. and Rodrik, D. (2018). The Political Economy of Ideas: on Ideas versus Interests in Policymaking. Technical report, National Bureau of Economic Research. Mullainathan, S., Schwartzstein, J., and Shleifer, A. (2008). Coarse thinking and persuasion. The Quarterly Journal of Economics, 123(2):577-619.

Persson, T., Tabellini, G., et al. (2000). Political economics.

Pinna, M. (2020). Binned scatterplots with marginal histograms: Binscatterhist.

Quadagno, J. S. et al. (1994). The color of welfare: How racism undermined the war on poverty. Oxford University Press.

Rodrik, D. (2014). When ideas trump interests: Preferences, worldviews, and policy innovations. Journal of Economic Perspectives, 28(1):189-208.

Rodrik, D. (2020). Why does globalization fuel populism?

Ruggie, J. G. (1998). What makes the world hang together? neo-utilitarianism and the social constructivist challenge. International organization, 52(4):855-885.

Sen, A. (2007). Identity and violence: The illusion of destiny. Penguin Books India.

Shayo, M. (2009). A model of social identity with an application to political economy:

Nation, class, and redistribution. American Political science review, 103(2):147-174.

Shepsle, K. A. and Noll, R. (1985). Comment of why the regulators chose to deregulate. Regulatory policy and the social sciences, pages 231-39.

Shiller, R. J. (2017). Narrative economics. American Economic Review, 107(4):967- 
1004.

Sides, J., Vavreck, L., and Warshaw, C. (2021). The effect of television advertising in united states elections.

Skidelsky, R. and Fraccaroli, N. (2017). Austerity vs Stimulus. Springer.

Stigler, G. J. (1971). The theory of economic regulation. The Bell journal of economics and management science, pages 3-21.

Strömberg, D. (2015). Media and politics. economics, 7(1):173-205.

Wendt, A. (1999). Social theory of international politics, volume 67. Cambridge University Press.

Wilkinson, S. (2006). Votes and violence: Electoral competition and ethnic riots in India. Cambridge University Press. 


\section{A Model Appendix}

\section{A.1 Summary of Model Payoffs}

Table A.1: Summary of Payoffs from Memes

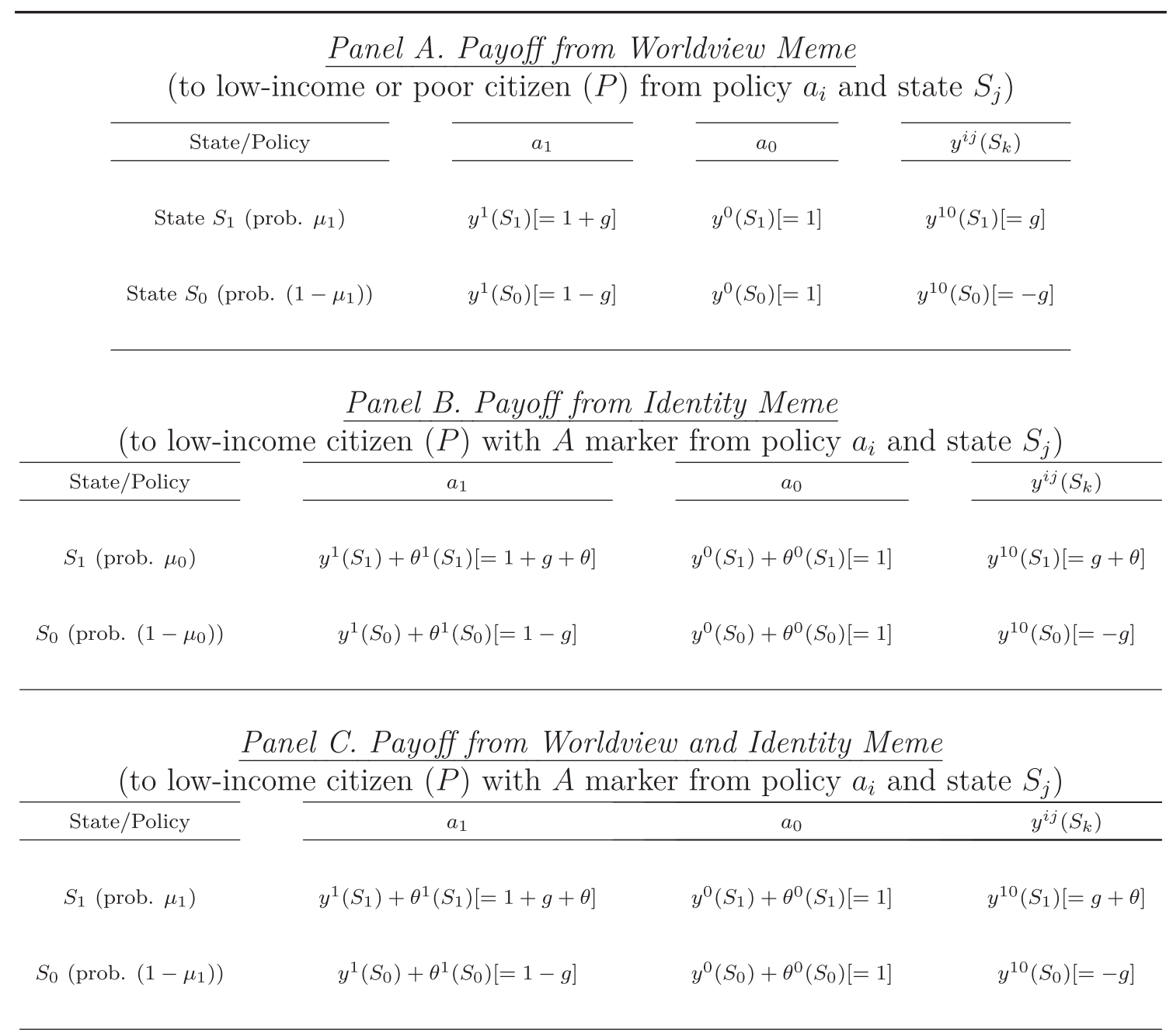

Notes. Summary of payoffs to meme production. Payoffs in the square brackets, correspond to Appendix A.2. 


\section{A.2 Model Proofs}

\section{Proof of Proposition 1.}

Since this is a finite-period game, we solve for the equilibrium backwards. As politicians are unable to credibly pre-commit to any particular policy, the political incumbent in the last period $(T=3)$ implements his preferred policy. Therefore, all citizen-voters in the penultimate period $T=2$ vote for the candidate under whom they perceive utility will be highest in the last period. That is, voters choose amongst candidates to maximize utility as a function of the relative congruence of their preferences across candidates, including the aggregate relative popularity shock $\delta$ (i.e. relative charisma) of the incumbent versus the political challenger. For simplicity (and without loss of generality), in period $T=2$, we focus on the sub-game where the rich political challenger with the $A$ identity marker has successfully generated both identity memes (i.e. identity is salient) as well as worldview memes (i.e. beliefs about the underlying state of the world have shifted towards $\mu_{1}$ ). He faces a political incumbent who is poor and has the identity $B$ and prefers the status quo policy $a_{0}$. In this case the perceived tradeoff facing an individual who is poor and whose $A$ identity is salient is given by ${ }^{32}$

$\mu_{1}\left[\left(\bar{y}^{1}\left(S_{1}\right)+g\right)+\theta^{1}\left(S_{1}\right)\right]+\left(1-\mu_{1}\right)\left[\bar{y}^{1}\left(S_{0}\right)+\theta^{1}\left(S_{0}\right)\right] \geq \mu_{1}\left[\bar{y}^{0}\left(S_{1}\right)+\theta^{0}\left(S_{1}\right)\right]+\left(1-\mu_{1}\right)\left[\bar{y}^{0}\left(S_{0}\right)+\theta^{0}\left(S_{0}\right)\right]+\tau+\delta$

The left-hand side is the expected payoff in a world where policy $a_{1}$ is enacted (by the political challenger if elected). The first term on the left-hand side is the income payoff $\left(\bar{y}^{1}\left(S_{1}\right)+g\right)$ and the identity payoff $\left(\theta^{1}\left(S_{1}\right)\right)$ if $a_{1}$ is adopted and the state of the world (with probability $\mu_{1}$ ) equals $S_{1}$. The second term is the payoff from adoption of policy $a_{1}$, if the state of the world remains $S_{0}$ (this occurs with probability $1-\mu_{1}$ ). In contrast, the right-hand side is the payoff from sticking to the status quo policy $a_{0}$ (i.e. if the incumbent remains in power).

We simplify the above expression to obtain the perceived tradeoffs facing a poor individual with the $A$ marker from voting for the challenger (and the adoption of $a_{1}$ ) as against voting for the incumbent (and policy $a_{0}$ ),

$$
\left.\left\{\mu_{1}[g]+\left(1-\mu_{1}\right) \bar{y}^{10}\left(S_{0}\right)\right]\right\}+\left[\theta^{10}\left(S_{0}\right)\right]+\mu_{1}\left[\theta^{10}\left(S_{1}\right)-\theta^{10}\left(S_{0}\right)\right] \geq \tau_{j}+\delta .
$$

The term in the curly brackets is the worldview effect (the expected payoff from adoption of $\left.a_{1}\right)$, where $\bar{y}^{10}\left(S_{0}\right)=\bar{y}^{1}\left(S_{0}\right)-\bar{y}^{0}\left(S_{0}\right)<0$. The higher identity payoff from adoption of $a_{1}$ is the identity polarization effect, and is captured in the second term of the right-hand side where $\theta^{10}\left(S_{0}\right)=\left[\theta^{1}\left(S_{0}\right)-\theta^{0}\left(S_{0}\right)\right]$. The last term on the left-hand side of the inequality is the increase in the magnitude of the identity polarization effect that accrues to a $A$ individual, due to a change in beliefs about the state of the world

\footnotetext{
${ }^{32}$ Since the focus of much of our analysis is on the median voter who is poor and $W$ (i.e. $P, W$ ) in what follows we suppress the $P, W$ notation unless we need to explicitly distinguish with those who are rich $R$ and/or $B$.
} 
being $S_{1}$.

We now calculate the set of voters who will support and vote for the high-income political challenger with the $A$ identity. First, consider the set of low-income voters with the $A$ identity where $\tau$ captures heterogeneity ${ }^{33}$ - that is, the set of low-income citizen-voters who vote for the challenger and stand to lose the least amount by doing so. This set is given by those individuals with adjustment $\operatorname{costs} \tau_{j}<\bar{\tau}^{I W}$, where we define $\bar{\tau}^{I W}$ as:

$$
\bar{\tau}^{I W}=\mu_{1} \cdot g-\left(1-\mu_{1}\right) \bar{y}^{01}\left(S_{0}\right)+\theta^{10}\left(S_{0}\right)+\mu_{1}\left[\theta^{10}\left(S_{1}\right)-\theta^{10}\left(S_{0}\right)\right]-\delta .
$$

This defines the person who is indifferent between the status-quo and the new policy under identity politics. We depict this equation of indifference in Figure A.1, which shows four zones. Zone 1 (Zone 2) represents parameters for which the worldview meme (respectively, identity meme) is powerful enough to ensure that the indifferent individual will support the political challenger. Zone 3 depicts the region where both policy and identity memes are needed to ensure that individual supports the challenger. In contrast, Zone 4 represents the set of parameters for which despite being exposed to the memes, the individual continues to support the status-quo.

Now consider the set of high-income citizens with the $A$ identity. Observe that for this sub-group of mass $n_{R A}$ there is a complete congruence of interests with those of the political challenger and they will be inclined to vote for him. Of course, since the high-income voters are a minority, the rich challenger needs some of the $P, A$ voters to cobble at least $n_{R A}+n_{P A}\left[1-G\left(\tau_{j}\right)\right]+n_{B R}\left[G\left(\tau_{j}\right)\right] \geq 1 / 2$ of the votes, where $G$ is the distribution function of $\tau$ in the $P, A$ population and is assumed to be uniform. ${ }^{34}$

This implies that given the heterogeneity in the strength of identity in the population (recollect that $\tau_{j}$ is drawn from the uniform distribution $G$ ), we have the following:

$$
\pi_{c}^{I W}=\operatorname{Prob}_{\delta}\left[n_{R A}+n_{P W} G\left(\bar{\tau}^{I W}\right) \geq 1 / 2\right]
$$

We now use equation (3) and the fact that $\delta \sim U\left[-\frac{1}{2 \psi}, \frac{1}{2 \psi}\right]$, to substitute for $G\left(\bar{\tau}^{I W}\right)$ in the preceding equation, (details are relegated to Appendix A), and arrive at the challenger's probability of getting elected when both identity and worldview memes

\footnotetext{
${ }^{33}$ The use of individual adjustment $\operatorname{costs} \tau_{i}$ is a parsimonious way of capturing differences in the support for the pro-rich policies amongst the poor who share an identity. For example, if these differences in adjustment costs are higher amongst those poor who work in the agricultural (as against industrial) sector, we should expect higher realised $\tau$ 's in the agricultural sector.

${ }^{34}$ For simplicity, we assume in what follows that the set of individuals who are rich and have the $B$ marker is negligible in size. This is without loss of generality. Alternatively, we can also obtain the same simple expressions by assuming that economic payoffs for all rich $B$ 's are high enough to ensure that they vote for $a_{1}$.
} 
Figure A.1: Individual $\bar{\tau}$ and the Four Zones

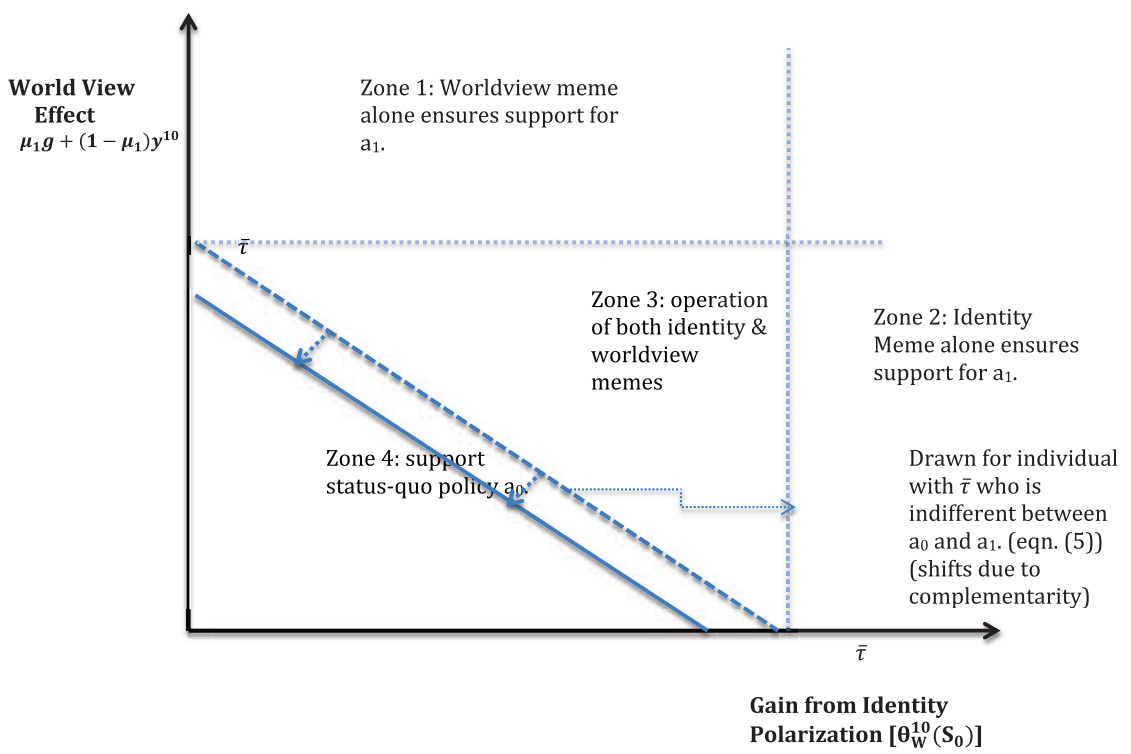

Notes. Illustration of the four possible equilibrium outcomes in terms of policy support depending on what kinds of memes are generated. See text for details.

are in operation, which is given by:

$$
\begin{array}{r}
\pi_{c}^{I W}=\frac{1}{2}+\psi\left\{\mu_{1} . g-\left(1-\mu_{1}\right) \bar{y}^{01}\left(S_{0}\right)+\mu_{1}\left[\theta^{10}\left(S_{1}\right)-\theta^{10}\left(S_{0}\right)\right]\right. \\
\left.+\theta^{10}\left(S_{0}\right)-\frac{1}{n_{P A}}\left(\frac{1}{2}-n_{R A}\right)+\frac{1}{2 \phi_{P}}\right\}
\end{array}
$$

Observe that $\pi_{c}^{I W}$ is increasing in the productivity of the new policy $a_{1}$ and the degree of potential polarization. Using a similar logic we derive (see further below) the probability of the political challenger overthrowing the incumbent in a world where ideational politics is restricted to the politics of identity $\left(\pi_{c}^{I}>0\right)$ or to the case where there is only worldview politics (i.e. $\pi_{c}^{W}>0$ ).

Using these expressions, we now turn to the political challenger's optimisation problem at the beginning of period $T=2$ :

$$
\max _{i, w}\left[i(1-p) \pi_{c}^{I}+w(1-i) \pi_{c}^{W}+i . w \pi_{c}^{I W}+(1-i)(1-w) \pi_{c}^{0}\right] \mathcal{R}-\frac{\beta\left[\varphi^{I} i+\varphi^{W} w\right]^{2}}{2 a}
$$

The expected payoff to the political challenger (given by the economic and ego rents $\mathcal{R}$ ) depends on the probability of getting elected - that differs on the probability of 
successfully discovering an identity meme (i.e. $i(1-w)$ ), worldview meme (i.e. $w(1-i)$ ) or both (i.e. $i w$ ). As pointed out earlier, even in the case where there is no ideational politics (this occurs with probability $(1-i)(1-w)$ ), there is the possibility (given by $\left.\pi_{c}^{0}\right)$ that the political challenger gets elected due to having higher 'charisma' relative to the incumbent. We should point out that the challenger will allocate resources towards discovering an identity meme, only if there exists a 'marker' (in this case the ethnic marker $A$ or $B$ ) that satisfies (a)-(c), where (a) the marker is shared by the majority and the challenger but not the incumbent;(b) an individual with an active marker gets utility from supporting policy $a_{1}$ and (c) it is technologically feasible to "prime" the characteristic. ${ }^{35}$

Under the assumption that the passive identity marker satisfies the above conditions, we can take first order conditions with respect to $i$ and obtain:

$$
\left(\pi_{c}^{I}-\pi_{c}^{0}\right) \mathcal{R}+p\left(\pi_{c}^{I W}+\pi_{c}^{0}-\pi^{I}-\pi^{W}\right) \mathcal{R}-\frac{\beta \varphi^{I}}{a}\left[\varphi^{I} i+\varphi^{W} w\right]=0
$$

Similarly with respect to $p$ :

$$
\left(\pi_{c}^{W}-\pi_{c}^{0}\right) \mathcal{R}+i\left(\pi_{c}^{I W}+\pi_{c}^{0}-\pi^{I}-\pi^{W}\right) \mathcal{R}-\frac{\beta \varphi^{W}}{a}\left[\varphi^{I} i+\varphi^{W} w\right]=0
$$

We can use the two preceding equations to solve for the pair $\left(i^{*}(\beta), w^{*}(\beta)\right)$ which are presented in the Appendix.

We now move to the beginning of the game, where the political incumbent chooses how much resources to allocate with aim of preventing (or making more difficult) for the challenger to engage in ideational politics that can upset the political status-quo. Accordingly, his optimisation is given by

$$
\max _{b}\left[b V\left(\beta_{1}\right)+(1-b) V\left(\beta_{0}\right)\right] \mathcal{R}-c(b)
$$

where $V\left(\beta_{k}\right)=\left[i^{*}\left(\beta_{k}\right)\left(1-w^{*}\left(\beta_{k}\right)\right)\left(1-\pi_{c}^{I}\right)+w^{*}\left(\beta_{k}\right)\left(1-i^{*}\left(\beta_{k}\right)\right)\left(1-\pi_{c}^{W}\right)+i^{*} \cdot w^{*}(1-\right.$ $\left.\left.\pi_{c}^{I W}\right)+\left(1-i^{*}\left(\beta_{k}\right)\right)\left(1-w^{*}\left(\beta_{k}\right)\right)\left(1-\pi_{c}^{0}\right)\right]$ for $k \in\{0,1\}$. The preceding equation gives us the expected payoff to the political incumbent from investing resources that raise the cost of engaging in ideational politics. The first-order conditions give us the optimal amount of resources spent by the incumbent in trying to make it difficult for any political challenger to successfully discover and deploy a meme. Accordingly, an equilibrium consists of a triple $\left(i^{*}, w^{*}, b^{*}\right)$ where the expressions are given by (20)-(22).

Given that we have derived the expression for $\pi^{I W}$ above, we now derive expressions for $\pi^{I}, \pi^{W}$. We then show that there exists a solution $\left(i^{*}, w^{*}\right)$ to the pair of equations given by $(7)$ and $(8)$ in the relevant range (i.e. $i^{*}, w^{*} \in[0,1)$ ).

\footnotetext{
${ }^{35}$ If the set of characteristic/markers that satisfies (a)-(c) is an empty set, then allocates no effort to the discovery of an identity meme. If the set of such markers is greater than one, the challenger chooses the marker that maximises his payoff.
} 
Derivation of $\pi^{I}$ : Once identity is made salient, following equation (1), an individual $j$ 's payoff from policy $a_{1}$ (LHS of inequality below) is greater than the payoff from the payoff from sticking to the status-quo policy $a_{0}$ (the RHS below) if:

$$
\left[\mu_{0} y^{10}\left(S_{1}\right)+\left(1-\mu_{0}\right) y^{10}\left(S_{0}\right)\right]+\mu_{0}\left[\theta^{10}\left(S_{1}\right)-\theta^{10}\left(S_{0}\right)\right]+\theta^{10}\left(S_{0}\right) \geq \tau_{p}+\delta
$$

The set of 'poor' individuals who vote for the challenger follows from the above equation and is given by $\tau_{j}<\bar{\tau}^{I}$ where $\bar{\tau}^{I}$ is the defined by the poor individual who is indifferent between the two policies under identity politics, where $\bar{\tau}^{I}=\left[\mu_{0} y^{10}\left(S_{1}\right)+\left(1-\mu_{0}\right) y^{10}\left(S_{0}\right)\right]+$ $\mu_{0}\left[\theta^{10}\left(S_{1}\right)-\theta^{10}\left(S_{0}\right)\right]+\theta^{10}\left(S_{0}\right)-\delta$.

In particular, for the challenger to get elected he needs to collect at least $n_{R A}+$ $n_{P A}\left[1-G\left(\tau_{j}\right)\right]+n_{B R}\left[G\left(\tau_{j}\right)\right] \geq 1 / 2$, where $G$ is the distribution function of $\tau$ in the $P, A$ population and is assumed to be uniform.

This implies that given the heterogeneity in the strength of identity in the population (recollect that $\tau_{i}$ is drawn from the uniform distribution $G$ with support $\left.\left[-\frac{1}{2 \phi_{P}}, \frac{1}{2 \phi_{P}}\right]\right)$, we have the following:

$$
\pi_{c}^{I}=\operatorname{Prob}_{\delta}\left[n_{R A}+n_{P A} G\left(\bar{\tau}^{I}\right) \geq 1 / 2\right]
$$

We now use equation $\bar{\tau}^{I}$ to substitute for $G\left(\bar{\tau}^{I}\right)$ in the preceding equation, substitute for $\delta \sim U\left[-\frac{1}{2 \psi}, \frac{1}{2 \psi}\right]$ to obtain:

$$
\begin{array}{r}
\pi^{I}=\frac{1}{2}+\psi\left\{\left[\mu_{0} y^{10}\left(S_{1}\right)+\left(1-\mu_{0}\right) y^{10}\left(S_{0}\right)\right]+\mu_{0}\left[\theta^{10}\left(S_{1}\right)-\theta^{10}\left(S_{0}\right)\right]\right. \\
\left.+\theta^{10}\left(S_{0}\right)-\frac{1}{n_{P A}}\left(\frac{1}{2}-n_{R A}\right)+\frac{1}{2 \phi_{P A}}\right\}
\end{array}
$$

Derivation of $\pi^{W}$ and $\pi^{0}$ :

His payoff from voting for the rich challenger (who adopts $a_{1}$ ) is greater than the payoff from voting for the poor incumbent (who retains status-quo $a_{0}$ ) if the following is true:

$$
\mu_{1}\left[y^{1}\left(S_{1}\right)+g\right]+\left(1-\mu_{1}\right) y^{1}\left(S_{0}\right) \geq \mu_{1}\left[y^{0}\left(S_{1}\right)\right]+\left(1-\mu_{1}\right) y^{0}\left(S_{0}\right)+\tau+\delta
$$

The term on the left-hand side of the inequality equals the payoff if policy $a_{1}$ is implemented and the individual believes that the state $S_{1}$ with probability $\mu_{1}$. The term on the right-hand side of the inequality is the expected payoff from sticking to the status-quo $a_{0}$. On further simplifying and rearranging, we obtain

$$
\mu_{1}[g]+\left(1-\mu_{1}\right) y^{10}\left(S_{0}\right) \geq \tau+\delta
$$

The term on the left-hand side of the inequality equals the payoff if policy $a_{1}$ is 
implemented and the individual believes that the state $S_{1}$ with probability $\mu_{1}$. The term on the right-hand side of the inequality is the expected payoff from sticking to the status-quo $a_{0}$.

Using a similar logic as earlier, the total votes for the challenger if a successful worldview meme had been discovered would be given by: $n_{R}+n_{P} G\left(\bar{\tau}^{W}\right)$. As previously, we can calculate the probability of a political challenger who discovers a worldview meme is successful in winning elections as given by:

$$
\pi_{c}^{W}=\frac{1}{2}+\psi\left\{\mu_{1} g-\left(1-\mu_{1}\right) y^{01}\left(S_{0}\right)-\frac{1}{n_{P} \phi_{P}}\left(\frac{1}{2}-n_{R}\right)+\frac{1}{2 \phi_{P}}\right\}
$$

Observe that $d \pi_{c}^{A} / d g>0$ and the absence of distributional effects is reflected in the fact that (unlike the case with identity politics) $\pi^{W}>1 / 2$.

Similarly, we can derive $\pi^{0}$. Only way that the challenger can win is if his popularity shock $\delta$ works sufficiently in his favour to ensure that it is greater than the income loss.

$$
\mu_{0} y^{1}\left(S_{0}\right)+\left(1-\mu_{0}\right) y^{1}\left(S_{1}\right) \geq \mu_{0} y^{0}\left(S_{0}\right)+\left(1-\mu_{0}\right) y^{0}\left(S_{1}\right)+\delta+\tau
$$

Rearranging we obtain,

$$
\mu_{0} y^{10}\left(S_{0}\right)+\left(1-\mu_{0}\right) y^{10}\left(S_{1}\right) \geq \delta+\tau .
$$

Following the same steps as earlier, this gives rise to

$$
\pi^{0}=\frac{1}{2}+\psi\left\{\left(1-\mu_{0}\right) g-\mu_{0} y^{01}\left(S_{0}\right)-\frac{1}{n_{P} \phi_{A}}\left(\frac{1}{2}-n_{R}\right)+\frac{1}{2 \phi_{A}}\right\}
$$

Derivation of Equation $i^{*}, w^{*}$ :

$$
\begin{array}{r}
\pi_{c}^{I W}=\frac{1}{2}+\psi\left\{\mu_{1} . g-\left(1-\mu_{1}\right) \bar{y}^{01}\left(S_{0}\right)+\mu_{1}\left[\theta^{10}\left(S_{1}\right)-\theta^{10}\left(S_{0}\right)\right]\right. \\
\left.+\theta^{10}\left(S_{0}\right)-\frac{1}{n_{A}}\left(\frac{1}{2}-n_{R A}\right)+\frac{1}{2 \phi_{P}}\right\}
\end{array}
$$

Observe that $\frac{d \pi_{c}^{I W}}{d g}>0$ and $\frac{d \pi_{c}^{I W}}{d \theta_{w}^{10}}>0$. Also note that changes in $g$ indirectly may affect the degree of identity polarization since the relative status between the two groups may change as a function of the changes in income (i.e. $\bar{y}_{P A}^{10}\left(S_{1}\right)$ is a function of $g$ and output).

Having solved for $\pi^{I}, \pi^{P}, \pi^{I P}$, we can substitute these expressions into the political challenger's optimisation (given by (6)) and obtain first order conditions given by (7) 
Figure A.2: Ideational Complementarity

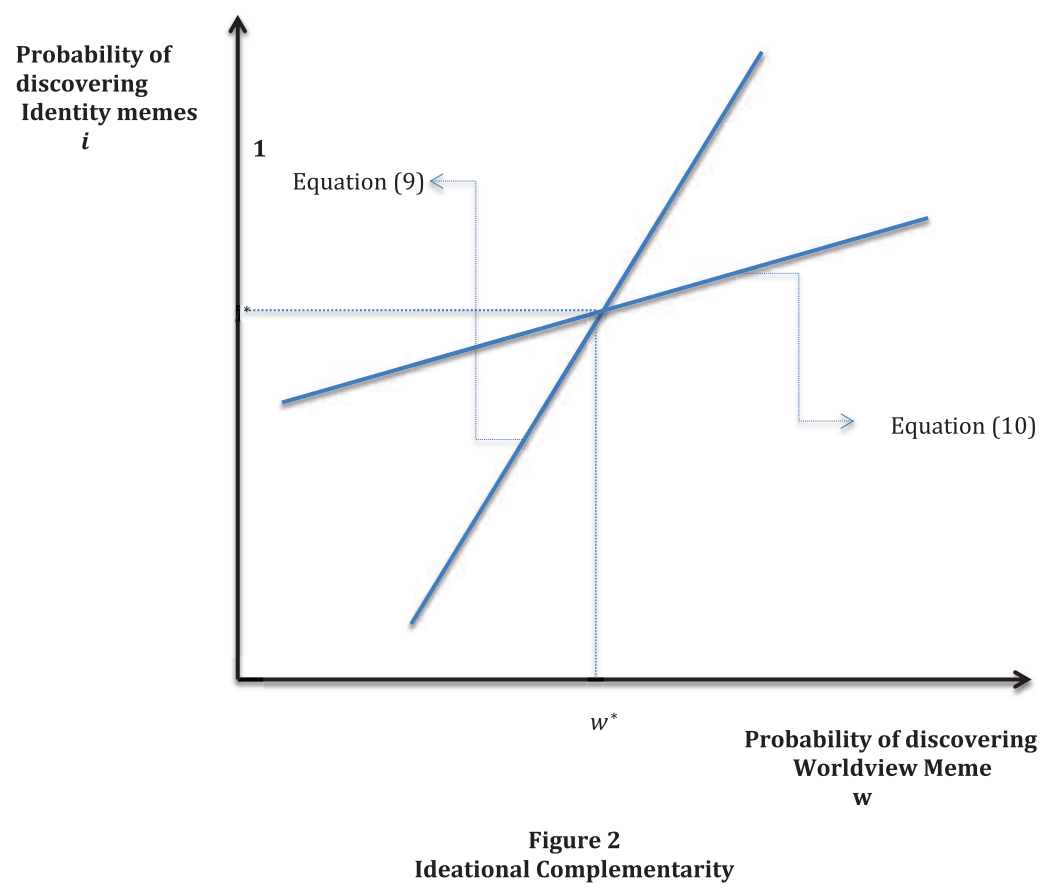

Notes. Illustration of the relationship between Equation (9) and Equation (10), showing the complementarity in the probability of discovering identity memes and worldview memes.

and (8). On solving (7) and (8) simultaneously we obtain (where $z=a / \beta_{i}$ ):

$$
\begin{aligned}
i^{*} & =\frac{z\left(\pi_{c}^{W}-\pi_{c}^{0}\right) \mathcal{R}\left[z\left(\pi^{I W}+\pi^{0}-\pi^{I}-\pi^{W}\right) \mathcal{R}-\varphi^{I} \varphi^{W}\right]+\left(\varphi^{W}\right)^{2} z\left(\pi_{c}^{I}-\pi_{c}^{0}\right) \mathcal{R}}{\left(\varphi^{I} \varphi^{P}\right)^{2}-\left[z\left(\pi^{I P}+\pi^{0}-\pi^{I}-\pi^{P}\right) \mathcal{R}-\varphi^{I} \varphi^{P}\right]^{2}} \\
w^{*} & =z \mathcal{R}\left\{\frac{\left(\varphi^{I}\right)^{2}\left(\pi^{W}-\pi^{0}\right)+\left(\pi^{I}-\pi^{0}\right)\left[z\left(\pi^{I W}-\pi^{0}-\pi^{I}-\pi^{W}\right) \mathcal{R}-\varphi^{I} \varphi^{W}\right]}{\left(\varphi^{I} \varphi^{W}\right)^{2}-\left[z\left(\pi^{I W}-\pi^{0}-\pi^{I}-\pi^{P}\right) \mathcal{R}-\varphi^{I} \varphi^{W}\right]^{2}}\right\} .
\end{aligned}
$$

Recollect that $z=a / \beta_{i}$ where $i \in\{0,1\}$. Now observe that since $z$ is decreasing in $\beta$, we have the numerator decreasing and denominator increasing in $\beta$. Therefore, $i^{*}, w^{*}$ are both decreasing in $\beta$. We further point out that while there exists a $i^{*}, w^{*}$ that solves the above equations, we need further condition to ensure that $i^{*}, w^{*} \in[0,1)$. These conditions are described in the proof of Proposition 2. Finally, given that $c(b)$ is continuous, we can solve for $b^{*}$ by examining the first order conditions for the political incumbent.

Proof of Proposition 2: For complementarity, we need to impose conditions such that not only does $i^{*}, w^{*}$ exist, but that $d i / d w>0$ as in Figure A.2. 
We show that the returns to investing in the discovery of an identity (or worldview) meme are increasing in the resources allocated to discovering a worldview (or respectively identity) meme. In particular, Appendix A.2 shows that $d i / d w$ is positive when complementarity between investment in identity and worldview memes is sufficiently strong. This condition is described in the proposition below.

Accordingly, (i) we evaluate (7) (LHS below) and (8)(the RHS below) when $p=0$. This gives rise to:

$$
\frac{2\left[\pi^{I}-\pi_{c}\right] \mathcal{R}\left(a_{i} a_{w}\right)^{2}}{\left[\varphi^{I}\right]^{2}} \leq \frac{\left[\pi^{W}-\pi_{c}^{0}\right] \mathcal{R}}{\frac{\varphi^{I} \varphi^{W}}{2 a^{2}}-\left(\pi^{I W}+\pi_{c}^{0}-\pi^{I}-\pi^{W}\right) \mathcal{R}}
$$

On simplifying we obtain:

$$
\varphi^{I} \varphi^{W} \leq\left(\varphi^{I}\right)^{2} \frac{\pi^{W}-\pi_{c}^{0}}{\pi^{I}-\pi_{c}^{0}}+2\left(\pi^{I W}+\pi_{c}^{0}-\pi^{I}-\pi^{W}\right) \mathcal{R} a^{2}
$$

This inequality is satisfied and RHS $>$ LHS for a variety of parameters (including $a_{i}, a_{w}, \pi^{I W}$ sufficiently large as well as $\left.\varphi^{I} \rightarrow 0\right)$.

Observe that equations (7) and (8) are linear in $i$ and $w$. Differentiating (7) we obtain:

$$
\frac{d i}{d w}=\frac{a\left(\pi^{I W}+\pi_{c}^{0}-\pi^{I}-\pi^{W}\right) R}{\left[\varphi^{I}\right]^{2}}-\frac{\varphi^{W}}{\varphi^{I}}
$$

Similarly differentiating (8) we obtain

$$
\frac{d i}{d w}=\frac{\left(\varphi^{W}\right)^{2}}{a\left(\pi^{I W}+\pi_{c}^{0}-\pi^{I}-\pi^{P}\right) \mathcal{R}-\varphi^{I} \varphi^{W}} .
$$

Further comparing slopes from (18) and (19) we observe the slope of (18) is steeper than the slope of (19) (and positive) if the following inequality holds:

$$
\frac{a \mathcal{R}}{2}\left[\pi^{I W}+\pi_{c}^{0}-\pi^{I}-\pi^{W}\right]>\varphi^{I} \varphi^{W}
$$

This is true for $\left[\pi^{I P}+\pi_{c}^{0}-\pi^{I}-\pi^{W}\right]$ being positive and $a, \mathcal{R}$ being sufficiently large. Observe that:

$$
\left[\pi^{I W}+\pi_{c}^{0}-\pi^{I}-\pi^{W}\right]=\left(\mu_{1}-\mu_{0}\right)\left[\theta^{10}\left(S_{1}\right)-\theta^{10}\left(S_{0}\right)\right]+\left(1-2 \mu_{0}\right)\left[g+y^{01}\left(S_{0}\right)\right]
$$

This implies that if (i) the ideational complementarity and/or the (ii) the incomeidentity tradeoff' effect (i.e. income loss to the poor from $a_{1}$ ) and $a, \mathcal{R}$ was sufficiently large we would expect an increase in $i^{*}$ to be complementary to an increase in $w^{*}$. Substituting (5), (11), (14), (15) into (20) gives us the condition for ideational complementarity described in Proposition 2. 
Given the differences in intercepts and the differences in slopes, the two curves will intersect in the positive $(i, w)$ quadrant. However, for existence we need an additional step that ensures that $\exists i^{*}, w^{*} \leq 1$. A sufficient condition for this is if parameters satisfy the following two conditions: (i) at $w=1$, we want $i^{*}$ (from (7)) $>i^{*}$ (from (8)) and (ii) at $w=1$ we also have $i^{*}$ (from $\left.(8)\right) \leq 1$. If both these conditions are satisfied, we will have demonstrated the existence of $i^{*}, w^{*}$.

The first of these conditions is satisfied if the following inequality holds (for $w=1$ ):

$$
\frac{2 a^{2}}{\left(\varphi^{I}\right)^{2}}\left[\left(\pi^{I}-\pi^{0}\right) \mathcal{R}+\left(\pi^{I W}+\pi_{c}^{0}-\pi^{I}-\pi^{W}\right)\right]-\frac{\varphi^{W}}{\varphi^{I}}>\frac{2 a^{2}\left(\pi^{W}-\pi^{0}\right) \mathcal{R}-\left(\varphi^{W}\right)^{2}}{\varphi^{i} \varphi^{W}-\left[\pi^{I W}+\pi_{c}^{0}-\pi^{I}-\pi^{W}\right] \mathcal{R} 2 a^{2}} .
$$

Observe that the LHS is increasing (and the RHS is decreasing) in $\left[\pi^{I W}+\pi_{c}^{0}-\pi^{I}-\pi^{W}\right] \mathcal{R}$. Further observe that RHS $<0$ for $\pi^{W} \rightarrow \pi^{0}$.

For (ii) above, we need the following inequality to be true:

$$
2 \mathcal{R} a^{2}\left(\pi^{W}-\pi^{I}\right)-\left(\varphi^{W}\right)^{2} \leq \varphi^{I} \varphi^{W}-\left[\pi^{I W}+\pi_{c}^{0}-\pi^{I}-\pi^{W}\right] \mathcal{R} 2 a^{2} .
$$

On simplifying this equals:

$$
2 \mathcal{R} a^{2}\left[\pi^{I W}-\pi^{I}\right] \leq \varphi^{I} \varphi^{W}+\left(\varphi^{W}\right)^{2}
$$

\section{A.3 Microfoundations for Worldview and Identity Memes}

In this appendix we relax a key assumption of our benchmark model. In particular, we provide micro-foundations for both identity and worldview memes and throw light on the question of how is it that these memes can alter beliefs of the populace. As a first step, we observe that we can interpret an individual's preferences as being statedependent on not only the income dimension but also the identity dimension. It is quite standard to assume that individuals may get a higher income payoff in some states of the world than in others. Using a similar logic we argue that in some states of the world, an individual receives more utilisay from their membership to an identity group than in others. We allow for the possibility that this makes identity salient and gives rise to an incentive for individuals to invest in their group identity. In this appendix we sketch a version of our model that shows how both memes work - essentially by changing beliefs that individuals have about the underlying state of the world (be it income or an identity related state). We elaborate on this below.

As discussed in the text, there are several channels through which the memes can alter beliefs about the state of world and/or get individuals to invest in their (otherwise 
passive) group identity. ${ }^{36}$ Rather than privilege a particular channel we take a different more direct route over here. In particular, we sidestep the issue of how this information manipulation is carried out by the entrepreneur. Instead, we assume that the discovery of (for example) a worldview meme 'blocks' information that a citizen receives about the underlying state of the world.

Accordingly, we assume that policy $a_{i}$ is state-dependent where the relevant states are $S_{j}$, where $i, j \in\{0,1\}$. However, we now allow for preferences regarding identity be a function of the underlying state also. In particular, we allow group identity to be much more important in state $S_{H}$ and much less (or of negligible) importance when the state is $S_{L}$. Of course, it is entirely possible that the policy relevant states $S_{0}$ (or $S_{1}$ ) are correlated with or even perfectly coincide with the states of the world that determine the magnitude of the identity payoff. However, for the purpose of the appendix we treat the policy and identity relevant states as uncorrelated. The payoffs in what follows corresponds to the numbers in the square brackets of Table A.1 Panels A through $\mathrm{C}$ above.

For simplicity, we assume that priors about both the policy and identity relevant states are such that $P\left(S_{0}\right)=P\left(S_{L}\right)=\mu$.

We assume that each individual obtains a correlated reliable (but imprecise) private signal about the underlying policy relevant state $s_{0}$ or a signal $s_{L}$ about the corresponding identity relevant state. The reliability of these correlated private signals equals $P\left(s_{0} \mid S_{0}\right)=q=P\left(s_{L} \mid S_{L}\right)$. When the political challenger allocates effort $(i, w)$, he blocks the signal $s_{0}$ with probability $w$ and the signal $s_{L}$ with probability $i$. Therefore, if the voter does not receive the signal about the underlying state, he updates using Bayes rule and obtains the following:

$$
P\left(S_{1} \mid \text { no signal } s_{0}\right)=\mu^{w}=\mu_{1}=\frac{(1-\mu)}{[w+(1-w)(1-q)] \mu+(1-\mu)}
$$

Similarly, on not receiving the signal $s_{L}$ we have

$$
P\left(S_{H} \mid \text { no signal } s_{L}\right)=\mu^{i}=\frac{(1-\mu)}{[i+(1-i)(1-q)] \mu+(1-\mu)}
$$

These two expressions give us the voter's posterior in the case the memes are discovered and manage to shift a voter's information set by blocking information that the voter may have received. In the case of the policy or identity meme, this results in an updated posterior about the likely success of adopting the new policy or the likelihood that investing in group identity is likely to provide a payoff.

\footnotetext{
${ }^{36}$ These channels include the role manipulating the media and information by the political entrepreneur by exploiting behavioural biases arising from framing (Breyer, 1981), anticipatory utility (Benabou and Tirole, 2002), coarse thinking (Mullainathan et al., 2008), salience and attention (Gennaioli and Shleifer, 2010), correlated neglect and peer influence heuristics (Levy and Razin, 2015; Enke and Zimmermann, 2019), or Bayesian persuasion (Alonso and Câmara, 2016).
} 
We now follow our earlier derivation of the probability of the political challenger winning the election (depending on whether an identity, or policy or both memes have been discovered $\pi^{I}, \pi^{W}, \pi^{I W}$ or none $\pi^{0}$. Therefore, the payoff from electing the rich challenger with the $W$ marker is greater than electing the incumbent so long as the following inequality holds,

$$
\mu^{W}\left[(1+g)+\mu^{i} \theta\right]+\left(1-\mu^{w}\right)\left[(1-g)+\mu^{i} \theta\right] \geq 1+\tau_{j}+\delta
$$

Rearranging, we get the set of voters with $\tau$ 's such that they will vote for the political challenger is given by

$$
\left.\tau_{j} \leq g\left[2 \mu^{W}-1\right]+\mu^{i} \theta-\delta\right] \equiv \bar{\tau}^{I W}
$$

We can use similar mechanics to derive expressions for $\pi^{I}, \pi^{W}$ and $\pi^{0}$. Given these probabilities of getting elected under different circumstances, the challenger's problem is

$$
\max _{i, p}\left[i(1-p) \pi_{c}^{I}+w(1-i) \pi_{c}^{W}+i . w \pi_{c}^{I W}+(1-i)(1-w) \pi_{c}^{0}\right] \mathcal{R}-\frac{\left[\varphi^{I} i+\varphi^{W} w\right]^{2}}{2}
$$

Taking first order conditions with respect to $i$ (and for simplicity take $\varphi^{I}=1$ and $\varphi^{W}=c$ ) we obtain:

$$
\left[w \pi^{I W}+i w \frac{\partial \pi^{I W}}{\partial i}+(1-w) \pi^{I}+i(1-w) \frac{\partial \pi^{I}}{\partial i}-w \pi^{W}-(1-w) \pi^{0}\right] R-(i+c w)=0
$$

Here we observe that,

$$
\frac{\partial \pi^{I W}}{\partial i}=\frac{\partial \pi^{I}}{\partial i}=\psi \theta \frac{\partial \mu^{i}}{\partial i}
$$

Using the above expression, substituting and simplifying we obtain,

$$
\left[\psi \theta \mu^{i}\left(1-\frac{i q \mu}{(1-\mu)} \mu^{i}\right)+\psi\left(\frac{n_{R W}-n_{B}}{2 n_{P W \phi_{P}}}-\frac{n_{R}}{2 n_{P} \phi_{P}}\right)\right] R=i+c w .
$$

Similarly, we can take first order conditions with respect to $w$ and obtain,

$$
\left[i \pi^{I W}+i w \frac{\partial \pi^{I W}}{\partial i}+(1-i) \pi^{W}+w(1-i) \frac{\partial \pi^{W}}{\partial w}-i \pi^{I}-(1-i) \pi^{0}\right] R-c(i+c w)=0
$$

Once again observing that

$$
\frac{\partial \pi^{I W}}{\partial w}=\frac{\partial \pi^{W}}{\partial w}=2 \psi \theta \frac{\partial \mu^{w}}{\partial w}
$$


Furthermore, observe that

$$
\frac{\partial \mu^{W}}{\partial w}=(-) \frac{\left(\mu^{W}\right)^{2}}{(1-\mu)} q \mu
$$

Once again we use the preceding two expressions to simplify and substitute in the first order condition with respect to $p$ to obtain,

$$
2 g \psi\left[\left(\mu^{w}-\mu\right)-\frac{w q \mu}{(1-\mu)}\left(\mu^{w}\right)^{2}\right] R=c(i+c w)
$$

Substituting for $(i+c w)$ from (22) into (23) and rearranging, we obtain

$$
Z(i, p) \equiv c\left[\theta \mu^{i}\left(1-\frac{i q \mu \mu^{i}}{(1-\mu)}\right)+\frac{n_{R W}-n_{B}}{2 n_{P W} \phi_{p}}-\frac{n_{R}}{2 n_{P} \phi_{P}}\right]-2 g\left[\left(\mu^{p}-\mu\right)-\frac{p q \mu}{1-\mu}\left(\mu^{p}\right)^{2}\right]=0
$$

Now we can use the above expression to obtain

$$
\frac{d i}{d w}=(-) \frac{\frac{\partial Z(i, w)}{\partial w}}{\frac{\partial Z(i, w)}{\partial i}}=(-) \frac{\frac{4 g\left(\mu^{w}\right)^{2} q \mu}{(1-\mu)}\left[1-\frac{w q \mu \mu^{w}}{1-\mu}\right]}{-\frac{2 c \theta\left(\mu^{i}\right)^{2} q \mu}{(1-\mu)}\left[1-\frac{i q \mu \mu^{i}}{1-\mu}\right] \text { equation }}
$$

Observe that $d i / d w>0$ iff both $q \mu<1$ and $\frac{i q \mu \mu^{i}}{1-\mu}<1$. 
Figure B.1: Example Storyboards for Political Ads

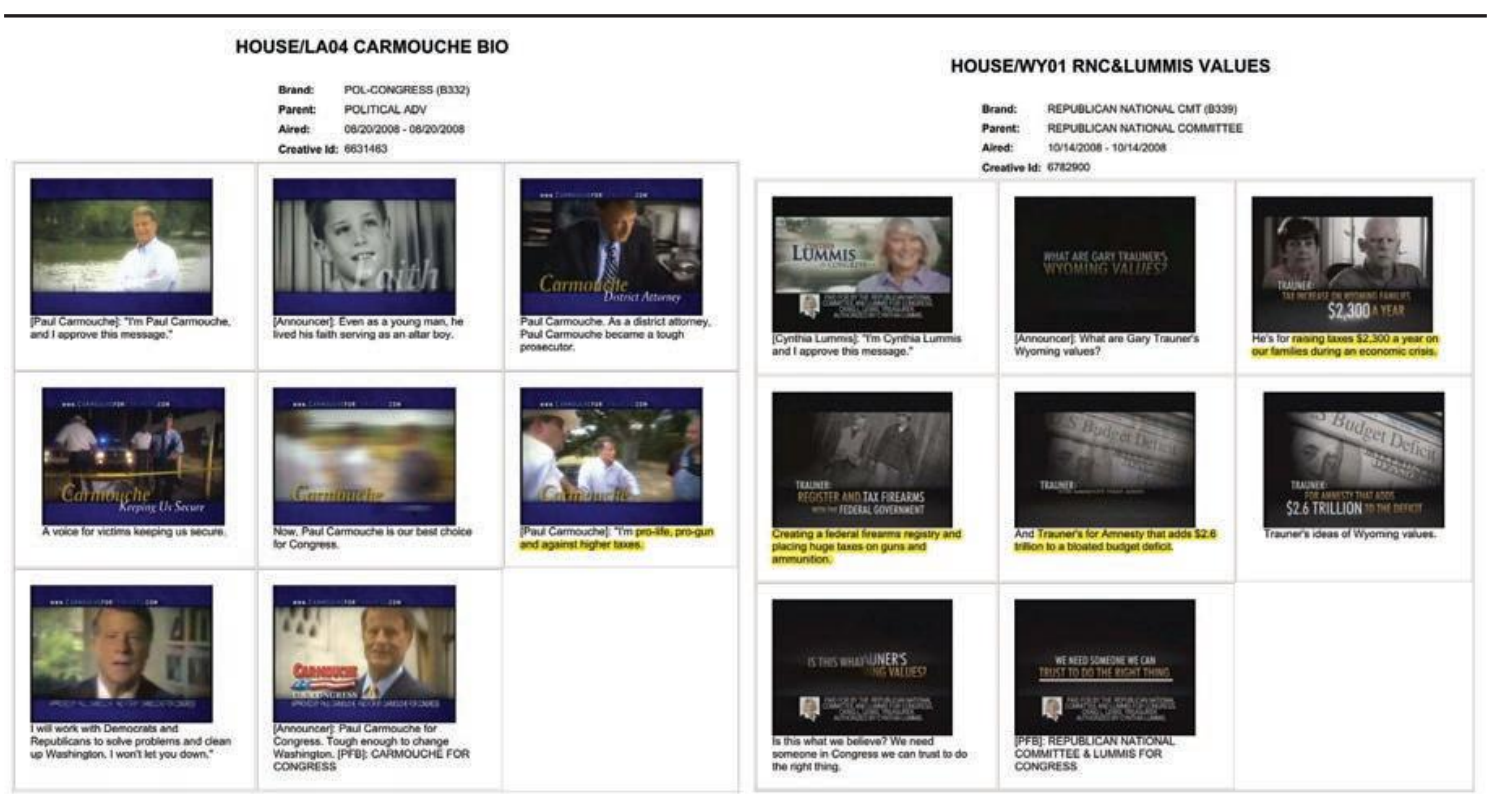

Notes. This figure shows two example storyboards from the ad archive, for a Democrat (on the left) and a Republican (on the right).

\section{B Empirical Appendix}

\section{B.1 Supplementary Materials on the Advertisements Data}

The Wesleyan Media Project (WMP) provides data on the content and location of political advertising (ads) content in the United States. It is the continuation of the Wisconsin Advertising Project (1998-2008) who aimed at studying campaign television advertisements in the largest U.S. media markets. For each two-year election cycle, they provide extensive information on political ads broadcast on television for a variety of elections and ballot measures.

The database includes two types of metadata. First, at the ad level, basic metadata includes the associated election and the sponsoring candidate or organization. Second, the database includes detailed records on each time the ad was displayed on television: the number and timing of airings, and the associated media markets. The election races include local (i.e city council and mayors, judges), gubernatorial, Senate, House, and presidential races. In total, there are 69'300 TV ads that have been aired around 10 million times at the media market level.

WMP obtains content of the ads from the Campaign Media Analysis Group (CMAG, Kantar Media). The Wisconsin ads data, up until 2008, include storyboards in PDF format. The storyboards include transcripts of the ad copy, alongside screenshots taken 
every 4 seconds of the video. For elections after 2008, the database includes the original audio/video files in MP4 format. Figure B.1 shows two example storyboards from the ad archive. We have highlighted mentions of policy issues.

WMP staff watch the ad content and annotate a detailed set of information about each ad. The annotations are generated by filling out a questionnaire on a web-based interface. The annotators are trained undergraduate students from Wesleyan University, and they seek a high degree of confidence and agreement in interpreting ad content. For validation, about $20 \%$ of the ads are annotated by two students. Reliability statistics for each variable are provided, including the percentage of mutual agreement between two different answers. This percentage is always above $80 \%$.

The questionnaire provides information on the following types of issues:

1. the actors involved (entity responsible for the ad, favored candidate, mentions, endorsements);

2. candidate and target characteristics (name, gender, party, approval for the ad);

3. the content of the ad: issues discussed, citations, music, action requested (i.e vote for, elect, support, vote against), mentions of politically relevant words (e.g. Tea Party, God/Faith, Wall Street, Big Government, Fake News);

4. the framing (positive or negative, general tone, emotions involved, voice-overs).

WMP has striven to maintain a consistent composition of variables over time. The issues have varied somewhat in response to notable events or policies, such as Hurricane Katrina or Obamacare. Ads are annotated for 84 different issues, which were mostly inherited from the Wisconsin ads methodology. The issues are grouped in 7 categories: economic policy, social issues, law and order, social welfare issues, foreign/defense policy, environment/energy, and 'others'.

Ads can be annotated for multiple issues. If all issue variables are missing, the ad hasn't been coded. If one/some issue variables are missing, these issue questions were not asked that year. If all issue variables are equal to zero, including the issue_others variable, then the ad does not talk about any issue at all (candidate presents himself/herself without referencing an issue). The dataset also includes some non-issue advertising annotations, such as "mentions big government", or "mentions Trump", or "language is Spanish". We do not use these because they vary a lot more in what is included across years. 
Figure B.2: Number of Ads in the Database, by Position and Party

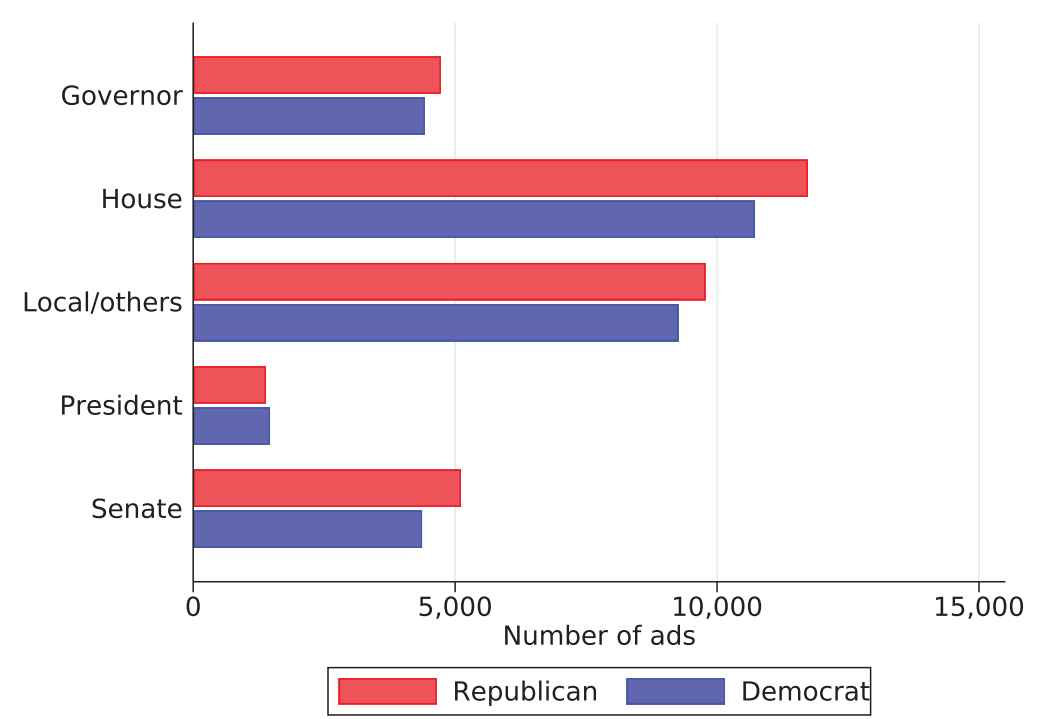

Notes. This figure shows the number of distinct ads across the different election types, separately by party.

Figure B.3: The Number of Ads Over Time

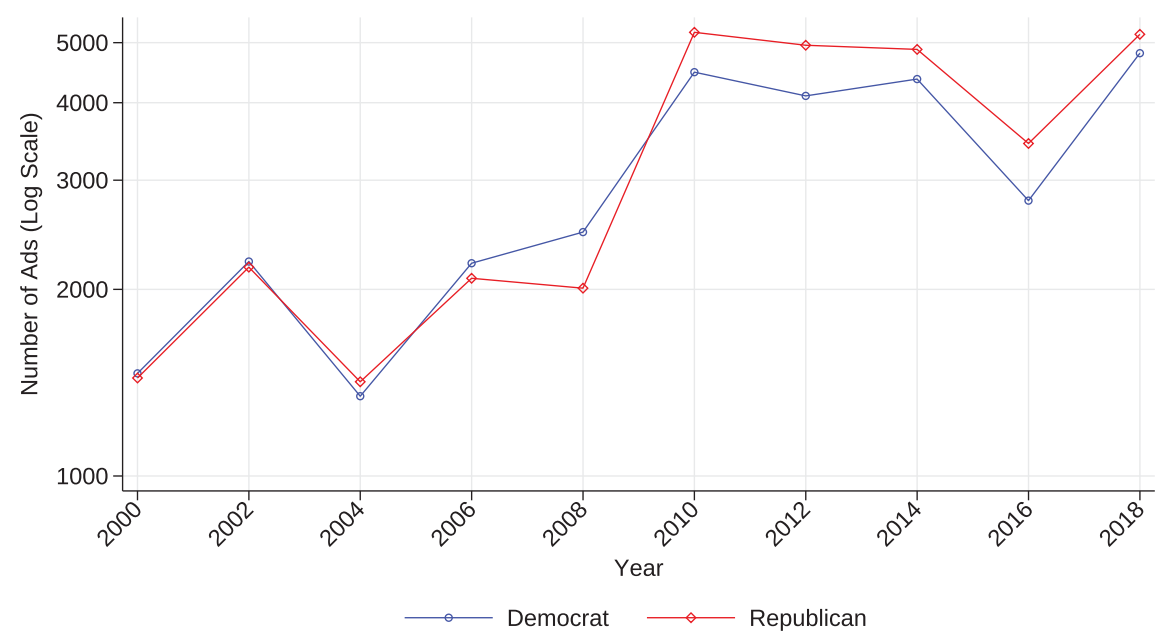

Notes. This figure shows the number of unique political ads per year, and the total number of airings per year. One can see in particular how local elections are added starting 2010. 
Figure B.4: Ad Distribution over Broad Issue Categories, by Party

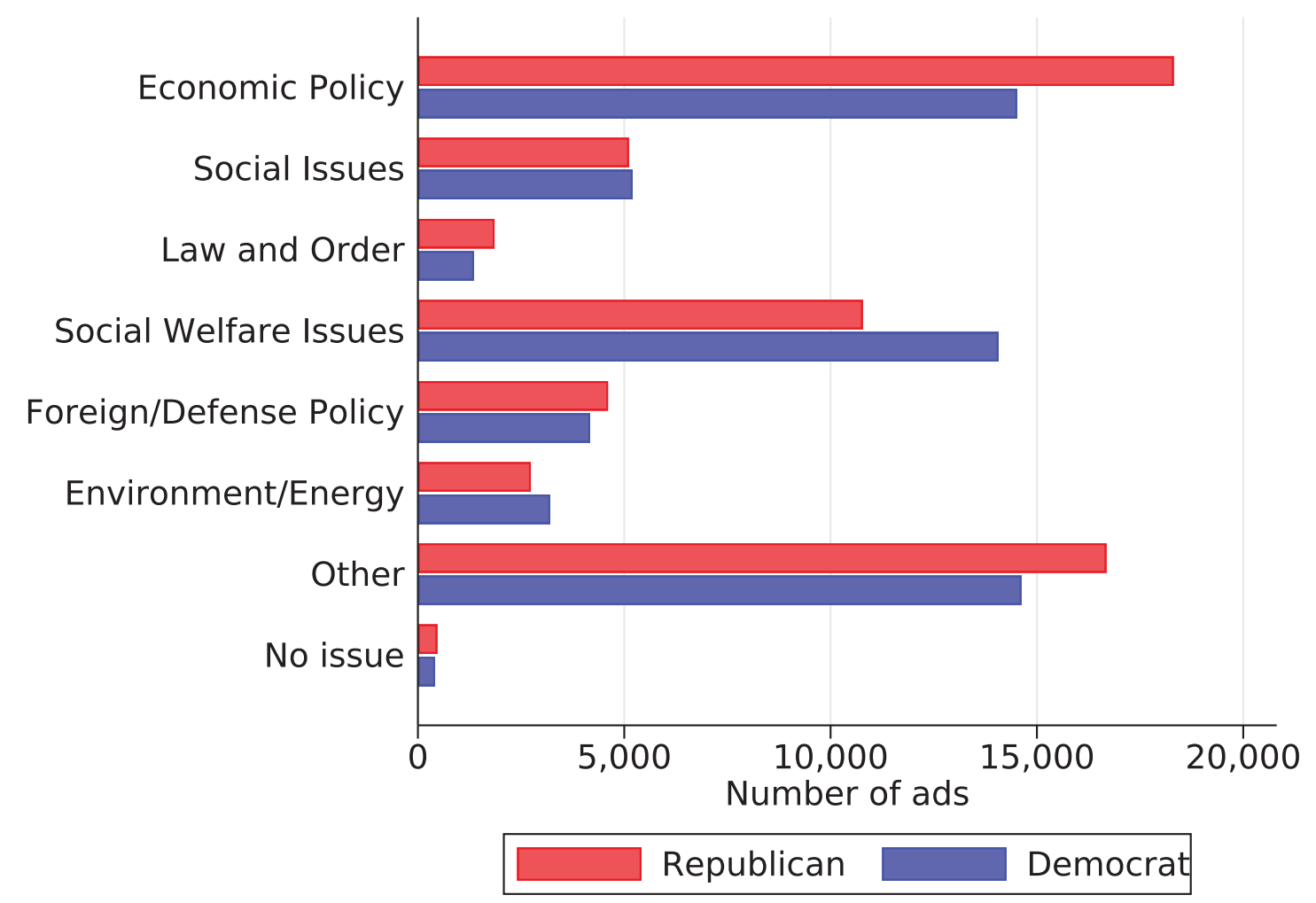

Notes. This figure shows the breakout of the ads by the 7 broad issue categories annotated by Wesleyan. Republicans focus on economic policy, while Democrats focus on social welfare issues. For the other issues, they are quite balanced. 
Table B.1: Ad Tabulation: Full List of 84 Ad Issues, By Broad Categories

\begin{tabular}{|c|c|c|c|c|c|c|c|}
\hline \multicolumn{2}{|l|}{ Economic Policy } & \multicolumn{2}{|l|}{ Social Issues } & \multicolumn{2}{|c|}{ Social Welfare Issues } & \multicolumn{2}{|c|}{ Foreign Policy and Defense } \\
\hline Taxes & 15824 & Moral / Fam Values & 3019 & Health Care & 12713 & Military (generic) & 2774 \\
\hline Employment / Jobs & 14331 & Abortion & 2604 & Education / Schools & 9698 & Veterans & 2678 \\
\hline Business & 4818 & Gun Control & 2211 & Social Security & 3796 & Iraq & 1132 \\
\hline Government Spending & 4604 & Race Relations & 1581 & Prescription Drugs & 2141 & Terrorism & 1090 \\
\hline Recession / Stimulus & 2007 & LGBTQ Issues & 448 & Obamacar & 1468 & Afghanistan & 281 \\
\hline Trade / Globalization & 1538 & Tax Reform & 305 & Women's Health & 821 & September 11 th & 236 \\
\hline Farming & 1050 & Civil Libs / Privacy & 250 & Child Care & 525 & Iran & 232 \\
\hline Housing / Mortgages & 1042 & Gambling & 61 & Health Care Reform & 319 & ISIL / ISIS & 192 \\
\hline \multirow[t]{4}{*}{ Poverty } & 195 & Assisted Suicide & 2 & Lottery for Educ & 58 & Israel & 51 \\
\hline & & & & Marijuana & 14 & Foreign Aid & 38 \\
\hline & & & & & & Russian / Putin & 31 \\
\hline & & & & & & North Korea & 12 \\
\hline
\end{tabular}

\begin{tabular}{lrlrlrcrc}
\hline \multicolumn{1}{c}{ Law and Order } & \multicolumn{3}{c}{ Environment/Energy } & & \multicolumn{2}{c}{ Other } \\
\hline Crime & 1896 & Environment & 4231 & Other & 26926 & Corporate Fraud & 618 \\
Narcotics / Illegal Drugs & 788 & Energy Policy & 3436 & Government Ethics & 3418 & Term Limits \\
Supreme Court / Judges & 532 & Global Warming & 266 & Immigration & 2346 & Emerg Response & 178 \\
Domestic Violence & 275 & Keystone XL Pipeline & 53 & Campaign Finance & 1949 & Govt Shutdown & 168 \\
Capital Punishment & 77 & & & Local Issues & 1709 & DACA / Dreamers & 63 \\
Parkland / Stoneman HS & 24 & & Gove Regulations & 1024 & Pledge of Allegiance \\
Police Brutality & 20 & & Transportation & 1019 & 36
\end{tabular}

Notes. This table shows the full list of 84 raw issue categories annotated in the Wesleyan data. We have the issues grouped by the seven broad issue categories provided in the dataset. In addition, we show the number of ads tagged with each issue. 
Table B.2: Merging of Issues to 30 Categories

\begin{tabular}{|c|c|}
\hline Economy & Economy / Business / Govt Regulation \\
\hline Taxes & Taxes / Tax Reform Bill (2017) \\
\hline Health Care & Health Care / Prescription Drugs / Medicare / Addiction / Opioids / Health Care Reforms \\
\hline \multicolumn{2}{|l|}{ Employment / Jobs } \\
\hline Deficit / Budget / Debt & Deficit / Budget / Debt / Govt Spending \\
\hline Education / Schools & Education / Lottery for Education \\
\hline Environment & Environment / Global Warming / Energy \\
\hline Military / Veterans & Military / Veterans / Iraq / Afghanistan \\
\hline Seniors (not Medicare) & Seniors (not Medicare) / Social Security \\
\hline Corruption (Govt and Corp) & Government Ethics / Corporate Corruption \\
\hline \multicolumn{2}{|l|}{ Moral Values } \\
\hline Foreign Policy & Foreign Policy / Foreign Aid / Nuclear Proliferation / Russia / North Korea \\
\hline Transportation / Local Issues & Transportation / Local Issues \\
\hline \multicolumn{2}{|l|}{ Abortion } \\
\hline Crime & Crime / Sentencing / Drugs / Marijuana \\
\hline Women's Issues & Women's Health / Gender Discrimination / Domestic Violence / Childcare / \#metoo \\
\hline Immigration & Immigration / DACA / Dreamers \\
\hline Gun Control & Gun Control / School Shootings \\
\hline \multicolumn{2}{|l|}{ Welfare } \\
\hline \multicolumn{2}{|l|}{ Campaign Finance Reform } \\
\hline Workers Rights & Minimum Wages / Union / Economic Disparity / Income Inequality \\
\hline Race Relations / Civil Rights & Race Relations / Civil Rights / Affirmative Action / Police Brutality / Racial Violence \\
\hline Terrorism / Middle East & Terrorism / Middle East / ISIS / Israel / Syria / Iran \\
\hline \multicolumn{2}{|l|}{ Trade / Globalization } \\
\hline \multicolumn{2}{|l|}{ Obamacare } \\
\hline Poverty / Housing & Poverty / Housing / Sub-prime Mortgages \\
\hline \multicolumn{2}{|l|}{ Farming } \\
\hline Judiciary & Supreme Court / Judiciary / Civil Liberties \\
\hline LGBTQ Issues / Rights & \\
\hline
\end{tabular}

Notes. This table shows the list of 30 policy issues which we use in the analysis, along with how the 84 specific issue categories are assigned. If an ad is in two of the specific categories, we still count it as matching once for the more generic category. 


\section{B.2 Supplementary Materials on Main Results}

This appendix provides additional results to support the main analysis.

Figure B.5: First Stage Effect of China Import Competition on Employment

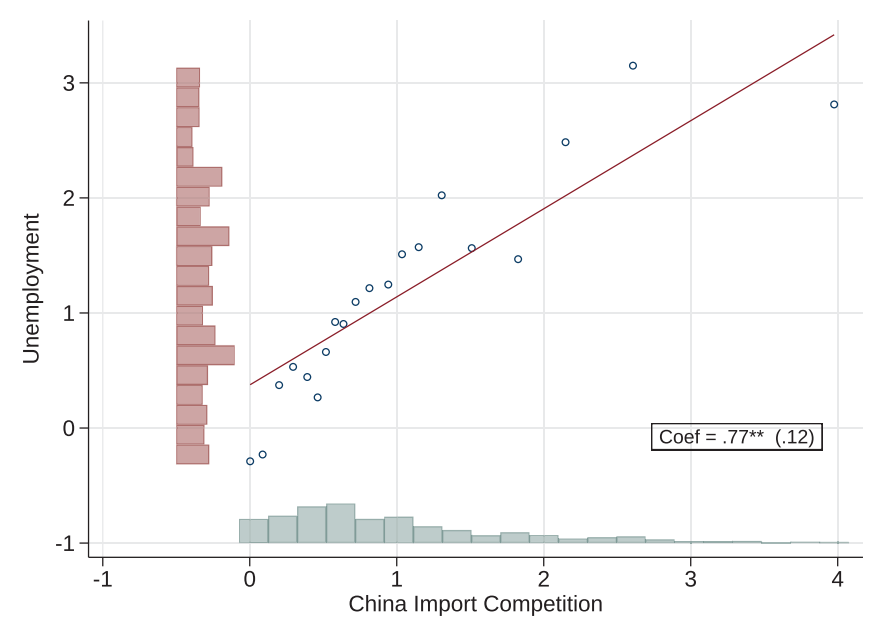

Notes. This figure shows a binscatter of the first-stage relationship between employment (vertical axis) and the Chineseimport-competition instrument. Constructed using the package from Pinna (2020). 
Figure B.6: Effect of China Shock on Broad Issue Categories, By Party

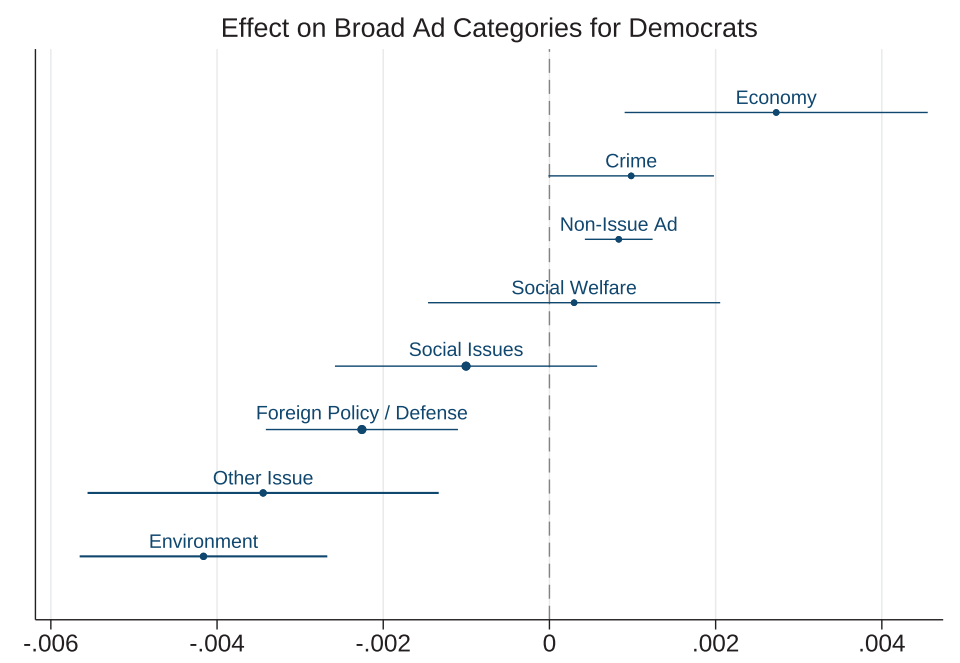

Effect on Broad Ad Categories for Republicans

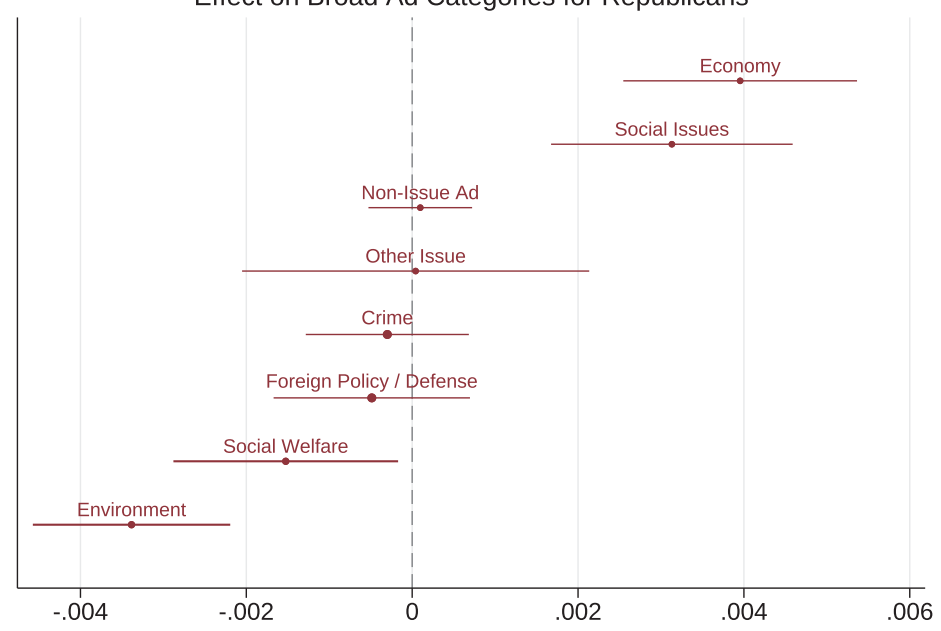

Notes. This figure shows the effect of the China shock on the seven broad issue categories, as categorized by Wesleyan. We see that both parties increase ads about the economy and decrease it about the environment. Republicans increase ads about social issues. 
Figure B.7: Effect of China Shock on All Issues, Overall

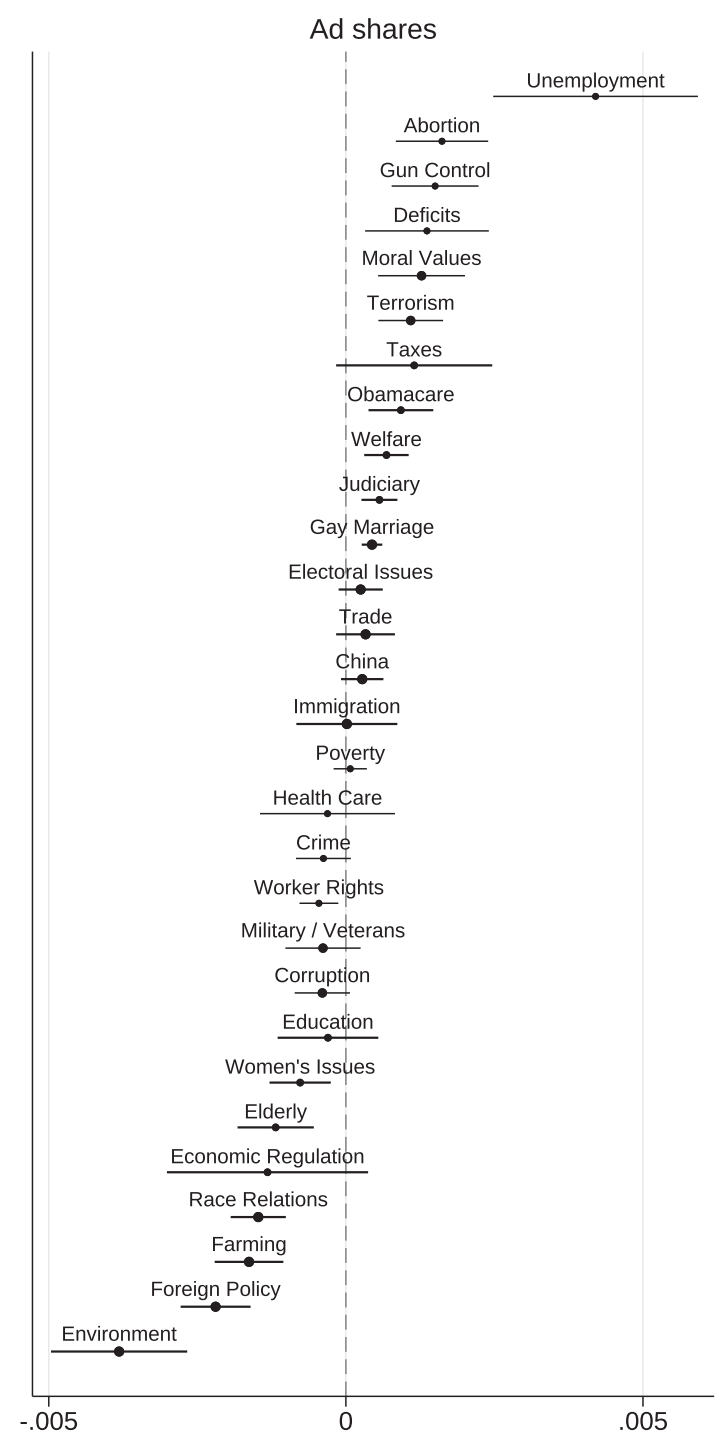

Notes. This figure shows the effect of the China Shock across the 30 policy issues. There is a big bipartisan increase in ads about unemployment, and a big bipartisan decrease in ads about the environment and economic regulation. Includes elections from 2008-2018. 
Figure B.8: Effect of China Shock on All Issues, By Party

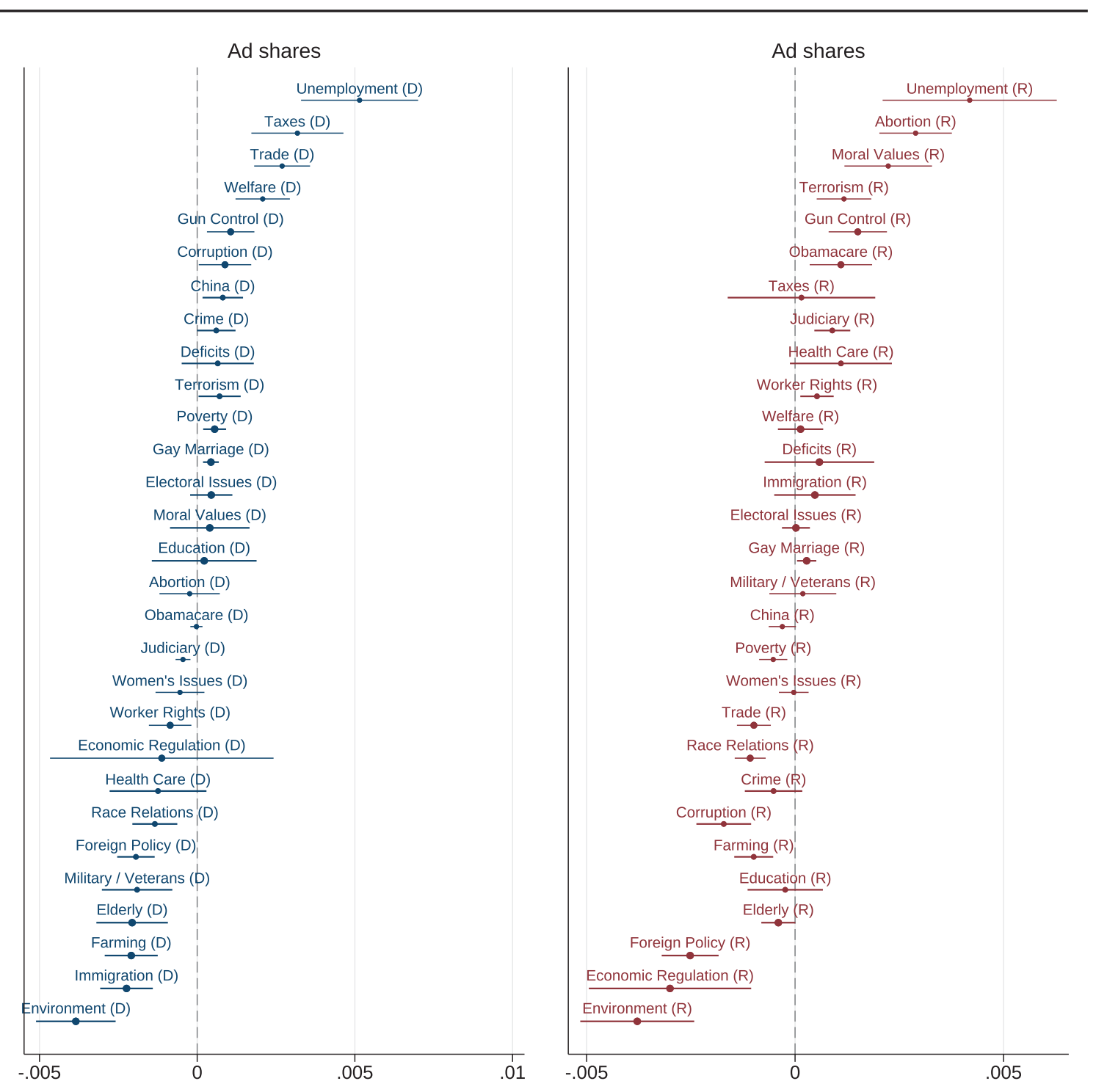

Notes. This figure shows the effect of the China Shock on all 30 policy issues, but separately by political party. Includes elections from 2008-2018. 
Figure B.9: China Shock Effect on Republican Ads, Alternative Outcome Specifications

A. Share of Airings

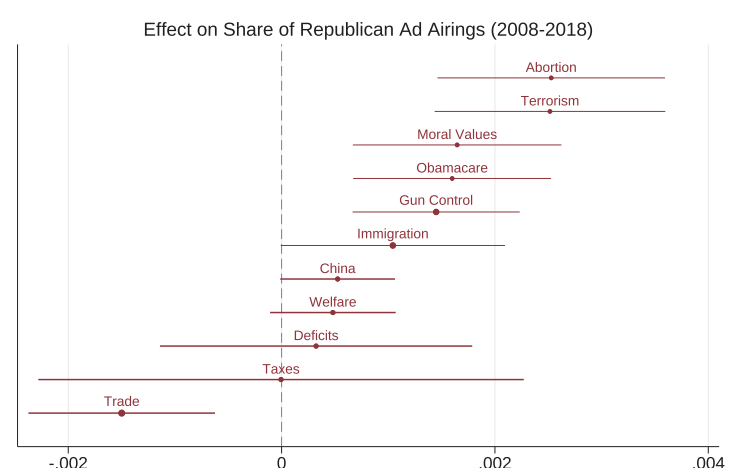

B. Log Ad Volume

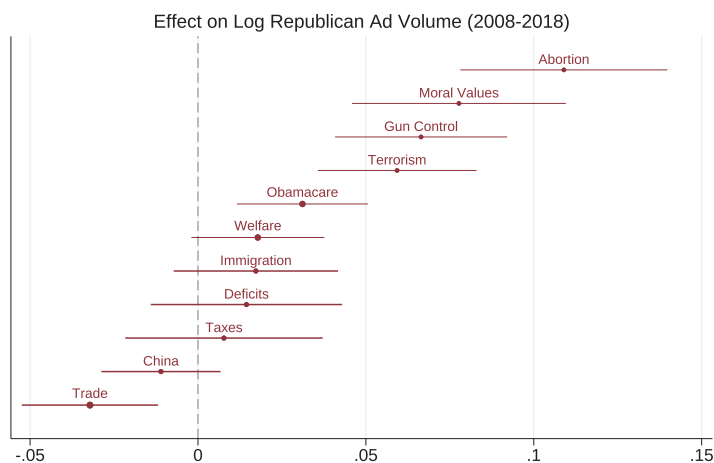

C. Standardized Shares

Effect on Standardized Share of Republican Ads (2008-2018)

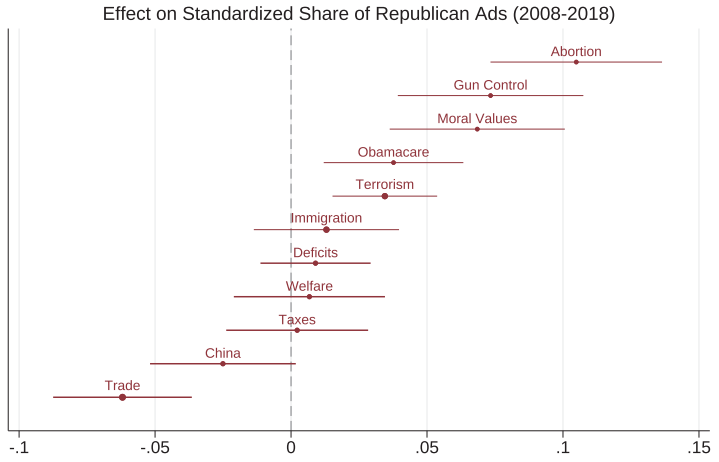

Notes. These figures shows a coefficient plot from the main regression of advertising shares by party on the China shock instrument. The panels show alternative outcome specifications, as indicated. Error spikes give $95 \%$ confidence intervals. Coefficients sorted by Republican effect size. 
Figure B.10: Pre-Treatment Reduced-Form Effect on Ad Shares, 2000/2002

\section{Ad shares}

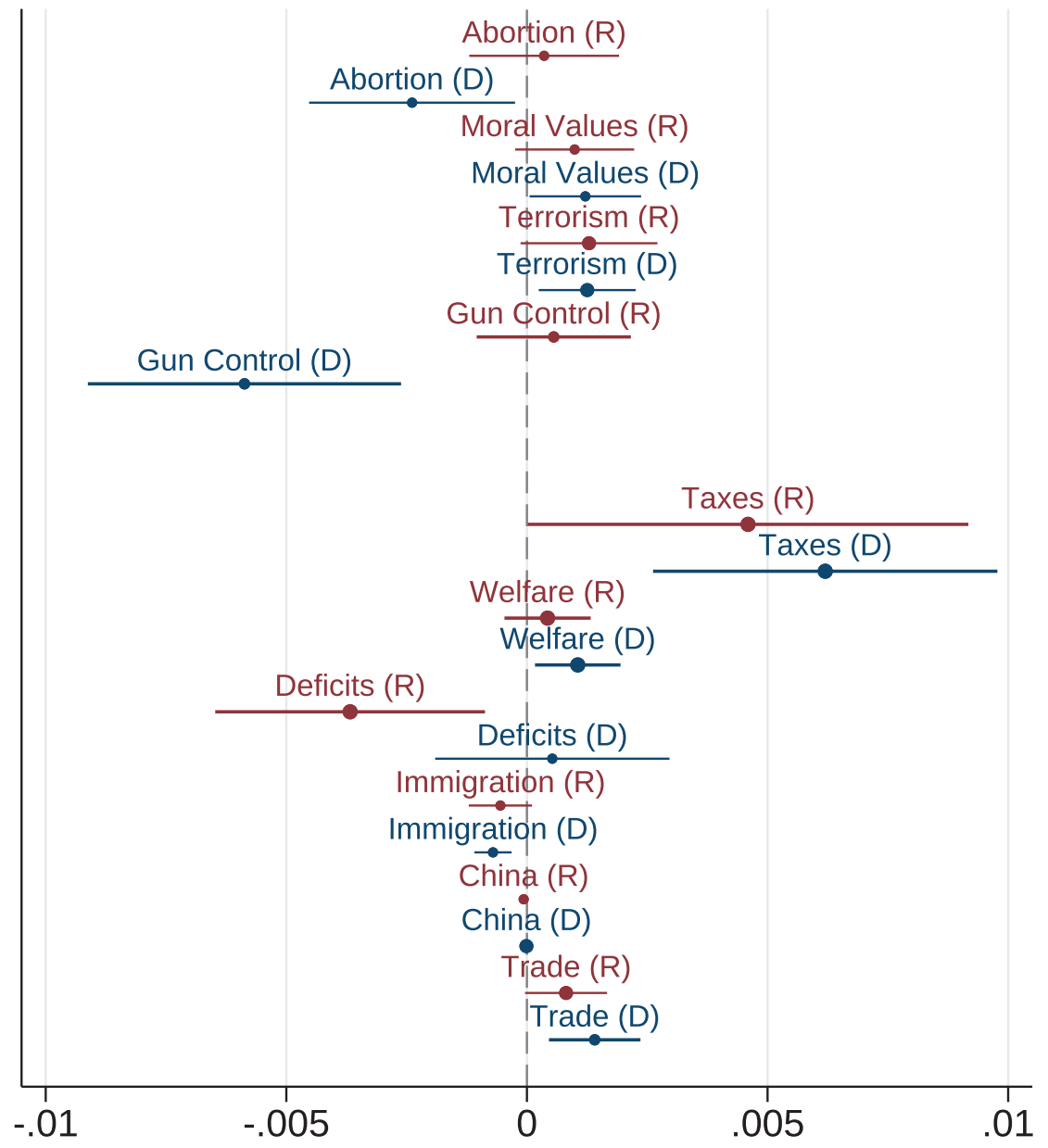

Notes. This figure shows a coefficient plot from the main regressions of advertising shares by party on the China shock instrument, for the first two election cycles of the data. Error spikes give $95 \%$ confidence intervals. Coefficients sorted as in Figure 2. 
Figure B.11: Effect on Ad Shares, controlling for 2000/2002 Ad Shares

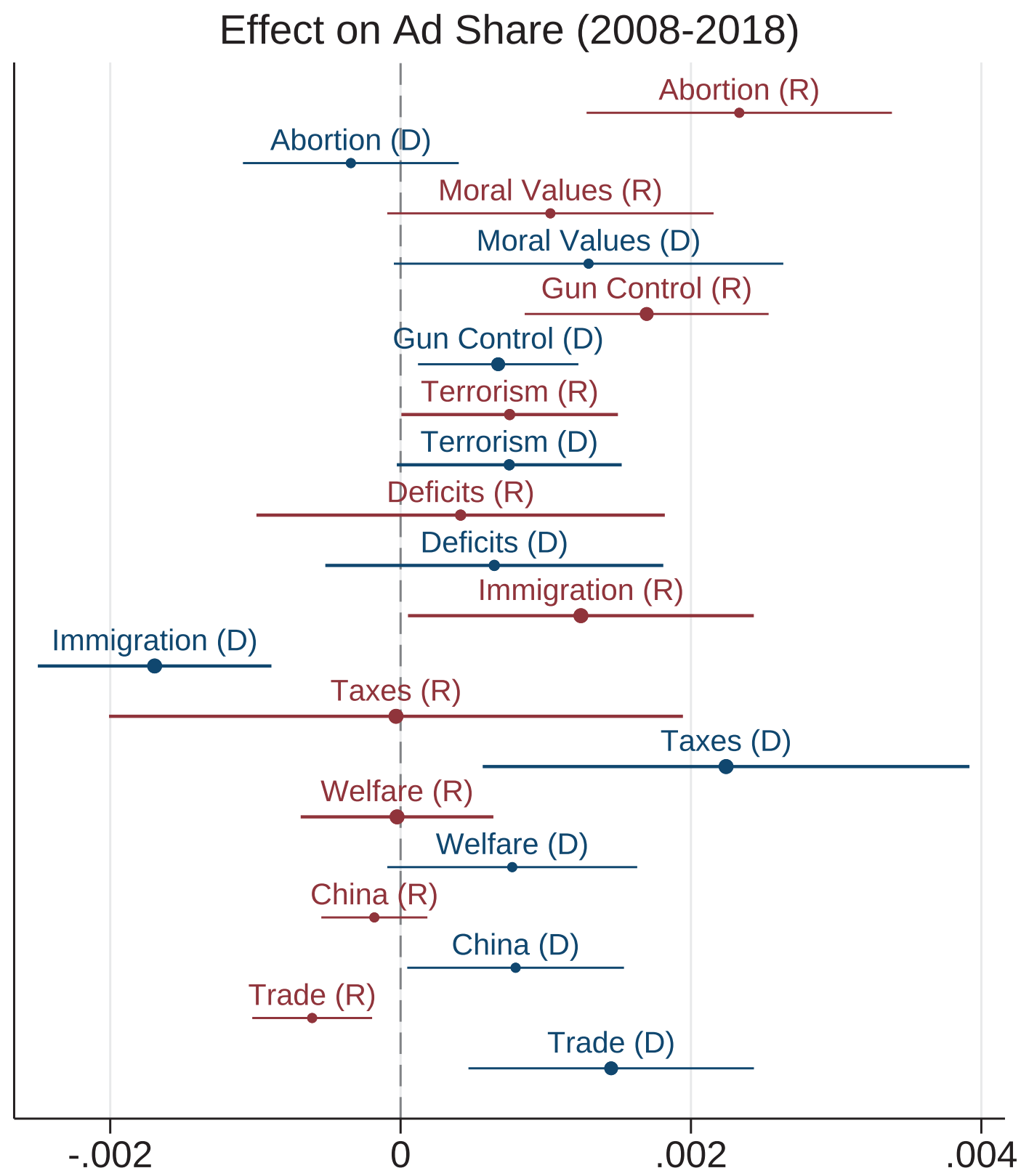

Notes. This figure shows a coefficient plot from the main reduced-form regression of advertising shares by party on the China shock instrument, for the elections from 2008 to 2018 . Includes controls for the ad shares for the associated issue but from 2000/2002, interacted with year fixed effects. Red series is for Republicans, while blue is for Democrats. Error spikes give $95 \%$ confidence intervals. Order of coefficients taken from Figure 2. 
Figure B.12: Additional Specification Checks

A. 2SLS Estimates

2SLS Effect on Ad Shares, 2008-2018

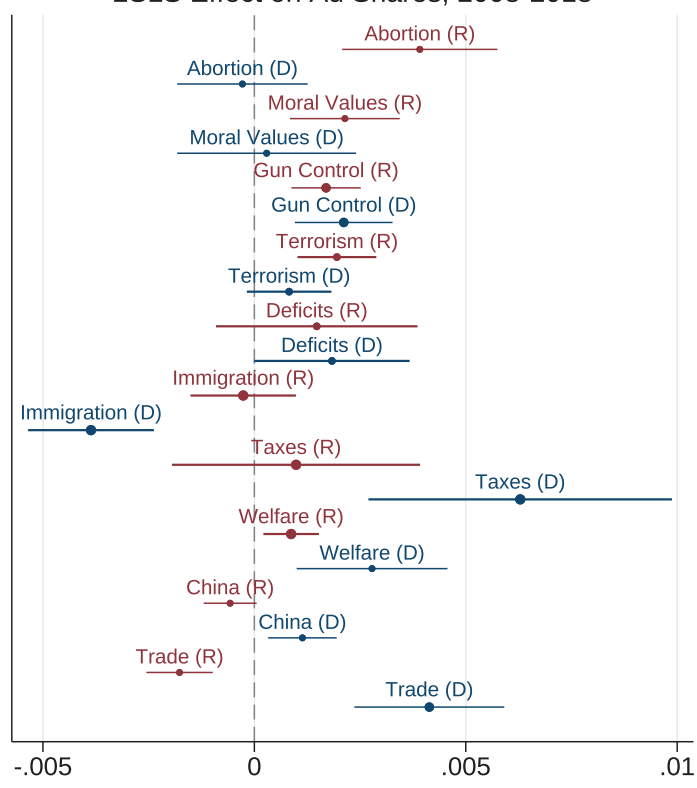

C. Political / Demographic Controls

Effect on Ad Share, with demographic controls

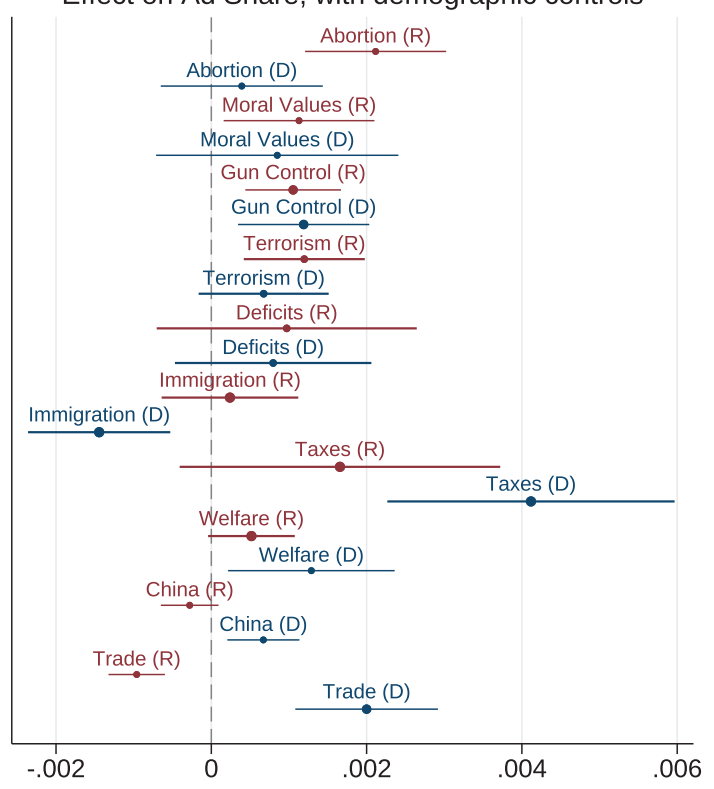

B. State Fixed Effects

Effect on Ad Share, with state fixed effects

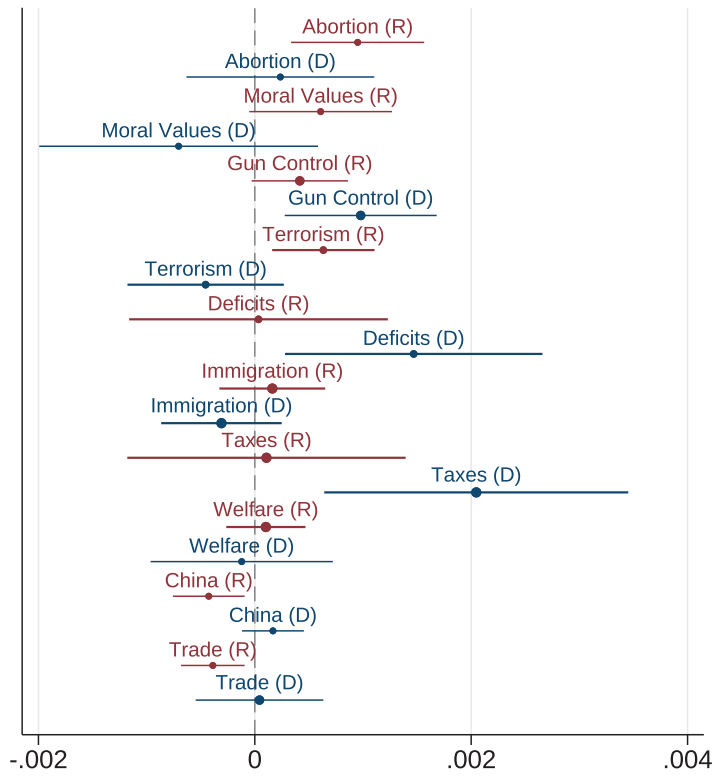

D. Two-Way Clustering

Effect on Ad Share, two-way clustering

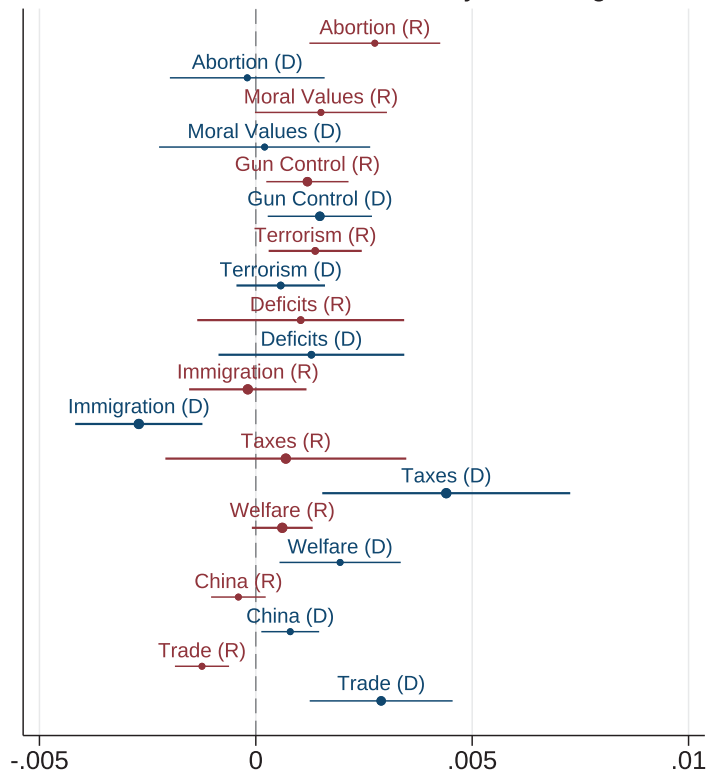

Notes. This figure shows coefficient plots from the main reduced-form regression of advertising shares by party on the China shock instrument, for the elections from 2008 to 2018. Red series is for Republicans, while blue is for Democrats. Error spikes give $95 \%$ confidence intervals. Order of coefficients taken from Figure 2. Panel A uses 2SLS, rather than reduced form OLS. Panel B includes state fixed effects. Panel C includes controls for 2006 Republican vote share, 2000 population, black population share, and Hispanic population share. Panel D uses two-way clustering by commuting zone and media market area. 
Figure B.13: China Shock Effect on Republican Ad Shares, 2008/2010 vs 2016/2018

A. China Shock Effect, 2008/2010

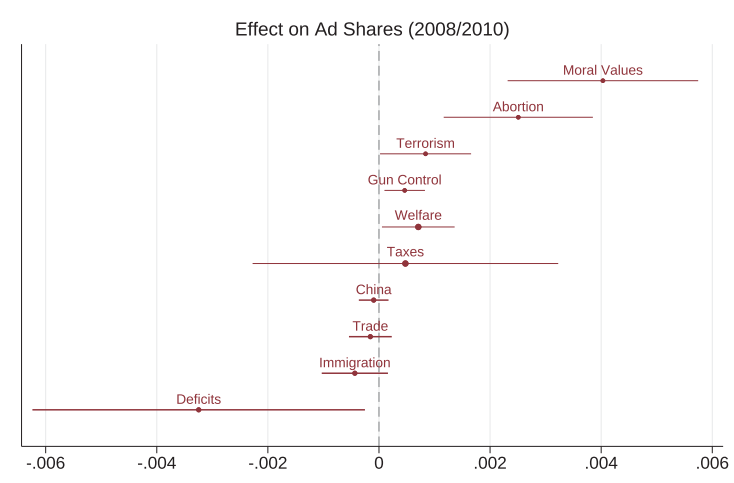

B. China Shock Effect, 2016/2018

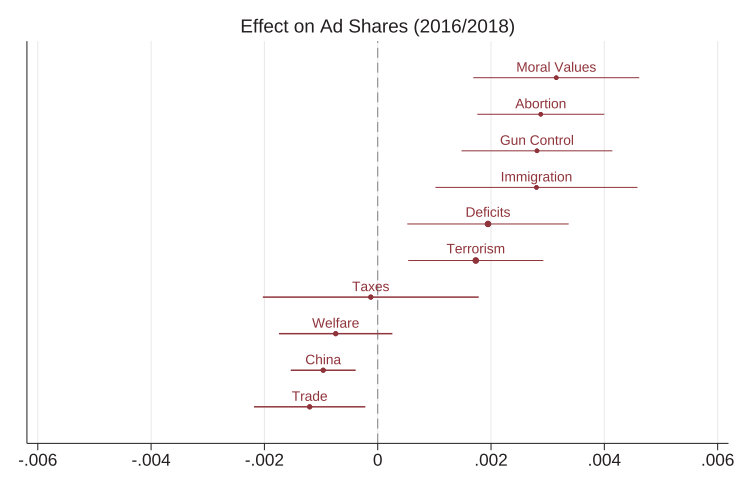

Notes. These figures shows a coefficient plot from the main regression of advertising shares by party on the China shock instrument. Panel A is from 2008/2010, while Panel B is from 2016/2018. Red series is for Republicans, while blue is for Democrats. Error spikes give 95\% confidence intervals. Coefficients sorted by Republican effect size.

Here we show how the effect of the China shock on political messaging changed over time. Appendix Figure B.13 shows equivalent regressions to the one reported in Figure 2 , but for subsets of years. We limit to Republicans. The graph shows that most of the relevant issues have a similar China-Shock response in the earlier years (2008/2010) and later years $(2016 / 2018)$. A particularly striking change is that there is no effect on immigration in 2008/2010s, yet by the last period 2016/2018 there is a large effect on Republican use of immigration language in response to the unemployment shock. 
Figure B.14: China Shock is not Polarizing the Parties

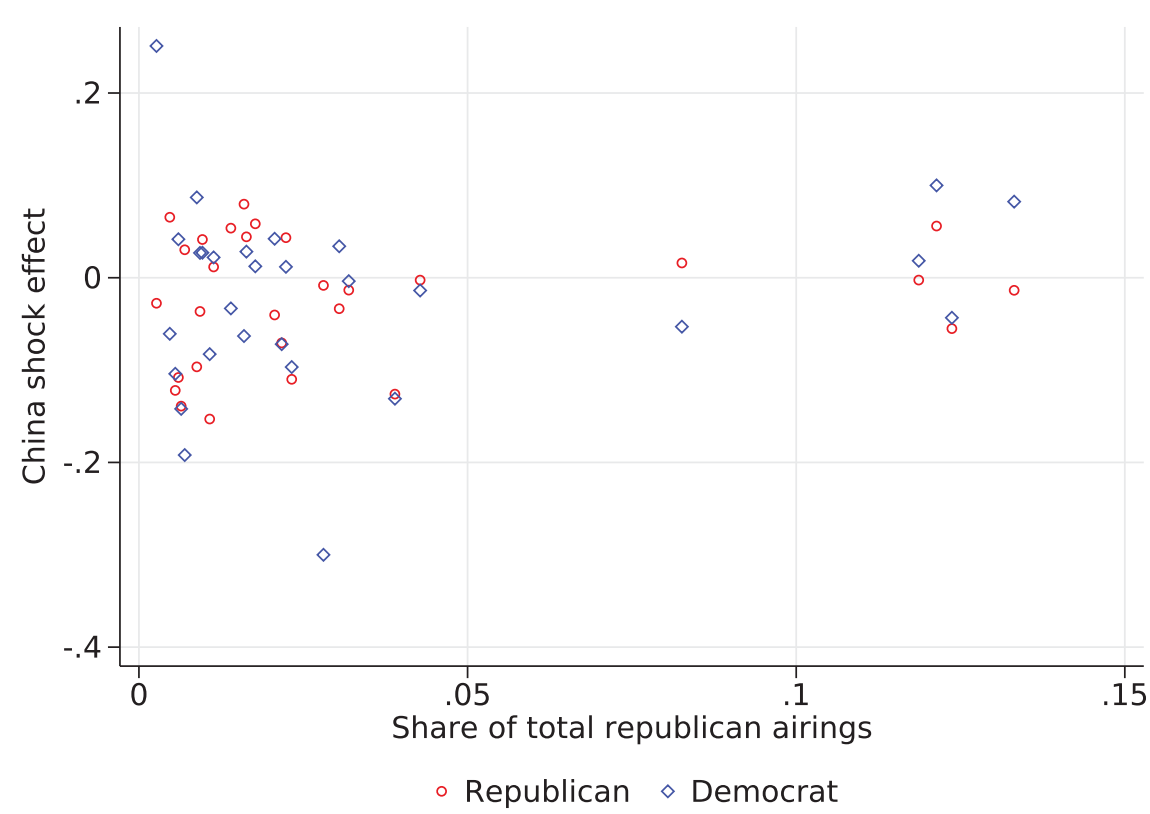

Notes. This figure plots the estimated china-shock coefficients by party (vertical axis) against the share of ads by Republicans. If the China shock were increasing polarization, there would be a positive slope for the red series (Republican ads) and a negative slope for the blue series (Democrat ads). 
Table B.3: Summary Statistics by Party on Gallup "Most Important Problem" Responses

\begin{tabular}{llllll}
\hline \multicolumn{2}{c}{ Democrats } & & \multicolumn{2}{c}{ Republicans } \\
\cline { 2 - 3 } \cline { 5 - 6 } Issue & MIP Rate & & Issue & MIP Rate \\
\cline { 5 - 6 } Unemployment & 0.106 & & Unemployment & 0.077 \\
Terrorism & 0.031 & & Immigration & 0.073 \\
Deficits & 0.023 & & Terrorism & 0.064 \\
Immigration & 0.022 & & Deficits & 0.053 \\
Moral Values & 0.019 & & Moral Values & 0.023 \\
Gun Control & 0.007 & & Taxes & 0.010 \\
Taxes & 0.005 & & Abortion & 0.007 \\
Welfare & 0.004 & & Welfare & 0.007 \\
Trade & 0.002 & & Gun Control & 0.004 \\
Abortion & 0.001 & & Trade & 0.003 \\
China & 0.001 & & China & 0.002 \\
Total & & & & Total & 0.32 \\
Notes. This table & 0.22 & &
\end{tabular}


Figure B.15: China Shock Effect on MIP Responses, 2008-2018

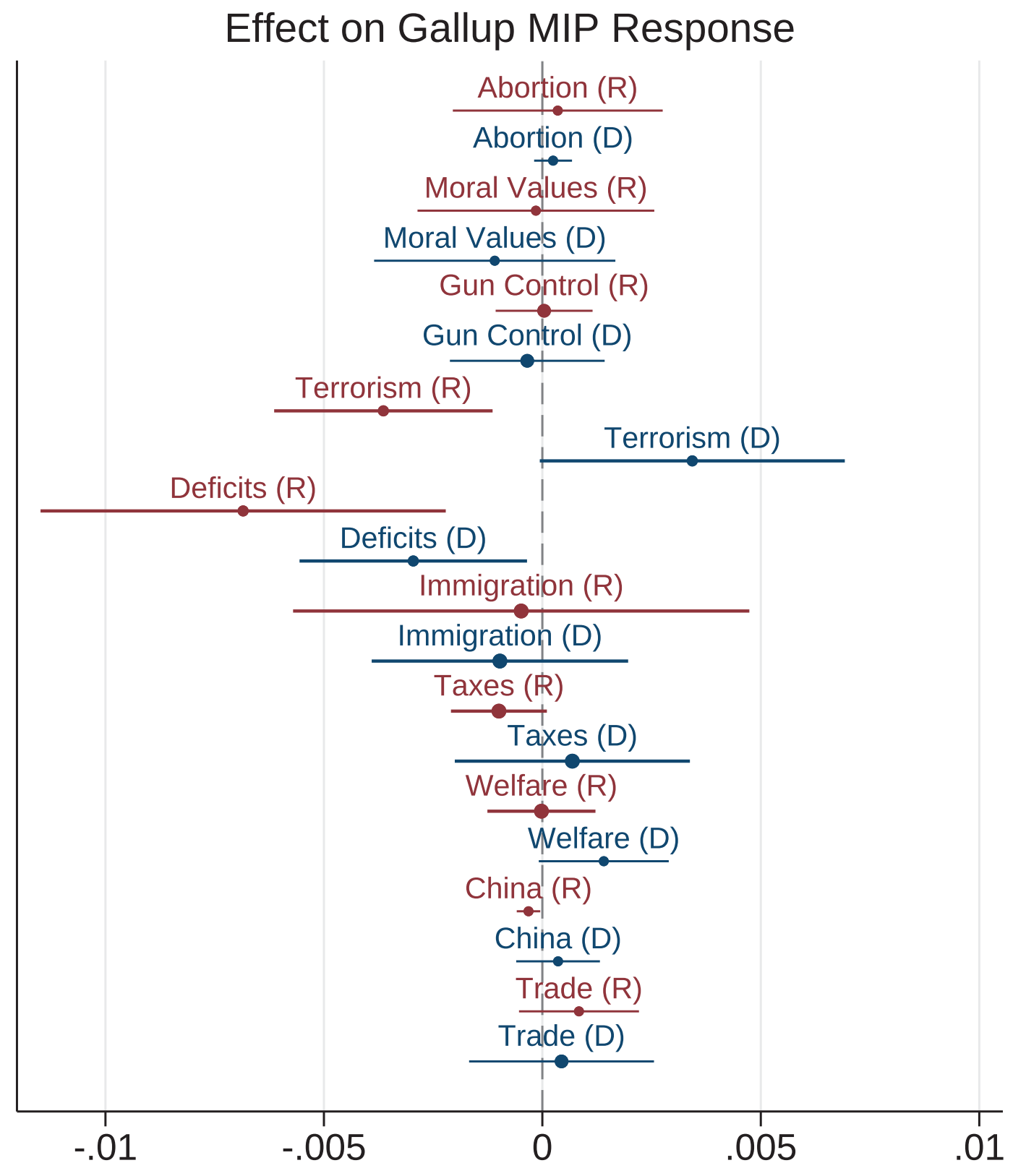

Notes. This figure shows the effect of the China shock on the proportion of Republican and Democrat respondents who show say the respective issue is the most important problem. Order of issues taken from Figure 2. 
Figure B.16: China Shock Effect on Ad Issue Shares, controlling for MIP

\section{Effect on Ad Share, Controlling for Gallup MIP Response}

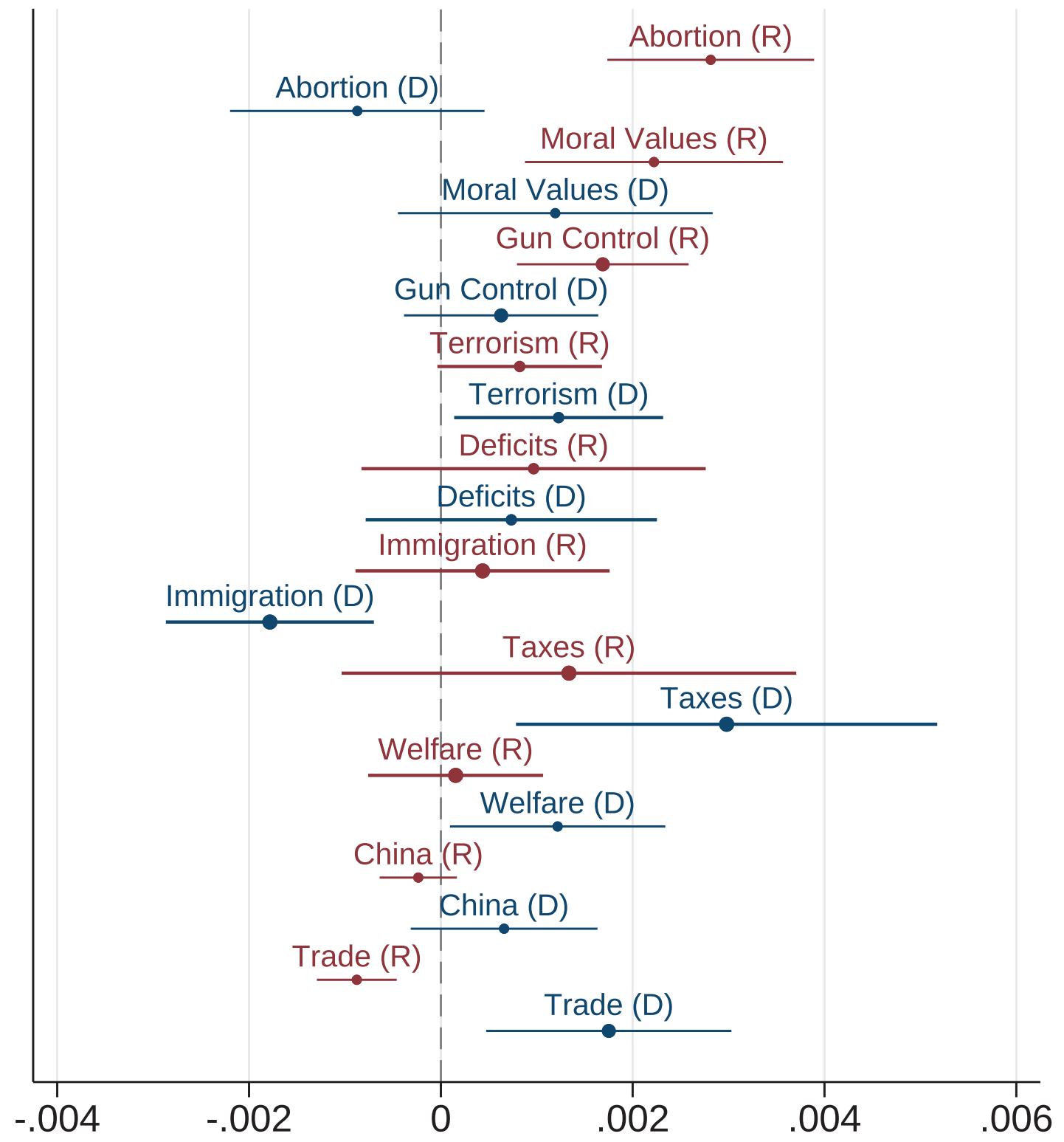

Notes. This figure shows a coefficient plot from the main reduced-form regression of advertising shares by party on the China shock instrument, for the elections from 2008 to 2018. Includes controls for the MIP response for the associated issue, interacted with year fixed effects. Red series is for Republicans, while blue is for Democrats. Error spikes give $95 \%$ confidence intervals. Order of coefficients taken from Figure 2. 


\section{B.3 Supplementary Materials on Complementarity Results}

Figure B.17: How Inequality Affects Republican Messaging on Unemployment

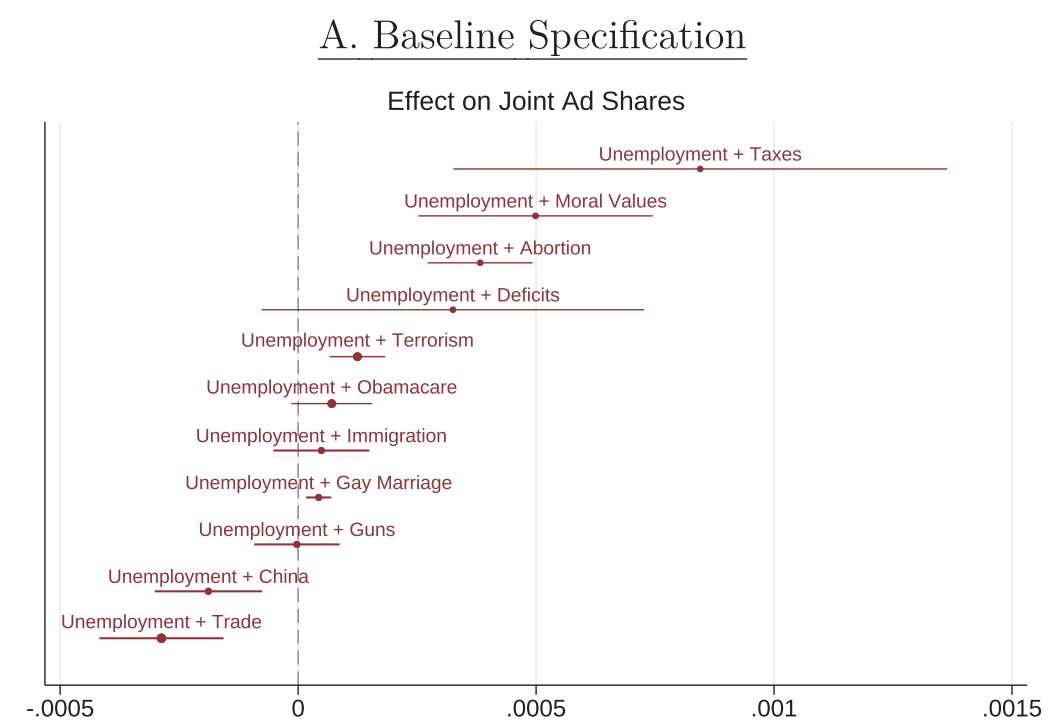

B. Adjusted for Individual Issue Mentions

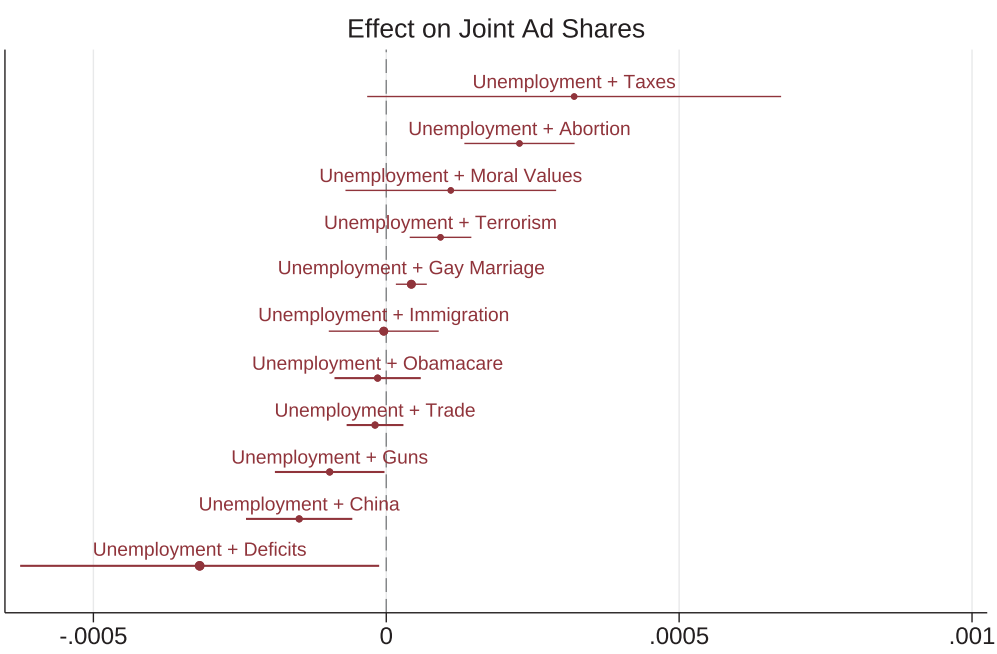

Notes. This figure shows a coefficient plot from the regression of joint advertising shares on the China instrument. Outcome is the share of ads mentioning both (un)employment/jobs and the other indicated issue (e.g. "+ Taxes"). Includes Republicans ads in the 2008-2018 sample. Error spikes give 95\% confidence intervals. In Panel B, regressions include the share of each issue on its own as a covariate. 
Figure B.18: Effect on Joint Issue Mentions (with Standard Errors)

\begin{tabular}{|c|c|c|c|c|c|c|c|c|c|}
\hline & Taxes & Deficits & Trade & Immigration & Obamacare & Terrorism & LGBTQ & $\begin{array}{l}\text { Moral } \\
\text { Values }\end{array}$ & Abortion \\
\hline Employment & $\begin{array}{c}0.0845 \\
(0.0264)\end{array}$ & $\begin{array}{c}0.0325 \\
(0.0204)\end{array}$ & $\begin{array}{l}-0.0287 \\
(0.0066)\end{array}$ & $\begin{array}{c}0.0049 \\
(0.0051)\end{array}$ & $\begin{array}{c}0.0071 \\
(0.0043)\end{array}$ & $\begin{array}{c}0.0125 \\
(0.0030)\end{array}$ & $\begin{array}{c}0.0043 \\
(0.0013)\end{array}$ & $\begin{array}{c}0.0499 \\
(0.0125)\end{array}$ & $\begin{array}{c}0.0382 \\
(0.0056)\end{array}$ \\
\hline Taxes & & $\begin{array}{l}-0.0386 \\
(0.0311)\end{array}$ & $\begin{array}{l}-0.0128 \\
(0.0038)\end{array}$ & $\begin{array}{c}0.0128 \\
(0.0064)\end{array}$ & $\begin{array}{c}0.0185 \\
(0.0058)\end{array}$ & $\begin{array}{l}-0.0038 \\
(0.0026)\end{array}$ & $\begin{array}{c}0.0042 \\
(0.0030)\end{array}$ & $\begin{array}{c}0.0191 \\
(0.0076)\end{array}$ & $\begin{array}{c}0.0367 \\
(0.0088)\end{array}$ \\
\hline Deficits & & & $\begin{array}{l}-0.0057 \\
(0.0030)\end{array}$ & $\begin{array}{c}0.0143 \\
(0.0053)\end{array}$ & $\begin{array}{c}0.0307 \\
(0.0096)\end{array}$ & $\begin{array}{c}0.0128 \\
(0.0035)\end{array}$ & $\begin{array}{c}0.0075 \\
(0.0018)\end{array}$ & $\begin{array}{c}0.0117 \\
(0.0069)\end{array}$ & $\begin{array}{c}0.0502 \\
(0.0097)\end{array}$ \\
\hline Trade & & & & $\begin{array}{l}-0.0168 \\
(0.0043)\end{array}$ & $\begin{array}{c}0.0010 \\
(0.0005)\end{array}$ & $\begin{array}{l}-0.0016 \\
(0.0008)\end{array}$ & $\begin{array}{c}0.0000 \\
(0.0000)\end{array}$ & $\begin{array}{c}0.0033 \\
(0.0013)\end{array}$ & $\begin{array}{c}0.0011 \\
(0.0014)\end{array}$ \\
\hline Immigration & & & & & $\begin{array}{c}0.0285 \\
(0.0049)\end{array}$ & $\begin{array}{c}0.0118 \\
(0.0047)\end{array}$ & $\begin{array}{c}0.0004 \\
(0.0008)\end{array}$ & $\begin{array}{c}0.0234 \\
(0.0046)\end{array}$ & $\begin{array}{c}0.0229 \\
(0.0047)\end{array}$ \\
\hline Obamacare & & & & & & $\begin{array}{c}0.0135 \\
(0.0026)\end{array}$ & $\begin{array}{c}0.0017 \\
(0.0005)\end{array}$ & $\begin{array}{c}0.0031 \\
(0.0021)\end{array}$ & $\begin{array}{c}0.0156 \\
(0.0034)\end{array}$ \\
\hline Terrorism & & & & & & & $\begin{array}{c}0.0003 \\
(0.0006)\end{array}$ & $\begin{array}{l}-0.0009 \\
(0.0069)\end{array}$ & $\begin{array}{c}0.0084 \\
(0.0023)\end{array}$ \\
\hline LGBTQ & & & & & & & & $\begin{array}{c}0.0096 \\
(0.0028)\end{array}$ & $\begin{array}{c}0.0133 \\
(0.0037)\end{array}$ \\
\hline Moral Values & & & & & & & & & $\begin{array}{c}0.0344 \\
(0.0086)\end{array}$ \\
\hline
\end{tabular}

Notes. Each cell in this figure reports the reduced-form coefficient from regressing the indicated joint issue outcome (share of ads mentioning both the row issue and the column issue) on the China shock instrument. Includes Republican Ads. 
Figure B.19: Effect on Joint Issue Mentions (Democrats)

\begin{tabular}{|c|c|c|c|c|c|c|c|c|c|}
\hline & Taxes & Deficits & Trade & Immigration & Obamacare & Terrorism & LGBTQ & $\begin{array}{l}\text { Moral } \\
\text { Values }\end{array}$ & Abortion \\
\hline Employment & 0.176 & 0.0597 & 0.1060 & -0.0144 & -0.0002 & -0.0041 & 0.0020 & 0.0080 & 0.0073 \\
\hline Taxes & & 0.0810 & 0.0530 & 0.0025 & -0.0016 & 0.0025 & 0.0028 & 0.0298 & 0.0205 \\
\hline Deficits & & & 0.0323 & 0.0018 & 0.0003 & 0.0029 & -0.0008 & 0.0319 & 0.0188 \\
\hline Trade & & & & 0.0015 & -0.0014 & -0.0013 & 0.0000 & 0.0206 & 0.0083 \\
\hline Immigration & & & & & -0.0012 & -0.0006 & -0.0008 & -0.0106 & 0.0004 \\
\hline Obamacare & & & & & & 0.0001 & -0.0001 & 0.0010 & -0.0011 \\
\hline Terrorism & & & & & & & 0.0000 & 0.0120 & 0.0003 \\
\hline LGBTQ & & & & & & & & 0.0113 & 0.0056 \\
\hline Moral Values & & & & & & & & & -0.0174 \\
\hline
\end{tabular}

Notes. Each cell in this figure reports the reduced-form coefficient from regressing the indicated joint issue outcome (share of ads mentioning both the row issue and the column issue) on the China shock instrument. This matrix shows results for Democrat ads. 
Figure B.20: Effect on Joint Issue Mentions (Adjusted)

\begin{tabular}{|c|c|c|c|c|c|c|c|c|c|}
\hline & Taxes & Deficits & Trade & Immigration & Obamacare & Terrorism & LGBTQ & $\begin{array}{l}\text { Moral } \\
\text { Values }\end{array}$ & Abortion \\
\hline Employment & 0.000321 & -0.0003 & 0.0000 & 0.0000 & 0.0000 & 0.0001 & 0.0000 & 0.0001 & 0.0002 \\
\hline Taxes & & -0.0005 & 0.0000 & 0.0001 & 0.0001 & -0.0001 & 0.0000 & 0.0000 & 0.0001 \\
\hline Deficits & & & 0.0000 & 0.0001 & 0.0001 & 0.0001 & 0.0001 & 0.0000 & 0.0000 \\
\hline Trade & & & & 0.0000 & 0.0000 & 0.0000 & 0.0000 & 0.0000 & 0.0000 \\
\hline Immigration & & & & & 0.0002 & 0.0001 & 0.0000 & 0.0002 & 0.0001 \\
\hline Obamacare & & & & & & 0.0001 & 0.0000 & 0.0000 & 0.0001 \\
\hline Terrorism & & & & & & & 0.0000 & -0.0004 & 0.0000 \\
\hline LGBTQ & & & & & & & & 0.0001 & 0.0001 \\
\hline Moral Values & & & & & & & & & 0.0001 \\
\hline
\end{tabular}

Notes. Each cell in this figure reports the reduced-form coefficient from regressing the indicated joint issue outcome (share of ads mentioning both the row issue and the column issue) on the China shock instrument. Regressions include the share of each issue on its own as a covariate. Includes Republican Ads. 